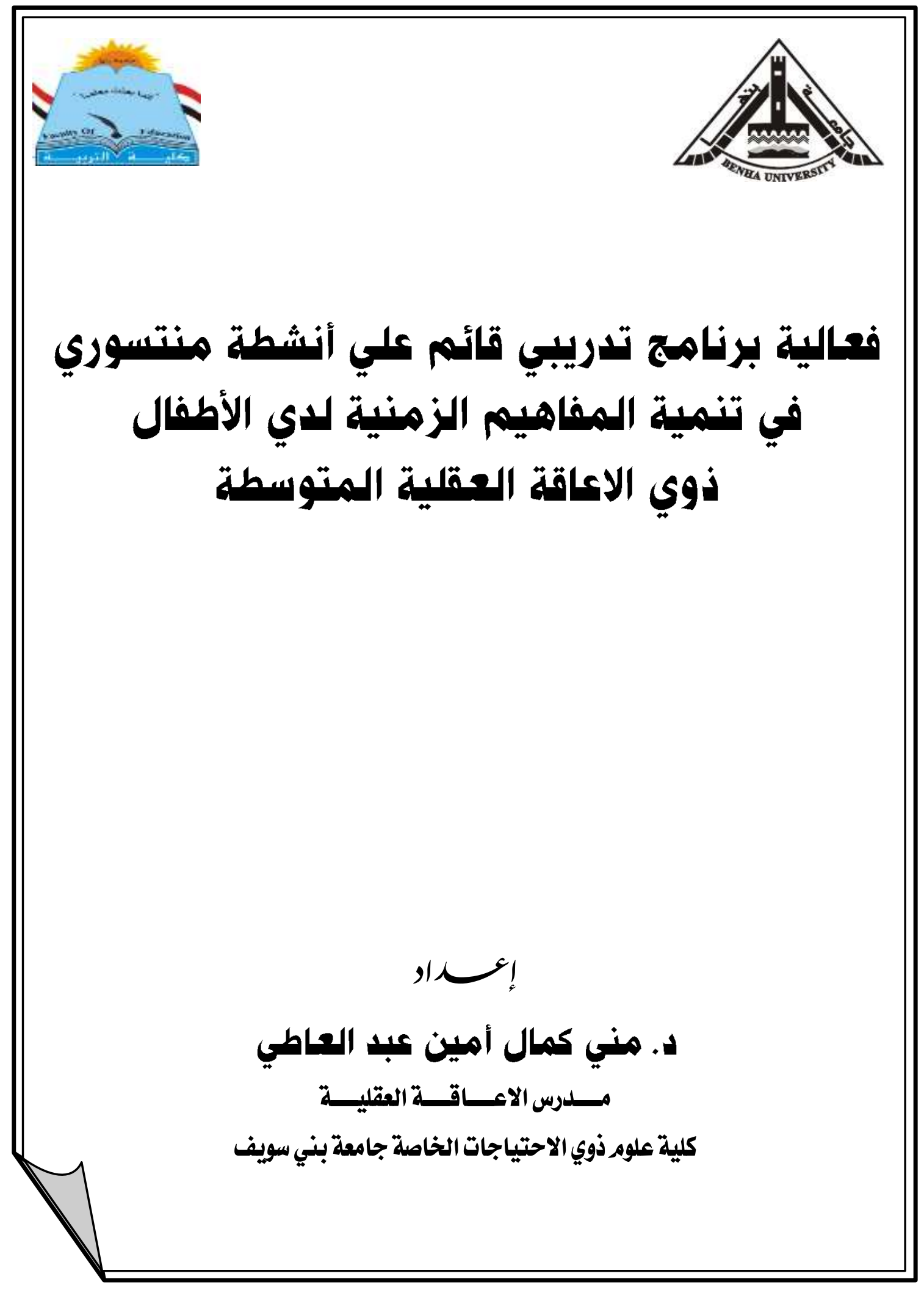


فعالية برنامج تدريبي قائم علي أنشطة منتسوري في تنمية المفاهيم الأمايم

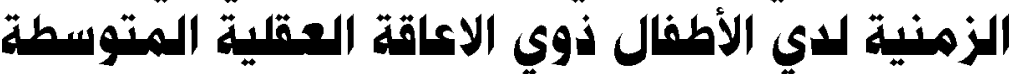<smiles>[AlH]C[AlH2]</smiles>

د. مني كمال أمين عبد العاطي

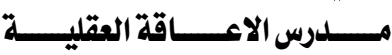

كلية علوم ذوي الاحتياجات الخاصة جامعة بني سويف

\section{مستخلــص البدـــ}

هدفت الدراسة الحالية إلى الكثف عن فعالية برنامج تدريبي قائم علي أنشطة منتسوري في تتمية بعض المفاهيم الزمنية لدي عينة من الاطفال ذوي الاعاقة العقلية المتوسطة. وتكونت عينة الدراسة الأساسية من (·r) طفلاً وطفلة من الأطفال المعاقين عقليًا من الدرجة المتوسطة بنطاق الدال

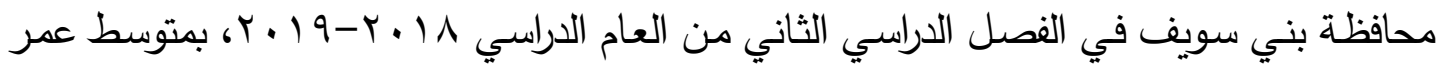

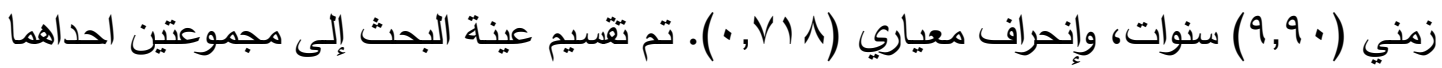
تجريبية: وهي المجموعة التي تعرضت للبرنامج التدريبي وذلك لتتمية المفاهيم الزمنية وقوامها ( • () أطفال، وأخري ضـابطة: وهي المجموعة التي لم تتعرض للبرنـامج التدريبي ولها نفس خصـائص التكافؤ مـع المجموعة التجريبية وقوامها ( • () أطفال، وقد راعت الباحثة تحقيق التكافؤ بين أفراد العينـة مـن حيث (العمـر الزمنـي، نسبة الذكاء، المستوى التعليمي لـلأب والأم، مستوى المفـاهيم الزمنية). وتمثلت أدوات الدراسة في إختبار إستانفورد بينه للذكاء الصورة الرابعة "إعداد كامل لويسة"، مقياس المستوي الإجتماعي والثقافي "إعداد حمدان فضـة "، مقياس المفاهيم الزمنية لذوي الإعاقـة العقلية "إعداد الباحثة"، وبرنامج تدريبي قائم علي أنثطة منتسوري " إعداد الباحثة" طبق على العينة التجريبيـة. وإســتخدمت الباحثـة الأسـاليب الاحصـائية اللابارمتريـة ممثلـة في اختبـار مـان ويتـي لـلزٔواج المستقلة ،وإختبار ويلككسونس Mellcoxon Test Test المرتبطـة. وتمـت معالجـة جميـع البيانـات إحصـائياً بواسـطة برنـامج الحزمـة الإحصـائية للعلـوم الاجتماعية (SPSS,V.20). هذا؛ وقد أسفرت نتائج الدراسة عن فعالية البرنامج التدريبي بإستخدام أنشطة منتسوري في تتمية بعض المفاهيم الزمنية لدى عينة الدراسة؛ حيث وجدت فروق ذات دلالة احصـائية بين متوسطي درجات المجموعة التجريبية في القياسين القبلي والبعدي لصـالح القياس

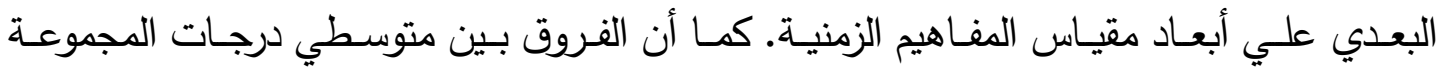
التجريبية في القياسين البعدي والتتبعي علي أبعاد مقياس المفاهيم الزمنية كانت غير دالة. الكلمات المفتاحية: المفاهيم الزمنية - أنشطة منتسوري - الإعاقة العقلية. 


\section{Efiectiveness of A Training program based on Montessori activities in Developing time concepts in Children with moderate Intellectual Disability}

\section{Abstract}

The current study aimed at measuring the effectiveness of A Training program based on Montessori activities in Developing time concepts in a sample of children with moderate intellectual disability. The basic study sample consisted of (20) children with moderate intellectual disability who in the governorate of Beni Suef in the second term of the academic year 2018-2019, with an average age of (9.90) years, and a standard deviation (0.718). The research sample was divided into two groups: the experimental group that was exposed to the training program in order to develop time concepts and it consists of (10) children, and a control group: it is the group that was not exposed to the training program and has the same characteristics with the experimental group and its strength (10) children. The study tools were :the StanfordPenne Test of Intelligence, "the fourth edition", "social and cultural level scale " "prepared by Hemdan Fada", the time concepts scale for people with intellectual disability "prepared by the researcher", and a program based on Montessori activities "prepared by researcher" applied to the experimental sample. The researcher used non-parametric statistical methods represented in the Mann-Whitney Test for independent pairs, and the Wellcoxon Test for dependent pairs. All data were processed statistically by the Statistical Package for Social Sciences (SPSS, V. 20). The current study resulted in the effectiveness of the training program using Montessori activities in developing some time concepts for the study sample.There were founded statistically significant differences between the mean scores of the experimental group in the pre and post test in favor of the post test of time concepts scale. Also, the differences between the mean scores of the experimental group in the post test and follow up test of time concepts scale were not significant.

Keywords: time concepts- Montessori Activities- intellectual disability. 


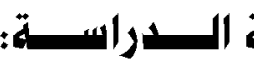

تعد الدفاهيم الأساسية ( الزمانية- الكمية- المكانية ) اللبنة الأولي لبناء مهارات التفكير

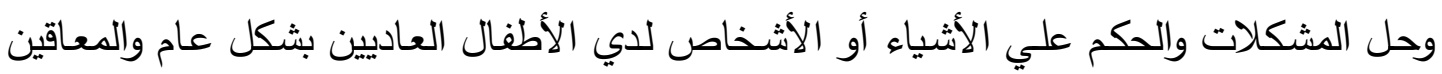
عقليا بثكل خاص. ومما لا شك فيه أن إكتسـاب الطفل للمفاهيم الأساسية يعزز من إدراكـه

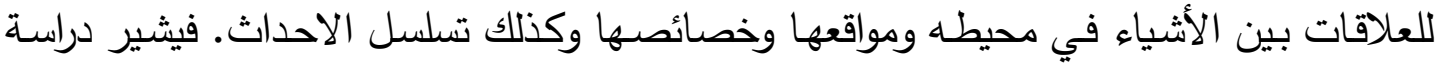
(Gabriela, 2006, 1103, Bohem, 2001, Bohem, 2004)

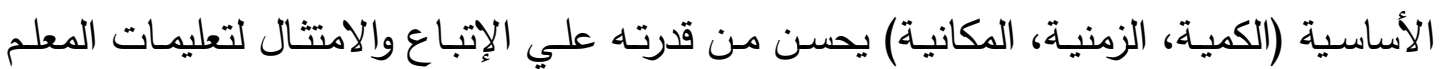
والاشتراك بالأنثطة وكذلك التعامل مع منطلبات الحياة اليومية. وتتكون الدفاهيم وتتثكل من خلال التعامل مع المثيرات والخبرات التي يمر بها الطفل، حيث تتكون لديه الصور الذهنية عن المواقف والموضوعات والاثياء، التي يتعامل معها، وذلك الكيات

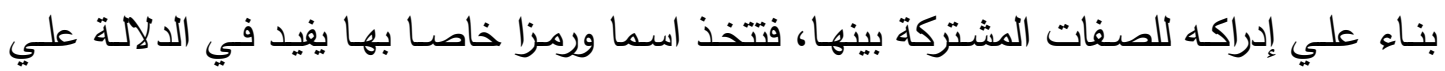

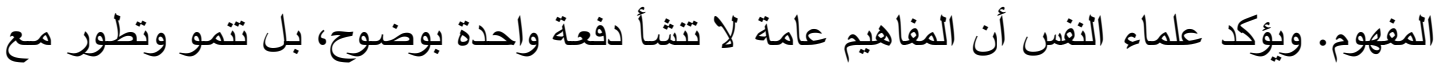

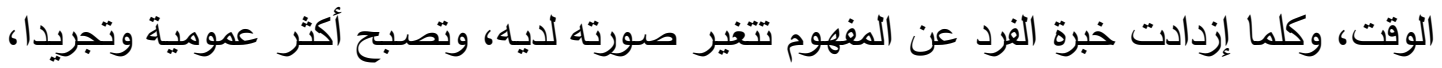

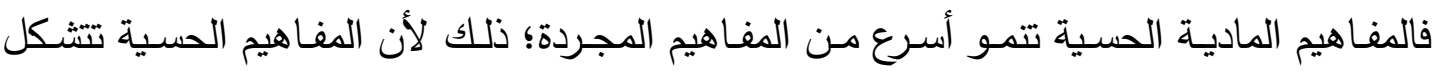

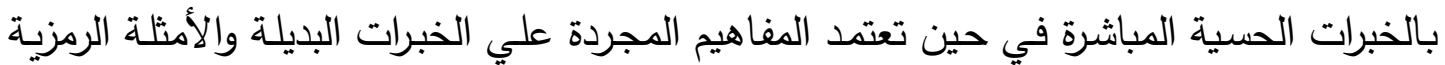

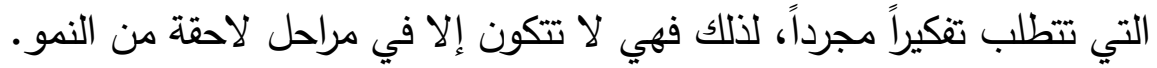

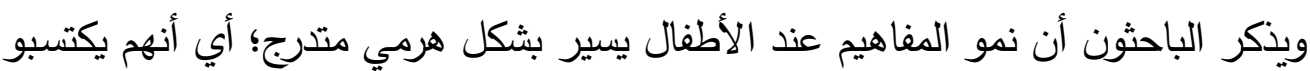

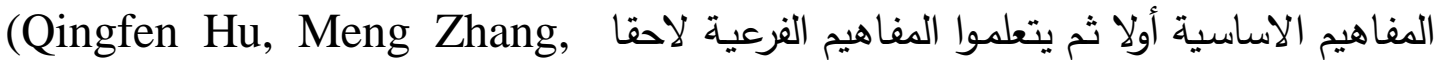
2019, 132 \& Tenenbaum, 2007) وقد ذكر بياجيه ان نمو الsفاهيم عموما تمر بالمراحل

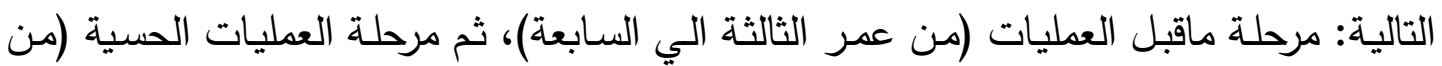

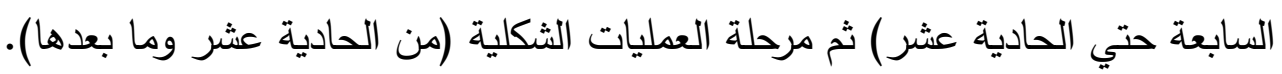

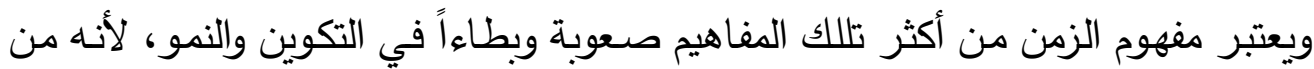

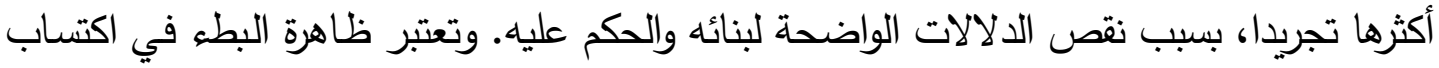

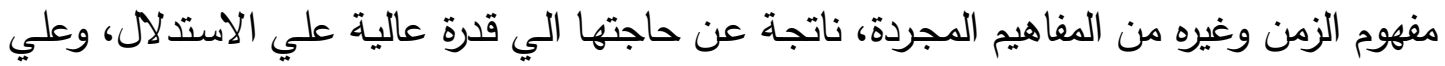

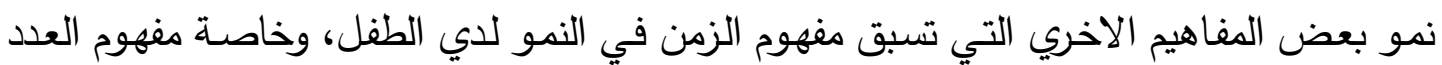
والدرجة والكم والثبات ـ فالطفل لا يستطيع ادرالك معني الثهر الا اذا تكونت لديه الفكرة الصحيحة

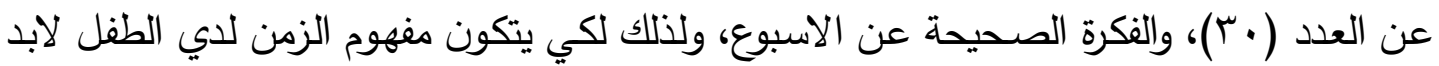

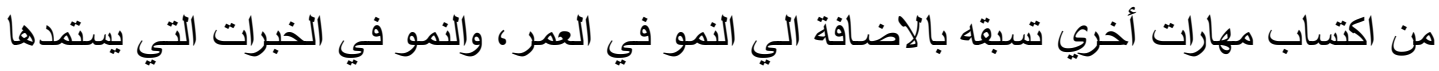

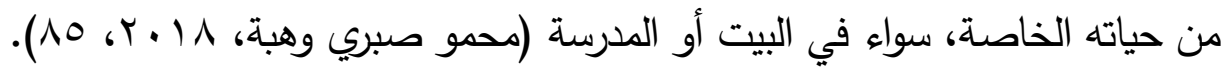


وتظهر أهمية إكتساب مفهوم الزمن بالنسبة للطفل المعاق عقلياً من خلال أنثطة الحياة

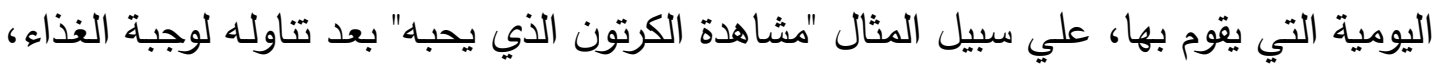

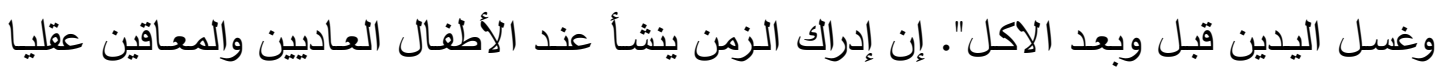
بصورة متعاقبة وبارتباطات متسلسة الواحدة تلو الأخري.

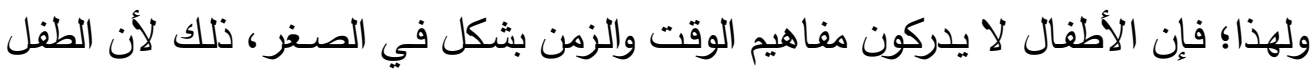

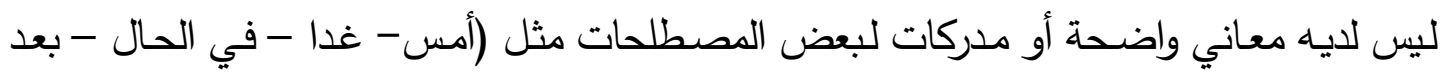

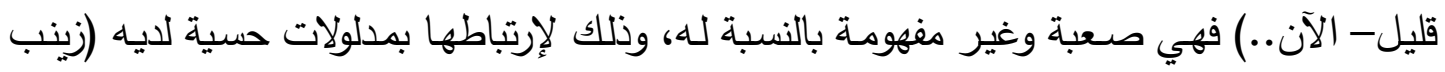

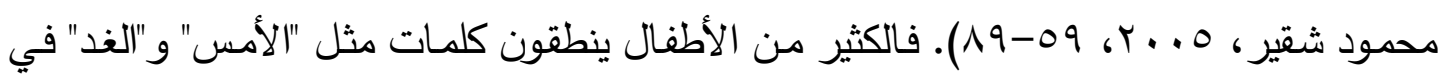

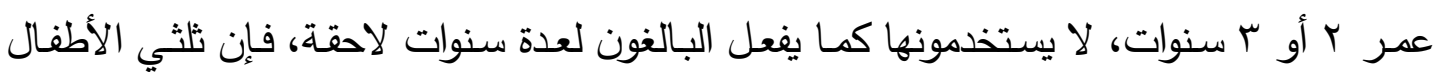

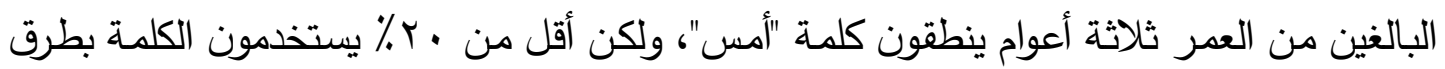

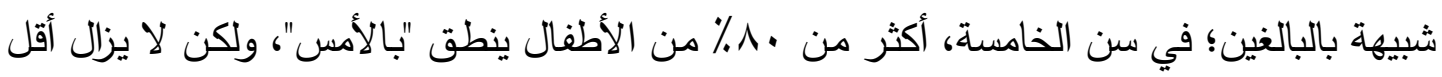

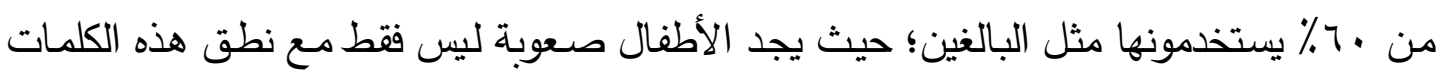

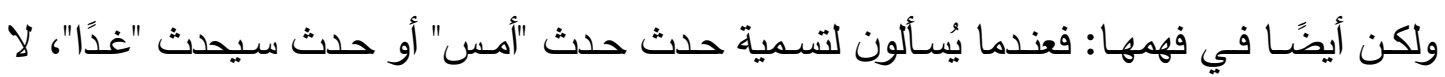
يستطيع سوى حوالي \% \% من الأطفال البالغين من العمر ثلاثتة أعوام تقديم إجابات معقولة.

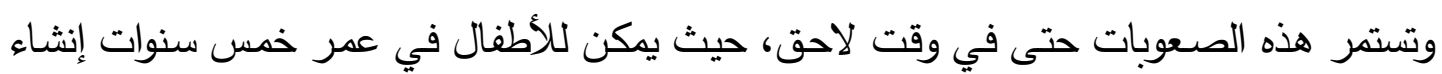

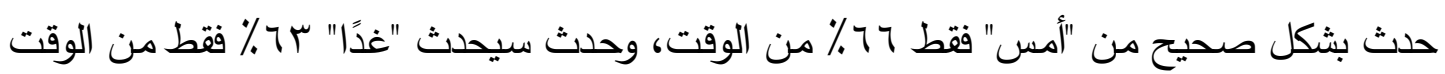
(Suddendorf, 2010), (Busby \& Suddendorf, 2005), (Busby Grant\&

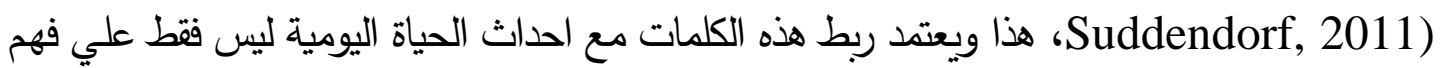
الاطفال لمعني هذه الكلمات ولكن يعتد أيضا علي القدرة علي إستدعاء وترتيب وتوقع الاحداث؛ وفي الاغلب تتمو هذه القدرة بشكل بطئ Busby \& Suddendorf, 2005,2009; Suddendorf, Nielsen, \& Von Gehlen, 2011; Schacter, Addis, \& Buckner, 2007) بصفة عامة للطفل العادي وبالتالي فالمثكلة أكبر بالنسبة للطفل المعاق عقليا القابل للتعلم، وذلك هالك لمـا يعانيه من مشكلات في العطليات العقلية المعرفية العليا مثل الإدرالك، والاتتباه، والتعرف،

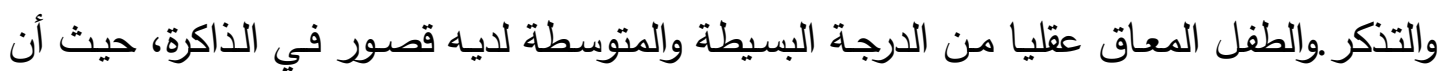

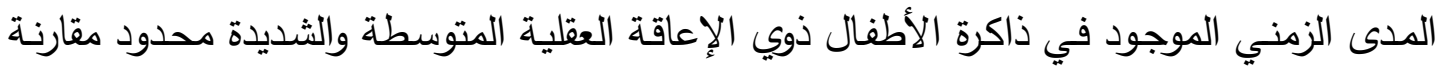
بالطفل العادي أو ذويهم من الدرجة البسيطة (Piaget, J. B. 1969, 233-235) 
فأهم ما يميز الأطفال المعافين عقليا بشكل عام وذوي الإعاقة العقلية المتوسطة والثديدة

هو بطء التعلم بشكل ملحوظ والتأخر في معظم مجالات النمو مع عدم القدرة علي تعميم الدهارات

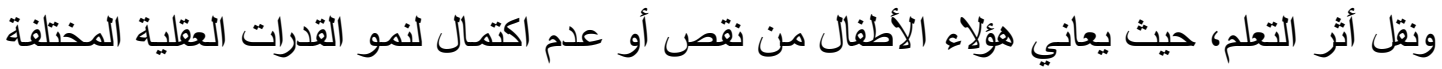
من تخيل وتنكير واستتلال منطقي وتعرف وفهم وإدراك وتحليل وتنظيم أفكار ، ويؤثر ذلك على علي الكي قدرتهم علي التحصيل والتعلم ونمو الدفاهيم لديهم (Springer, A. \& Campbell, 2000,105)

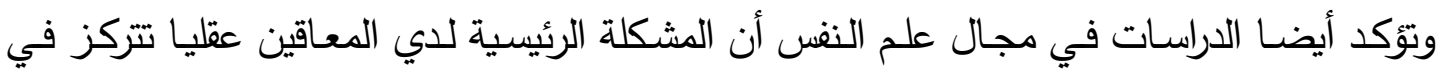
التعلم والمعالجة المعرفية والتي تحول دون اكتساب مفهوم الزمن، كما أثار بياجيه إلي الدور الهام الذي تلعبه القدرات العقلية المتعقة بالذاكرة والمنطق في إكتساب مفهوم الزمن، وهذا مايفتر إليه المعاق عقليا ومن ثم يجد صعوبة في اكتسابه (Lovell \& Slater,1960, David,1972) وهذا

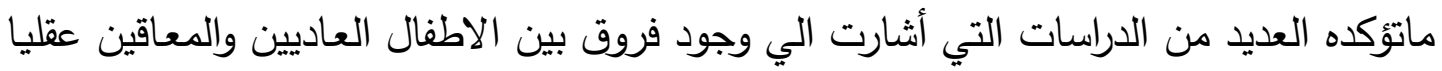

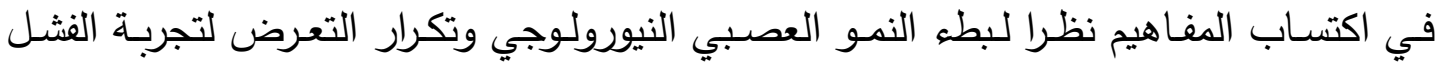
والإحباط والتعرض للسخرية (James B., 1970, 9-10) فالطفل المعاق عقليا يصعب عليه إدراك المدى الزمني لحدث معين وكيفية ربطه وتتابعها وفق أحداث أخرى تالية أو سابقة، وذلك لأنه لا يستطيع التركيز لفترة طويلة فهو في أمس الحاجة الدئ

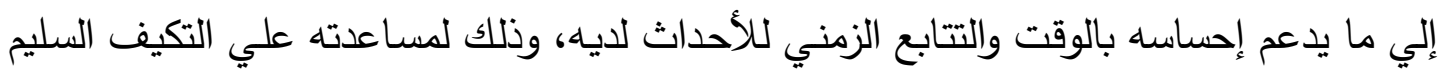

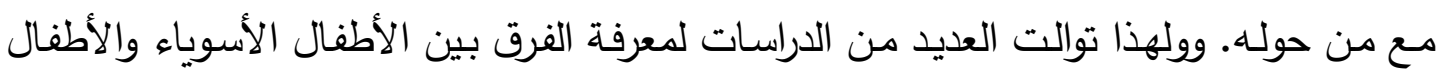
المعاقين عقليا القابلين للتعلم في إدراك مفهوم الزمن، حيث هدفت إلي تتبع نمو مفهوم الزمن لدي

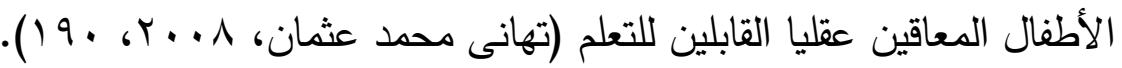

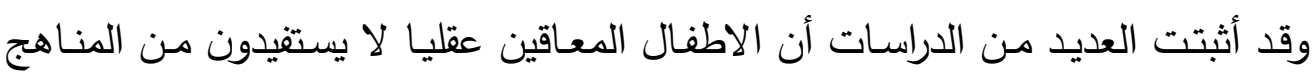

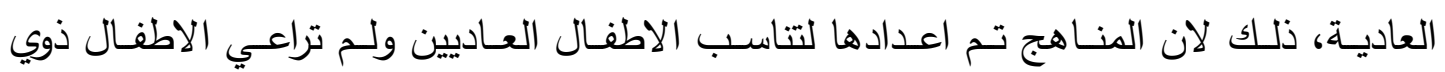
الاحتياجات الخاصة (Muijs, D \& Reynold, D., 2001). ومنهج منتسوري هو طريقة لتعليم المعاقين عقليا، حيث يعطي الأطفل الفرصة لتحسين أنفسهم، والحرية في الحركة واختيار الانشطة (Montessory, 1997, 7). (sema ongoren \& Ali Ishan, 2009, 1163), (Me). ويعد منهج منتسوري من أكثر المداخل التعليمية والأكثر فعالية مع المعاقين عقليا، فهو ( A

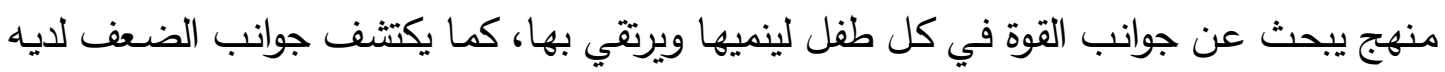
فيعالجها بوسائل حسية تربوية مدروسة؛ لذا فهو يطبق بشكل فردي حسب ميول وقدرات كل طفل؛ 
حيث أكدت ماريا منتسوري علي إحترام فردية وشخصية الطفل، والفروق الفردية بين الأطفال، كما أنها ترتكز علي أهمية الفترات الحساسـة في تعلم المفاهيم وإكتسابها. فتري منتسوري أن السنوات الأولي من عمر الطفل هي فترات هامـة للتعلم، حيث يسهل اكتساب المفاهيم والمهارات في هذه الفترات المبكرة مقارنة بالفترات اللاحقة من عمر الطفل. كما أنها ركزت علي التعليم المحسوس، فقد ركزت علي تعلم المفاهيم بطريقة التعليم المحسوس، بإعتباره الطريقة الأكثر فعالية مع الطفل.

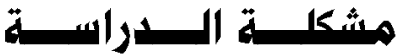

تعد المفاهيم الأساسية (الكمية - الزمنية - المكانية) أهم مكونات البنية المعرفية لأي مبحث دراسي، بل تعد حجر الزاوية لهذه البنية، لانها تساعد في عدم تكرار المادة التعليمية، بما يعني إختصار الزمن، علاوة علي أن تعلم المفاهيم تتضمن الكثير من الحقائق، التي تساعد في

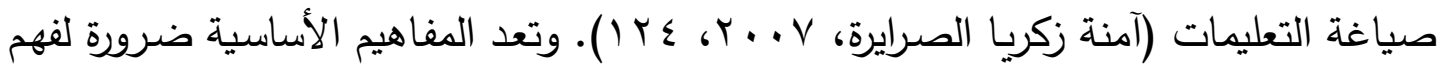
التعليمات الثفهية والمكتوبـة. فعلي سبيل المثال؛ تحتوي التعليمات الخاصـة بمقاييس الذكاء وإختبارات الأداء علي كثير من المفاهيم الأساسية ومتطلبات لغوية؛؛ فعندما يسمع ويقرأ الطفل التعليمات، فإنه يستخدم عمليات معرفية متزامنة التي لها علاقة بالتعلم. فالطفل يضع المصطلح في إتجاه ويفكر في الأداء الصحيح وتنفيذه. والطفل هنا لابد أن يفهم التغير في المفاهيم عبر هذا السياق (Zou \& bohem, 2004) ويكتسب الطفل هذه المفاهيم في عمر 0-7 سنوات تقربياً (Helayana Hershkom, 2015, 15). ويتعلم الطفل مفهوم الزمن من خلال الأحداث المتغيرة ببيئته، فيستطيع ربط الحاضر

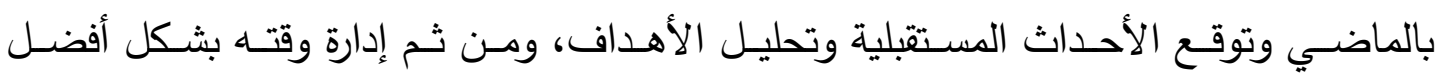
(Lakein, 1970)، ومن ثم يقلل من احتمالية تدخل الصدفة في ادارة وقته ويكون الطفل أكثر قدرة علي تخطيط حياته وأكثر تحكما في سلوكه (Helayana Hershkom, 2015, 15). ويـرتبط تعلـم مفهـوم الـزمن بـالتطور العقلـي للمـتعلم والـذي يعـد أساسـاً للفهـم وتعلـم التعميمـات، وحل المشكلات؛ لذلك يقوم المعلمون بإختبار محتوي المـاد التعليمية، وتطوير الاجراءات، من أجل اكتساب المتعلمين للمفاهيم بمستوي عالي من النجاح. وقد أشـار برونر بإئر الى أن الأطفال باستطاعتهم تعلم المفاهيم من خلال بعض النماذج العقلية، وقد اشتمل نموذجهـ

$$
\text { على مستويات هرمية ثلاث هى: }
$$

المستوى الحسى: تقدم المفاهيم الأكثر عمومية وشمولا ثم بعد ذلك تتميز باطراد فى مي

التفاصيل والتخصيص لتصل الى المعلومات التفصيلية الدقيقة المتخصصة. 
ه المستوى الصورى: وفيه تترابط التصورات العينية بطريقة منظمة وغير عشوائية.

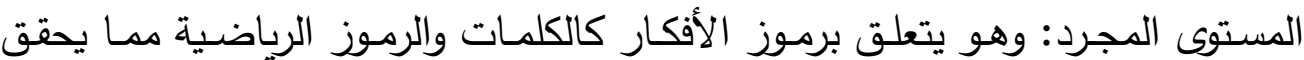

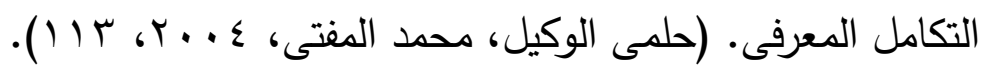
وقد أورد عبد المجيد النشواتي (9101، 107-17\% (1) مراحل النمو العقلي التي حددها

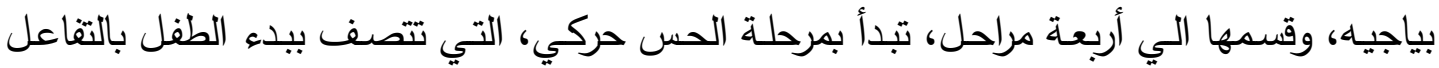
الحركي مع البيئة، وممتد منذ ميلاد الطفل حتي عمر سنتين، ثم مرحلة ما قبل العمليات التي تتميز

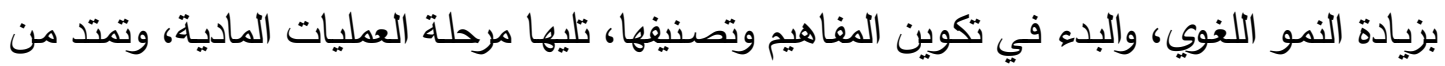
عمر > : 11 عاما، وأهم ما تتميز به تطور العمليات التجميع والتصنيف، وتكوين الكفاهيم، وأخرها

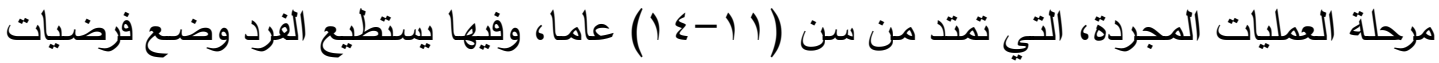
والتوصل الي إستتاجات وتعميمات، وتقدير عواقب المستقبل ونتائج الماضي. ويعتبر مفهوم الزمن مـن أكثر المفـاهيم صعوبة، لأنـهـ أكثر تجريدا، بسبب نقص

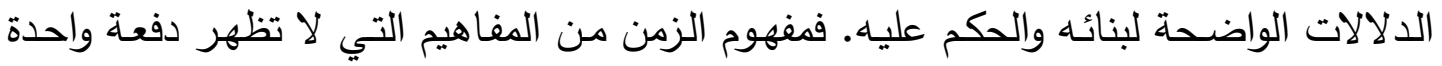

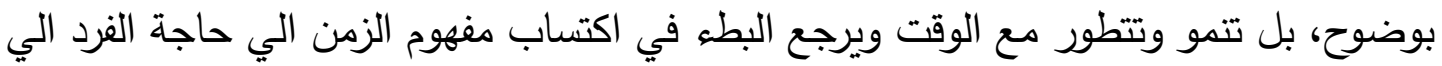

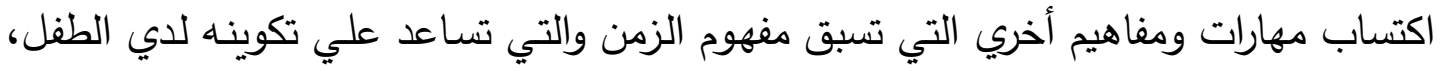
ومن هذه المهارات القدرة علي الاستدلال، والتسلسل والتتابع الزمني، الانعكاسية، والتحويلية،

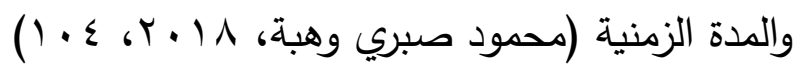
ويمر الأطفال ذوي الاعاقة العقلية بنفس مراحل النمو العقلي التي يمر بها الطفل

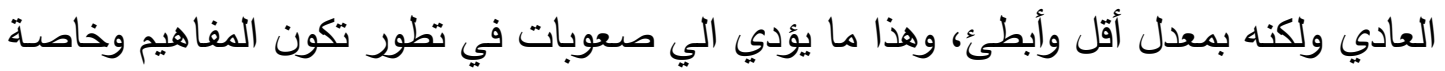

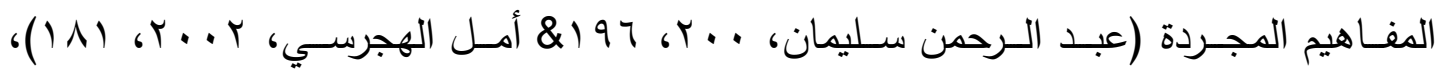
حيث تتكون وتتثكل المفاهيم من خلال التعامل مع الشيرات (Masj and Barkley, 2003) والخبرات التي يمر بها الطفل في المراحل المبكرة من عمره (piaget, J., \& Inhelder, B.,1982) وحيث يعاني هولاء الأطفال من مشكلات في التفاعل داخل البيئة في الطفولة المبكرة، فيتأخر لديهم تطور العديد من المفاهيم وخاصة المفاهيم المجردة كمفهوم الزمن.

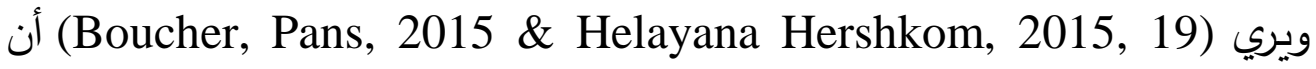
هناك ضعف عام في اكتساب مفهوم الزمن لاي الأطفال ذوي الإعاقة العقلية والتوحد مقارنة

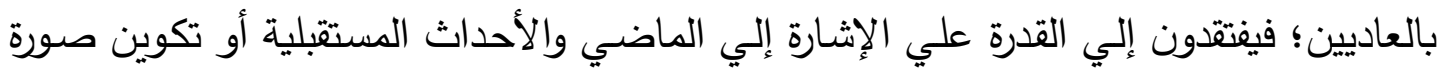

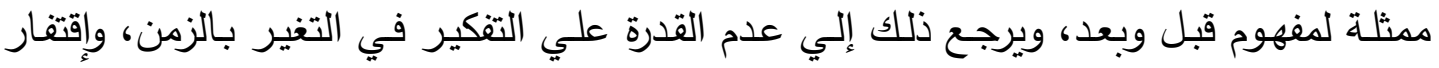
للتعميم، وإنخفاض الدافعية، وضعف لعفوم الإنتباه. 
وتؤكد العديد من الدراسات والخبرة الأكاديمية والعملية للباحثة أن المعاقين عقلياً لا يستوعبون الموقف التعليمي إلا بعد تكراره لعدة مرات وسرعان ما ينسون ما يقدم لهم، ومما يساعد على التذكر والاستفادة من مواقف التعلم، والتكرار دائمسا يكون نـاجح في حالـة ربطه من خـلال أنشطه تعليميه مدعمه بالوسائل البصرية والسمعية قدر الإمكان حتى يستوعبها المعاق عقليا بصورة صحيحة. إن المعاق عقليا يحتاج إلى أساليب وطرق تعليمية تتتاسب مع خصائص وطبيعة نموه، ولكنه في الواقع يتلقي الطفل المعاق عقلياً خدمات تروبويـة تقليديـة في مدارس التربية الخاصـة ترتكز علي تتمية المهارات الأكاديمية فقط، بينما لا تلقي إهتماماً كبيراً علي المفاهيم الاساسية كمفهوم الزمن. في حين أن التعلم حسب منهج مونتيسوري التعليمي يكون فعالا وداعما وموجها لطبيعة الطفل، لأنه يستخدم نظام بسيط من التعليم مبتعداً عن تراكم المعلومات والتلقين والحفظ، ففيه يتعرف الطفل على العالم من حوله من خلال حواسـه. لذا فان منهج ماريـا منتسوري يعد منهجا مناسبا جداً لتدريب الطفل المعاق عقلياً من حيث خصائصه وقدراته العقلية. ويعد منهج منتسوري أحد المداخل التي تعنى بتعليم الأطفال بإستخدام المحسوسات، ومن هنا يمكن وصفه على أنـه نظام تعليمي قائم على إستخدام الحواس وملاحظـة الأطفال وتتميـة العلاقة بين المعلم والطفل والبيئة والتفاعل بين المكونـات الثلاثة (Isaacs, 2015) ، هذا وتختلف بيئة منتسوري عن البيئة في الغرفة الصفية في المدارس السـائدة (Montessori, 1995. \& Hiles, 2015)، فهي تتصف بأنها بيئة جذابة ومشوّقة للأطفال لما تتضمنه من أجهزة تعليمية جاهزة في رفوف الأركان المختلفة، وأنشطة تعليمية تعكس جميع جوانب نمو الطفل، وتلبي حاجات الأطفال وميولهم، وقد وضعت منتسوري طرق تعلم وأنشطة (Montessori, 1985 Montessori, 1976, متنوعة تتناسب مع خصائص كل مرحلة من

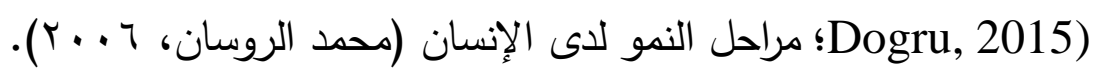
وقد صممت منتسوري أدوات خاصـة لاكساب المفاهيم الزمنية للأطفال المعاقين عقلياً في عمر مبكر • فهي تمنح الطفل المعاق عقلياً الفرصة في المشاركة ببرنامج يعتمد علي أدوات مجسمة. فقد صمم برنامج منتسوري علي أسـاس العمر ومستوي النموي والثقافة، بحيث تتاسب كل طفل (Poyraz ve Dere, 2001, 148)؛ وبطريقة تسهل علي الطفل اكتساب المفاهيم الزمنيـة كالمناسبات الاجماعية والسـاعة فصول السنة....الخ، عـلاوة الحريـة في إستخدام هذه الأدوات الملائمة لمستوي نموهم (sema ongoren \& Ali Ishan, 2009, 1164). 
لذا تمتاز الدراسة الحالية بإعتمادها علي منهج مونتيسوري في تتمية المفاهيم الزمنية لدي الأطفال ذوي الإعاقة العقلية؛ حيث حاولت الدراسة الحالية الإجابة عن التساؤل الرئيسي التالي:

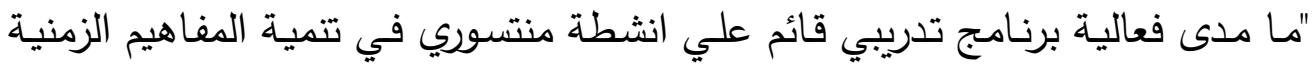

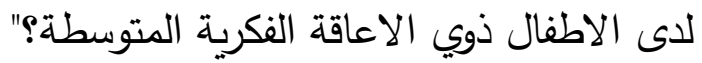

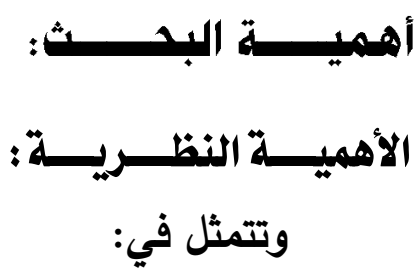

• إلقاء الضوء علي مفهوم الزمن لدي المعاقين عقليا من الدرجة المتوسطة.

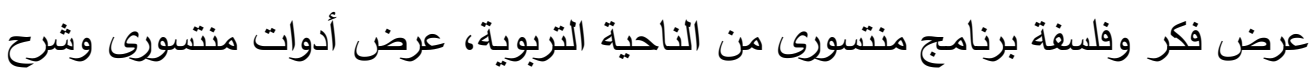
طبيعـة هذه الأدوات في مجال المفاهيم الزمنيـة والاستفادة من تطبيقاتها في مجال الأطفال ذوي الإعاقة العقلية.

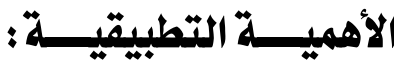 \\ تتمثل في: - 20 - n}

الإستفادة من نتائج تطبيق البحث بتقديم أداه لقياس لدي المعاقين عقلياً، ومعرفة مدي

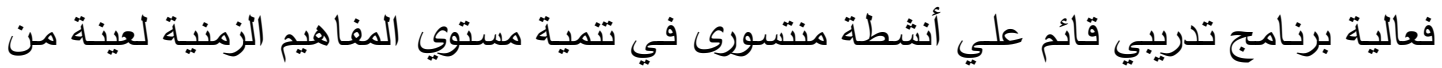

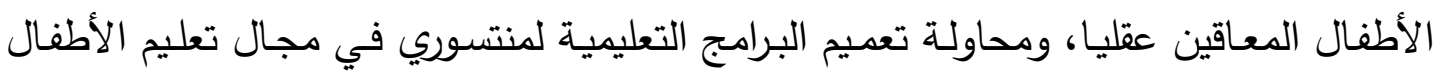
المعاقين عقليا؛ مما يضمن بيئة تعليم أفضل لهؤلاء الأطفال.

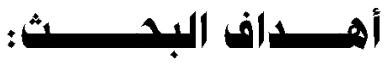

تهدف الدراسة الحالية إلي: تتمية مفهوم الزمن لدي الأطفال المعاقين عقليا من الدرجة

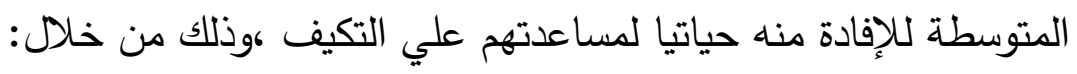

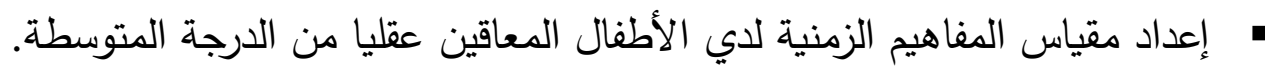

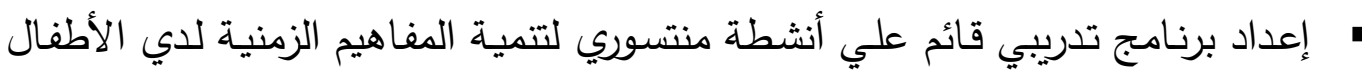
ذوي الاعاقة العقلية المتوسطة. • التوصل إلى بعض المقترحات والتوصيات التي يمكن أن تفيد العاملين والباحثين في

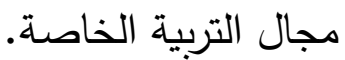




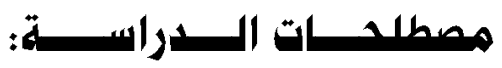

أولاً : برنامج تدريبي قائم علي أنشطة منتسوري

يعرف منهج منتسوري هو منهج وطريقة في التعليم صمدت لإعطاء الفرصسة للأطفال العاديين والمعاقين عقلياً لتحسين ذواتهم والحرية في الحركة وإختيار الأنثطة في بيئة معدة لذلك. وتعرفه الباحثة البرنامج إجرائيا بأنه هو برنامج ونظم ولتهين ومخطط يستند الي مبادئ منهج ماريا منتسوري من خلال مجموعة من الأنثطة؛ والهصممة بهدف إكتساب الأطفال ذوي الإعاقة العقلية

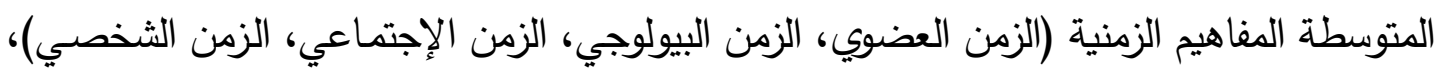
وقد صممت هذه الادوات بشكل يعطي الطفل الفرصة للتعلم بحرية ووفقا لمستواه النمائي.

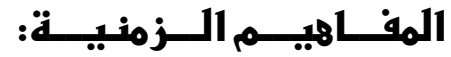

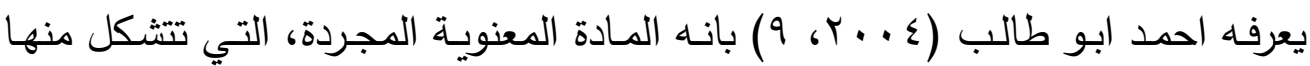
الحياة، فهو حيز كل فعل، ومجال كل تغير وحركة. ويقاس إجرائيا بالدرجة التي يحصل عليها الطفل علي مقياس المفاهيم الزمنية

\section{الطفل ذو الاعاقة العقلية المتوسطة:}

وتعرف الباحثة الطفل ذا الاعاقة الفكرية على أنه "الطفل الذي يقع معامل ذكاءه بين

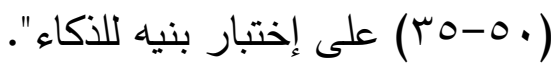

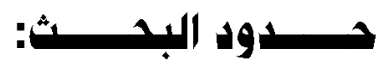

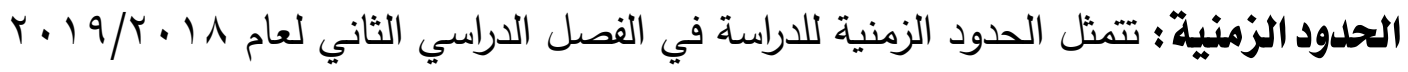
الحدود المكانية؛ وهى تتمثل في مدرسة للتربية الفكرية بحافظة بني سويف.

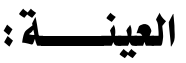

اولاً: عينة البحث الأساسية:

تمثلت عينـة الدراسة الحالية في (· (Y) طفلا من الأطفال المعاقين عقليا من الدرجة

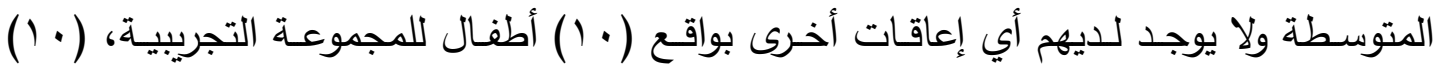
أطفال للمجموعة الضابطة

\section{ثانياً: عينة البحث الاستطلا عية:}

تكونت من (•r) طفلاً من طلاب مدارس التربية الفكرية التابعة لإدارة التربية الخاصة بمحافظة بني سويف ومراكزها (مركز الواسطي- مركز بوش). 
1- مقياس المفاهيم الزمنية للأطفال المعاقين عقليا (إعداد الباحثة). r- برنامج قائم علي منهج منتسوري لتتمية مفهوم الزمن (اعداد الباحثة). r- مقياس إستانفورد بنيه للذكاء "الصورة الرابعة إعداد لويس كامل مليكة (991 (1). ع - مقياس المستوى الاجتماعى الاقتصادى والثقافى، إعداد حمدان فضه (997 ( ).

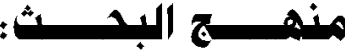

يتبنى البحث المنهج شبه التجريبيQuassi-Experimental لإعداد وتطبيق برنامج قائم علي منهج منتسوري وقياس مدى فعاليته في تتمية الدفاهيم الزمنية لاى الأطفال عينة البحث.

\section{فـــروض الــدراســة:}

1- توجد فروق دالة إحصائيا بين متوسطي رتب درجات أطفال المجموعتين التجريبية والضابطة في القياس البعدي علي أبعاد مقياس المفاهيم الزمنية لصالح المجموعة التجريبية. ץ-توجد فروق دالة إحصائيا بين متوسطي رتب درجات أطفال المجموعة التجريبية بين

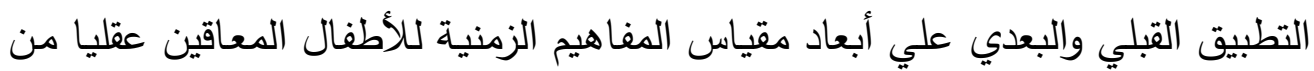
الدرجة المتوسطة لصالح التطبيق البعدي.

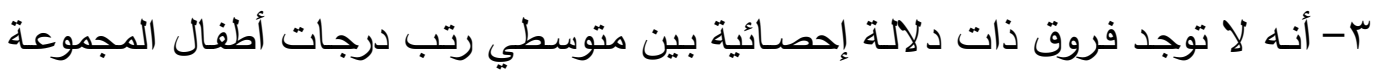
التجريبية في القياسين البعدي والتتبعي على أبعاد مقياس المفاهيم الزمنية.

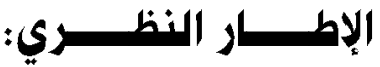

\section{: Intellectual Disability الإعاقة العقلية}

يعد موضوع الإعاقة بشكل عام والاعاقة العقلية بشكل خاصـة من أهم الموضوعات

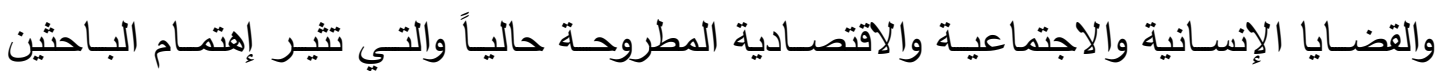
والعلماء. فقد أكد العديد من الباحثين إن العناية بالمعاقين تمثل إحدى مؤشرات الحضارة للأكم

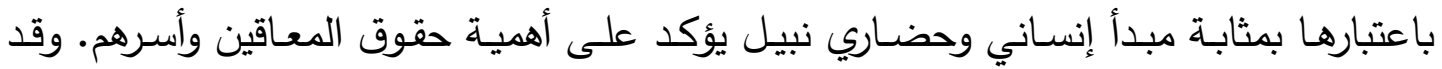

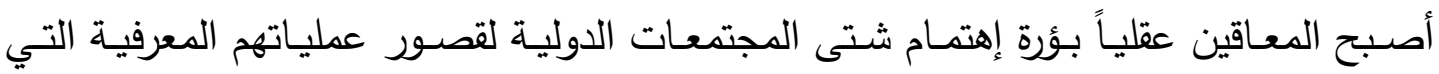
تتعكس سلباً على أدائهم الأكاديمي عند مقارنتهم بأقرانهم. 


\section{مفهــوم الإعـاقــة العقليــة:}

تثير الجمعية الأمريكية للإعاقات العقلية والنمائية American Association Intellectual Developmental Disabilities, 2008) تتميز بإنخفاض ملحوظ في كل من الأداء العقلي والسلوك التكيفي الذين تمثلههـا المهارات الهفاهيمية والإجتماعية والتكيفية العملية وتظهر هذه الإعاقة قبل بلوغ الفرد الثامنة عشرة من عمره (جمال الخطيب، · (1.Y، ع (1). ويثير جروسمان (Grossman, 1983) إلى: تمثل الإعاقة العقلية مستوى من الأداء الوظيفي العقلي والذي يقل عن متوسط الذكاء بإنحرافين معياريين ويصاحب ذلك خلل واضح

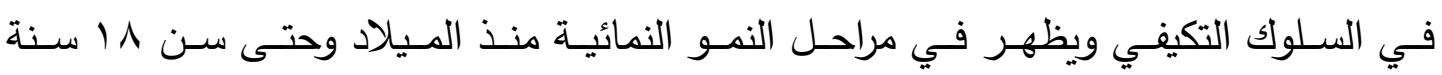

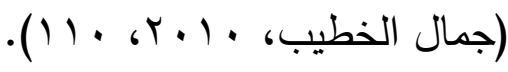

\section{تصنيـذف الإعـاقـة العقليـة:}

لقد ظهرت العديد من التصنيفات التي تصنف الإعاقة العقلية إلى فئات حسب معايير مختلفة فقد تصنف الإعاقة العقلية بحسب درجة الذكاء أو بحسب الثكل الخارجي وبحسب القدرة على التعلم كالتصنيف التربوي الذي يصنفها حسب القابلية للتعلم أو القابلية للتدريب.

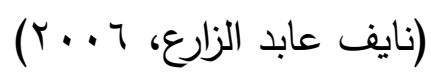

ويعتبر التصنيف المتعدد الأبعاد الأكثر إنتثـارا وإستخداما لأنسه يعتمد على مستوى الأداء الوظيفي الذهني وعلى درجـة النمو والنضـج بالإضـافة إلى درجـة القصـور في السلوك التكيفي وأعلنت الجمعية الأمريكية للضعف العقلي (AAMD) تصنيفا لفئات الإعاقة العقلية حيث تم تقسيم حالات الإعاقة العقلية إلى الفئات التالية: 1- الإعاقة العقلية البسيطة (الخفيفة): وتتراوح نسبة ذكاء أفرادها بين (••) إلى (•V) درجة. r- الإعاقة العقلية المتوسطة: وتتراوح نسبة ذكاء أفرادها بين (•0) إلى (0ب) درجة. ب- الإعاقة العقلية الثديدة: وتقع نسبة ذكاء أفرادها بين (ب0) إلى († (Y) درجة.

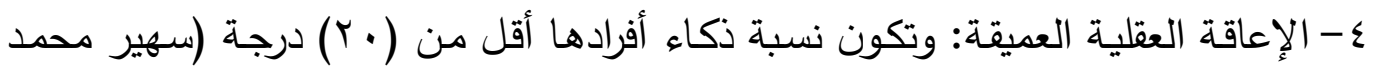

$$
\text { سلامة شاش، r . . r، 0 ؛). }
$$




\section{فمـائـم الأطفـال المعـاقيـن عقليـا:}

يتسم الأطفال المعاقين عقلياً بمجموعة من الخصائص وهي كالتهالي التصالي:

\section{أ) خصـائسـص النمــو المعـرفـي:}

يتميز هؤلاء الأطفال عن غيرهم ببطيء التعلم والقدرة المحدودة على التعلم، كذلك فإنهم يتصفون بسرعة النسيان وقدرتهم على التركيز متدنية وقدرتهم على التعميم محدودة كما أنهم يواجهون صـوبات في نقل أثر التعلم إلى مواقف جديدة ؛علاوة على أن تعلمهم للمهارات التعليمية المجردة صعب للغاية فهم يتعلمون عن طريق الأشياء المحسوسة وعن طريق العمل التراكل والتكرار والتسلسل المنظم (أحمد السيد إسماعيل، 990 (1)

\section{ب) خصسـائسص النمـو اللغـوي:}

تعتبر الخصائص اللغوية والمشكلات المرتبطة بها مظهرا مميزا للإعاقة العقلية ولذلك ليس مستغربا أن نجد أن مستوى الأداء اللغوي للأطفال المعاقين عقليا هو أقل بكثير من أقرانهم

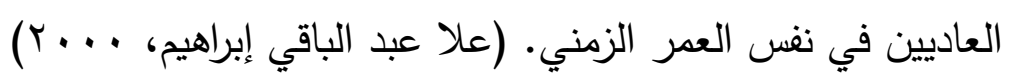
إن التعلم اللغوي لـى الأطفال المعاقين عقليا محدود وحصيلتهم اللغويـة ضـعيفة؛ ولا غرابة في ذلك لأن النمو اللغوي يرتبط إرتباطا وثيقا بالنمو المعرفي ولذلك يعاني الأطفال المعاقون عقليا من صعوبات جمة في فهم التعليمات وإستيعاب التوجيهات (جمال الخطيب، ب . . ب).

\section{ج) خصسائسص النمـو الإجتماعسي:}

يواجه الأطفال المعاقون عقليا العديد من المشكلات الإجتماعية فقد يواجهون صعوبات في التعامل مع المواقف الإجتماعية المختلفة فتصدر عنهم إستجابات غير مناسبة إضافة إلى الى

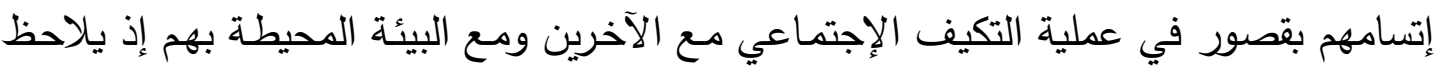
على الطفل المعاق عقليا الإنسحاب وعدم القدرة على إنثاء علاقات إجتماعية فعالة مع الغير الإعائ

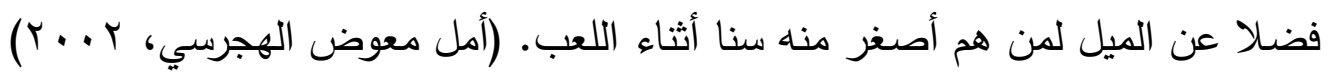
د) خصــائسص النمـو الحسركسي:

يتصف النمو الحركي لاى الأطفال المعاقين عقليا بالتباين بشكل عام فكلما زادت شدة

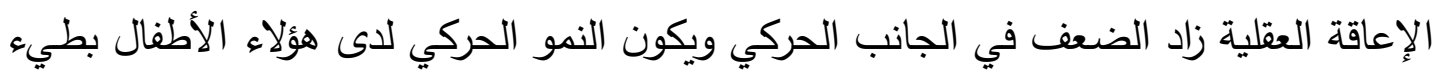

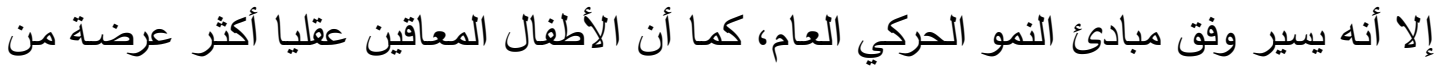

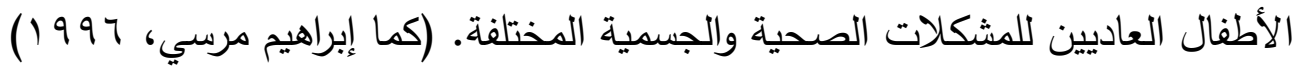




\section{Time Concept}

يعد مفهوم الزمن من المفاهيم التي إهتم بها جان بياجيه ـ فقد درس بياجيه مفهوم الزمن وإعتبره عنصـرا اساسيا من عناصـر الفكر؛ اذ يعمل علي ترتيب البينـة الموضـوعية للمحيط، وتتمثل في علاقة الأحداث فيما بينها (يعلاوي خليدة، ع ا ـ ب، 0). فمفهوم الزمن من المفاهيم المعقدة حيث لا نتمكن من رؤيتها أو لمسها فهي تشتمل على الإحساس بالمسافة الزمنية التي تحدث بين الحدث والأخر وهو ما يعرف باسم تسلسل الأحداث وما يرتبط بالزمن من معرفة الأيام، الأسبوع، الشهور والسنوات (Nain Liu, 2012, 1). ويعرف أحمد ابو طالب (ع . . Y، 9) الزمن: بانه المادة المعنويـة المجردة، التي تتشكل منها الحياة، فهو حيز كل فعل، ومجال كل تغير وحركة. وعرفه (paule Aimard,1994,10) بانه مجموعة من الاحداث المتناسقة فيما بينها، وكل ماهو منظم في حياة الانسان هو عبارة عن وحدة من وحدات الزمن باختلاف المدة. ويقصد بالزمن أنه مجموعه من المفردات التي يدركها الطفل في محيطه المباشر والتي تعبر عن إحساس زمني بين المواقف والخبرات التي يعيشها في حاضـره مثل: قبل - بعداليوم- غدًا - الأمس - صباحًا- مساءًا - زمن السـاعة- زمن التوقيت (اليوم والأسبوع والثـهر والسـنة) - تتابع الولادات وربطها بالأعمـار - وصـف أحداث بثكل متسلسـل (فاضـل خليل،

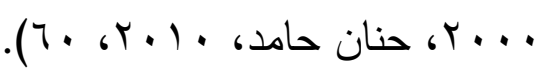

وتعرفه الباحثة بأنه قدرة الطفل علي إدراك مفهوم الزمن العضـوي والزمن الاجتمـاعي والزمن الثخصسي والزمن البيولوجي. ويقاس إجرائيا في الدراسة الحالية دن خلال الدرجة التي يحصل عليها الطفل علي أبعاد مقياس المفاهيم الزمنية

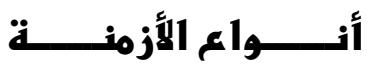

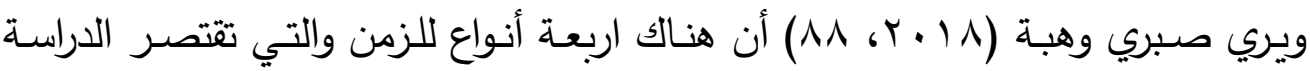

$$
\text { الحالية علي دراستها وهي: }
$$

1- الزمن العضوي: وهو الزمن الذي نستطيع أن نتحكم فيه، من خلال إستعمالاتتا للوقت

بواسطة الساعة. حيث تشمل قدرة الطفل علي قراءة الساعة كاملة وأنصافها. ץ- الزمن البيولوجي: انه الزمن الذي تحتمه علينا الظواهر المادية، كالتتباع بين النهار والليل، والثـتاء والصـيف، وهذه التغيرات التي تجعلنـا نتاقلم لكي نسـطيع أن نعيش في العـالم المحيط. وتثمل قدرة الطفل علي التمييز بين فصول السنة والتغيرات المميزة لكل فصل. 
r- الزمن الثخصي أو الفردي: انه الطريقة التي يدرك بها كل شخص الزمن في مجالات

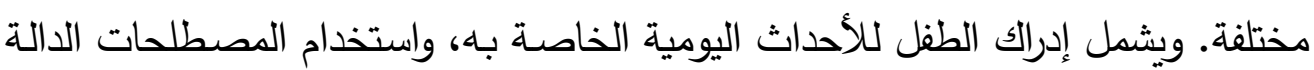
علي الزمن كفهوم قبل وبعد- مفهوم أمس واليوم والغد، ومفهوم الليل والنهار ...الخ. ع - الزمن الاجتماعي: وهو الزمن المدرك من ظرف مجتمعات من نفس الحضارة، كتقسيم الايام والاسابيع والأشهر، وكذلك المناسبات الخاصة بالاعياد الوطنية والدينية.

\section{مراحل تطور مفهوم الزمن في ضوء نظرية بيابيه}

إن مفهوم الزمن وفق بياحيه لا يأتي بوضوح دفعة واحدة، بل ينايه ينمو ويتطور مع مرور

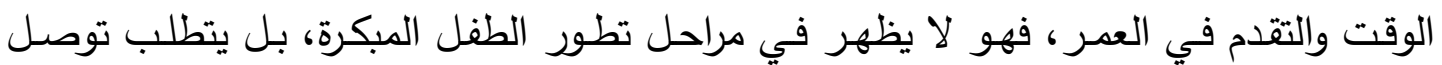
الطفل إليه وجود عمليات بنائية تدريجية مثل باقي المفاهيم، مثل السرعة والقيمة والكم والوزن

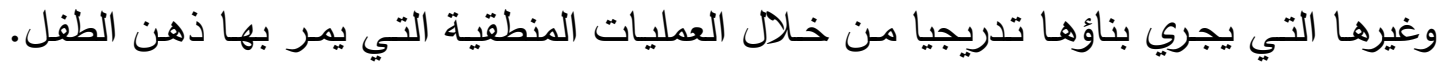

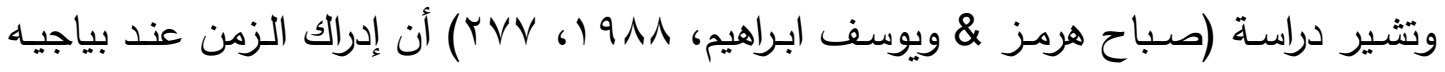
ينشأ لدي الأطفال بصورة متعاقبة وبارتباطات متسلسلة الواحدة بالاخري.

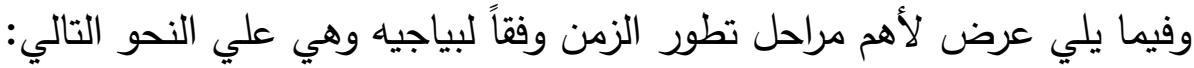

\section{1- المرحلة الحس حركية Sensori-motor:}

تمتد هذه المرحلة من عمر (صفر - سنتين)، ويطلق عليها التنكير من خلال الحركة،

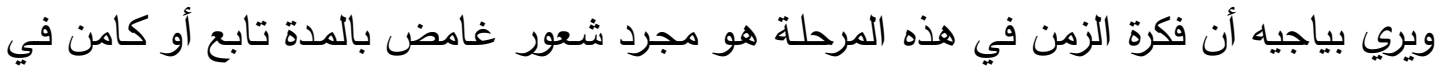

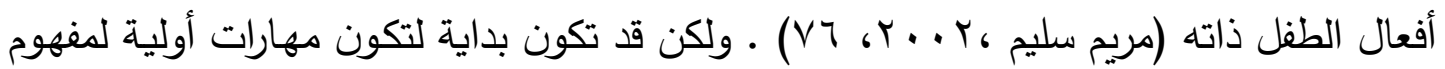

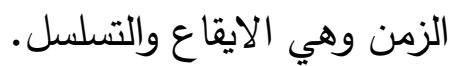

ومع نهاية هذه المرحلة يتطور مفهوم التتابع لدي الطفل قليلاً؛ حيث يظهر الرضيع في

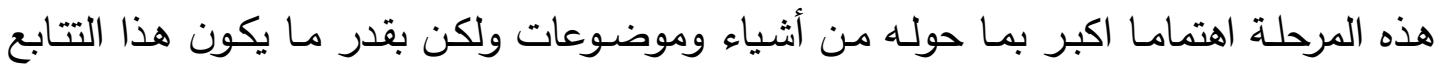

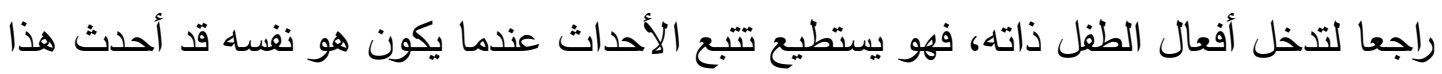

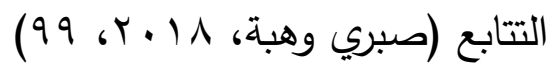

وفي عمر (9-11 شهراً) يتحـول الطفل من التسلسل الزمنسي الي التسلسل الزمنسي

الموضوعي. كما أنه بنهاية هذه المرحلة يدرك الطفل مفهوم قبل وبعد والحاضر والمستقبل. ويري بياجيه ان الطفل في نهاية هذه المرحلة، يبدا في فهم الزمن كوسطاً عاماً كما في لئي

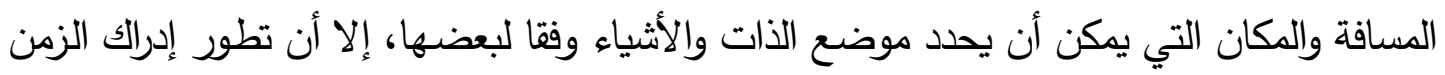




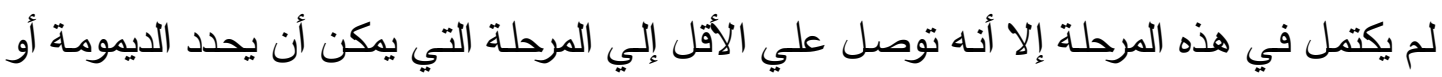

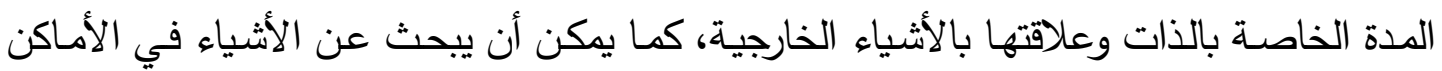
المناسبة والمحتملة بنجاح. بذلك يصبح السبيل ممهاً ومهيأ لترتيب تسلسلي ومتتابع للأحداث زمنياً.

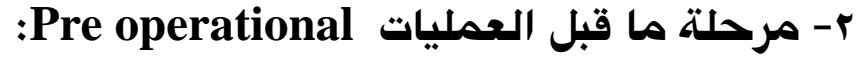

تمتد هذه المرحلة من عمر (r-Y سنوات) وتسمي مرحلة التفكير التصوري. والطفل في

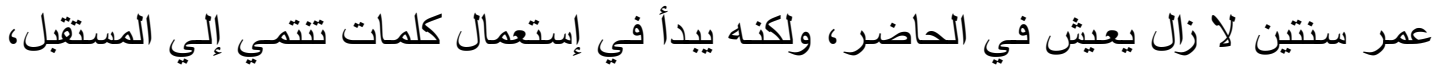

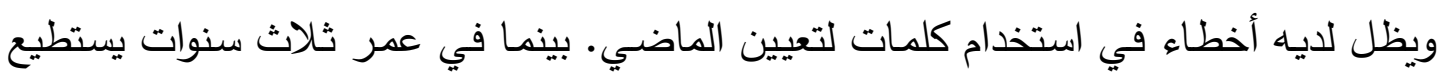

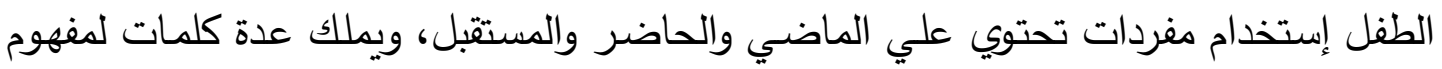

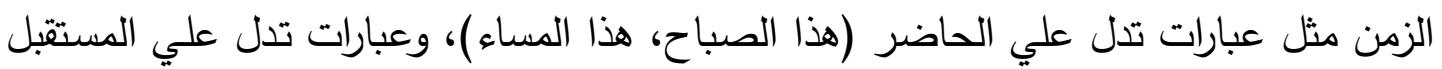

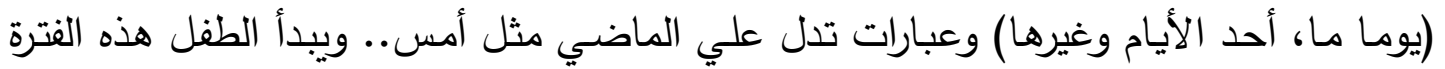

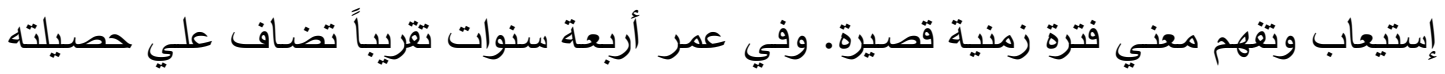

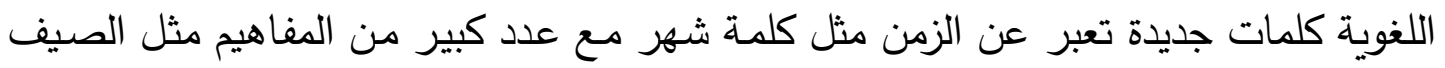

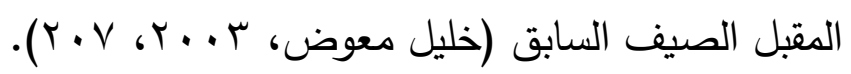
وعند خمس سنوات يكتسب الطفل الكثير من المفاهيم مثل هنا والان ويعرف ترتيب الأحداث خلال اليوم، وذكر وترتيب أيام الأسبوع، كما أنه يستطيع أن يجيب علي لئي اسئلة كم

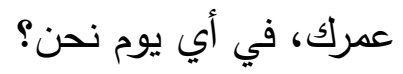

وعند ست سنوات تقريبا تزداد معرفته أكثر للمدة؛ فيستطيع تمييز الفصـول علي حدود

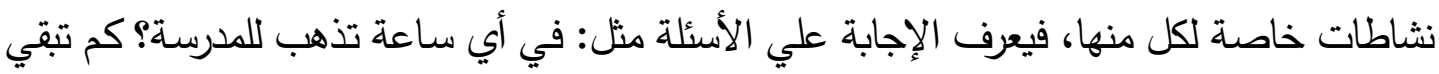

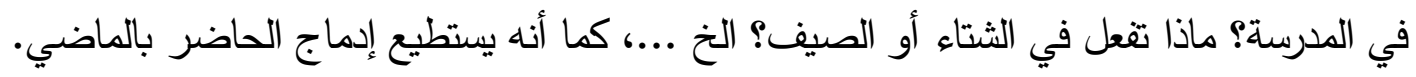
r- مرحلت العمليات المجردة Concrete operation: تمتّ من (V-11 (1 سنة) عند سبع سنوات تقريبا، يدرك مفهوم الساعة والدقائق وتسمية

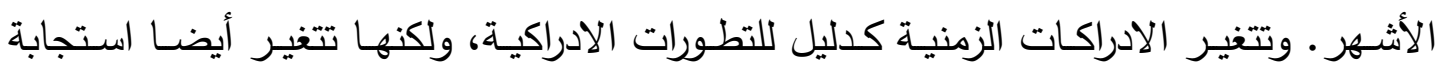

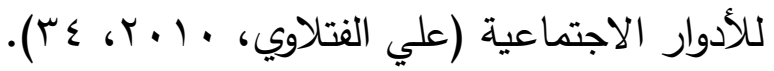

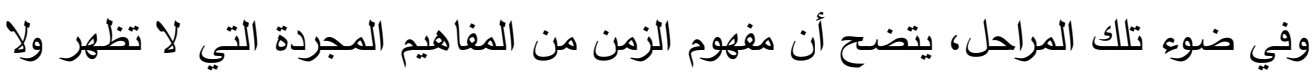

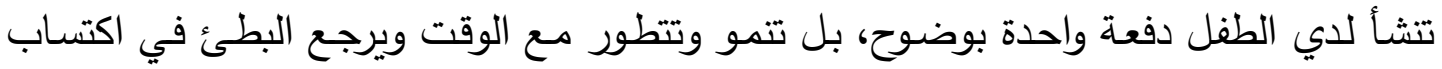

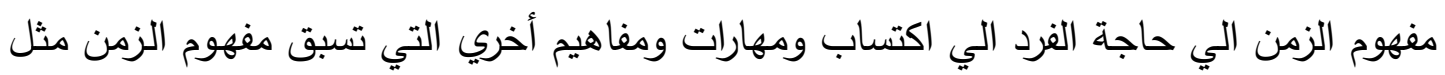
القدرة علي الاستدلال، التسلسل والتتباع الزمني، الانعكاسية، التحويلية، المدة الزمنية. 
ويري (Robinson, 1976) أن المعاقين عقليا يمرون بمراحل النمو المعرفي لجان

بياجيه مثل العاديين (مرحلة الحس حركية، ومرحلة ماقبل العمليات، مرحلة المفاهيم المجردة) ولكنهم بمعدل أبطأ. فيذكر (Piaget \& inhelder, 1968) أن المعاقين عقليا من الدرجـة البسيطة يصلون الي ما قبل مرحلة المفاهيم المجردة بينما يصل المعاقين عقلياً من الدرجة المتوسطة الي مرحلة ما قبل العمليات فقط، في حين يصل المعاقين عقلياً من الدرجة الثديدة والعميقـة الي المرحلـة الحس حركية فقط. في حين أن الافراد في الفئسة البينيـة يتعدوا مرحلـة العمليات المجردة. ويؤكد (lovell \& slater, 1960, 40) أن مراحل النمو المعرفي لدي المعاقين عقلياً تكتمل في عمر زمني متأخر .

\section{مظــاهـــر اضطــراب مفهـوم الـززمــن}

هناك مجموعة من المظاهر أو الأعراض التي قد يعاني منها الطفل الذي لديه إضطراب في الوعي بالزمن، مثل معانـاة الطفل من صسعبات في تعلم كتابـة وقراءة الحروف بالترتيب، صسوبات في القراءة والكتابة، صسوبة في إعادة ترتيب الجمل والأعداد، صعوبة في سرد قصـة وعدم القدرة علي إيجاد نظام لتسلسل الأحداث، نسيان إتباع الترتيب والتسلسل في إرتداء ملابسـه، عدم معرفة الأبعاد، غياب مفهوم الساعة، ضعف التتظيم الخاص بالجدول المدرسي أو اليومي، صعوبة في ذكر تاريخ ميلاده ...الخ (جاد البحيري واخرون، 0 (، ـ ( • ب).

\section{تــدربــب الأطفــال علي تنـمبـة مفهــوم الـزمـن}

يعـاني الأطفال ذوي الإعاقـة الفكريـة مـن قصـور في النهـو العقلي، وهذا يؤدي إلـي صعوبات في تطور تكون المفاهيم وخاصـة المفاهيم المجردة (عبد الرحمن سليمان، ا +.. ب،

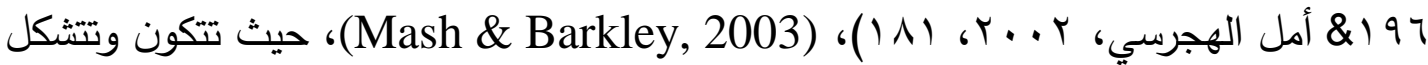
المفاهيم من خلال التعامل مـع المثيرات والخبرات التي يمر بها الطفل في المراحل المبكرة من عمره (piaget, J., \& Inhelder, B., 1969) وحيث يعاني هؤلاء الأطفال من مشكلات في التفاعل داخل البيئة في الطفولـة المبكرة، فيتأخر لديهم تطور العديـد مـن المفـاهيم وخاصــة المفاهيم المجردة، ويعتبر مفهوم الزمن من أكثر المفاهيم صسوبة، لأنـه أكثر تجريدا، بسبب نقص الدلالات الواضحة لبنائه والحكم عليه.

وقد أثتتت العديد من البحوث أن هؤلاء الأطفال لا يستفيدون من المناهج العادية في

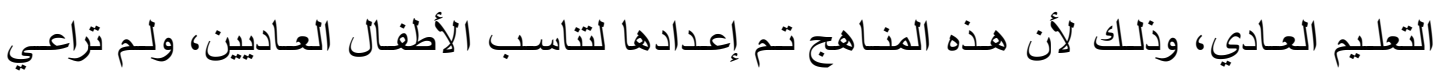


احتياجات الطفل ذوي المشكلات في التعلم (جيستن وآخرون، Reynolds, D., 2001 العقلية، حيث تتعامل مع الطفل وفقا لقدراته العقلية، وسرعته الفردية.

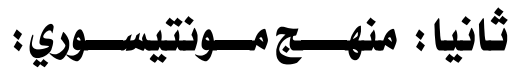

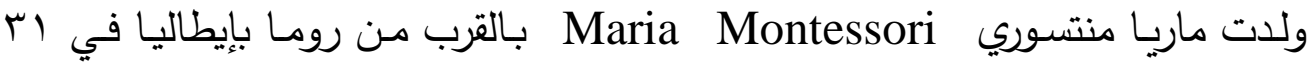
أغسطس • NVV وعملت كمدرس مساعد في العيادة النفسية بالجامعة ثم قامت بالتدريس في مدارس ضـعاف العقول، ولـذلك أسست مـا يطلق عليه وأسمته "دار الطفل". وتركز ماريـا منتسوري على ذات الطفل وقدرته على التكيف مـع البيئة من حوله أكثر من تركيزه على كم المعلومات التي يختزنها في عقله الباطن رغم ما يحتويه منهج المونتيسوري من تفصيلات دقيقة قد لا نتوقع أن يعيها الطفل، وفي الحقيقة هو يفهمها ويختزلها في عقله حتى يستفيد منها عندما

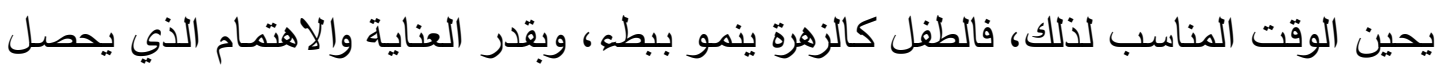
عليه بقدر جمال الزهرة والتي تتضح معالمها عليه في سلوكه وأدائه.

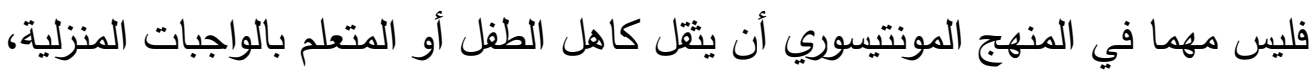
بل الأهم أن يعرف كيف يؤدي واجبه بحب وبإقبال شديد بداخل المدرسة، ولكي نجعل المنزل

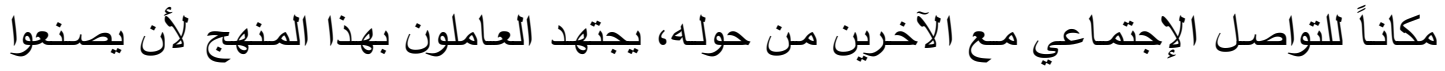
للمتعلم عالماً يحبه كثيراً، ويمده بخيارات تساعده على الحوار والمناقثنة والاكتشاف والاستتناج بناء على رغباته وميوله بالإضـافة إلى تعميق أواصر المحبة بينه وبين عائلته، فالأسرة هي أساس نجاحه وهي المحرك الإيجابي في حياته.

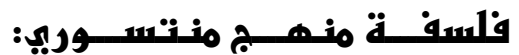

تقول ماريا منتسوري "إن الطفل ليس مخلوقاً جامداً غير قادر على التحرك، يدين لنا بكل ما يفعله بل وكل ما يستطيع القيام به، بل إن الكبار يعتبرون الطفل وعاء فارغ نقوم نحن بملئه لكن المسألة على العكس من ذلك تماهاً، فإن الطفل هو والد الكبير البالغ أي أن الكبار

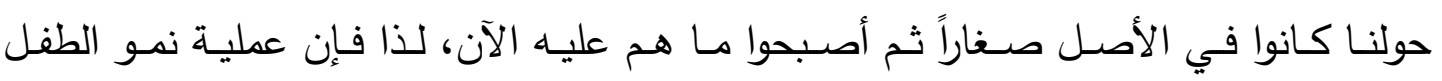
وشخصيته هي التي تحدد ما يكون عليه الإنسان البالغ، الطفل يتفاعل ويتلقى بعقله ثم يثكل ما ها

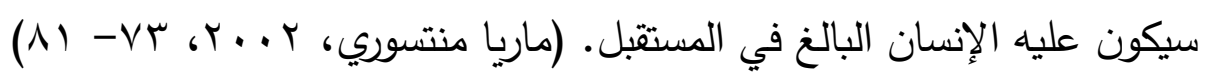


وعرفت منتسـوري عـاملين داخلين يسـاعدان على نـــو الطفـل "الفترات الحساسـة،

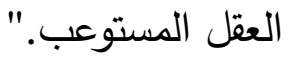

\section{أ ) الفترات الحساسة Sensitive Periods:}

وهي فترات محددة تظهر فيها إستعدادت معينـة وتتـاح إمكانيـات معينة أو تدريبات تتنهي بانقضـاء هذه الفترات، فيكون الطفل في لحظـات معينـة من حياته يظهر إهتمام بالغ

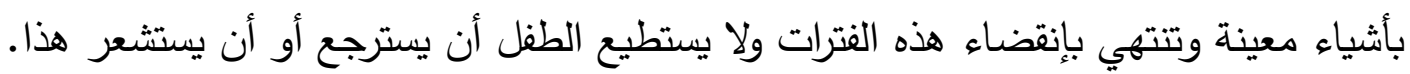
وإن هذا الإهتمام والتركيز ما هو إلاشعور جارف يشد الطفل إلى تلك الجوانب تتبع من اللاوعي ثم تبدأ هذه العاطفة تتحرك في نثاط إبداعي رائع مع العالم الخارجي. وتتمثل هذه الهـ

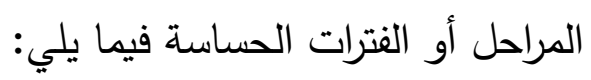

هساسية الطفل للنظام والترتيب Sensitive for Order Sensory Learning through Five Senses التعلم من خلال حواس الطفل الخمس ولن Interest in Small Objects. حساسية الطفل للأجسام الصغير الصنام هefinement of Motor Skill حساسية الطفل لتنسيق الحركة والمشيكير Language\& Mathematic Acquisition حساسية الطفل للغة والرياضيات

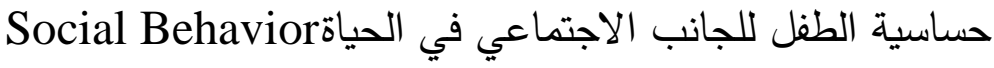

ب) العقل المستوعب:The Absorbent Mind لاحظت منتسوري أن الأطفال الصغار يتعلمون بشكل فريد منذ الولادة وحتى الست

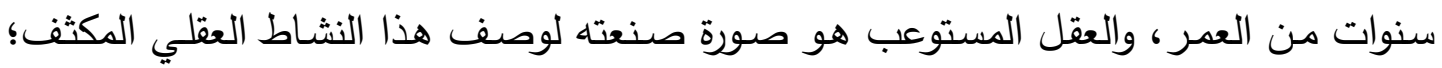
حيث يصف ويشرح العمليات التي يقوم بها الطفل من أجل اكتساب المعرفة من خلال البيئة المحيطة به (Silvana Montanaro, 1991, 83). فالطفل منذ الولادة عليه أن يتعلم كل شيء، حيث لا يوجد لديه أدوات غير ردود الأفعال

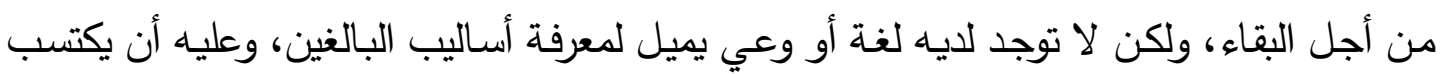

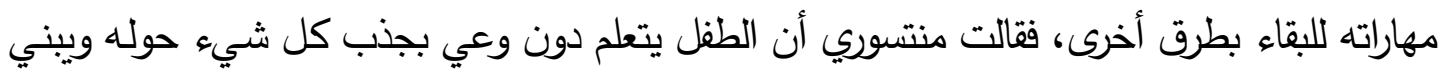
ذاته في الواقع، وذلك باستخدام حواسه فينشئ نفسه من خلال استيعاب بيئته بتصرفه الجدي المفعم بالحياة، ويفعل ذلك بسهولة وبشكل طبيعي دون تفكير أو اختيار (montessory, 1967, 19). 


\section{منـتستسوري والابتتكــار:}

الابتكار للدى منتسوري أمـر حيوي منذ أن أدركت أنـهـ الجزء الذي يسـاعد الأطفـال

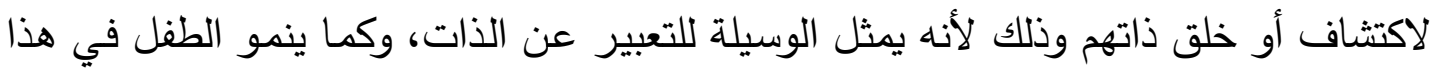
العالم فإن استكثاف الذات مهم في تثكيل وجودهم. وترى أن نمو الابتكار يتطور بصورة تلقائية وأن ذكاء الطفل يؤسس من خلال تفاعله مـع البيئة المعدة، فتطوير الابتكار يعتمد على تطور الطفل خلال مراحل النمو المعرفي من لاند

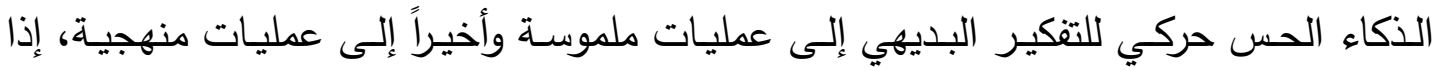
الابتكار ليس مطور بصورة كبيرة خلال التركيز على تحفيزه بقدر ما أنه يتطور في نهاية عملية طويلة من التطور المعرفي. وهناك عدة خطوات للقيام بأنثطة المنتسوري يراعي فيها التسلسل ليتمكن الطفل من تطبيقها بشكل أمثل، ويحقق الهدف من كل نثاط مطلوب منه تحقيقه دون التقيّد بزمن معين.

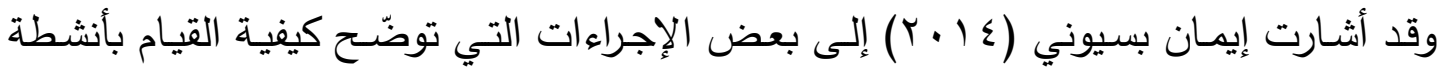

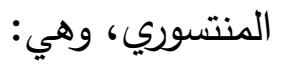

• أن تكون الأنشطة متدرّجة من الأسهل إلى الأصعب في رفوف قاعة منتسوري.

يكرّر الطفل النشاط عدة مرات حتى يصل إلى مرحلة الإتقان لينتقل إلى النشاط الذي يليه.

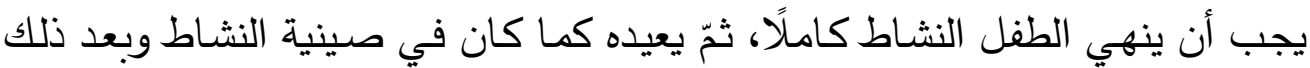
يرجعه إلى رفوف القاعة في مكانه السابق، وعدم الاستسلام للطفل في حالة رغبته في ترك النشاط دون إكماله، فقد لا يستطيع الجلوس فترات طويلة، لذا يجب إعطائه في البداية أنثطة قصيرة حتى يتعود على ذلك تدريجيًا.

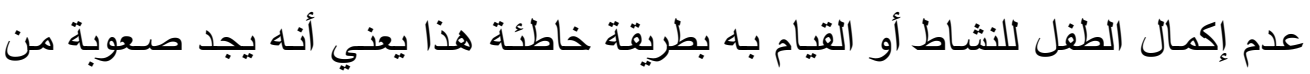
ناحية إيلامه لعضلات يده مثلا يحاول نقل حبات الفول بالملعقة ولكن يستسلم فينقلها

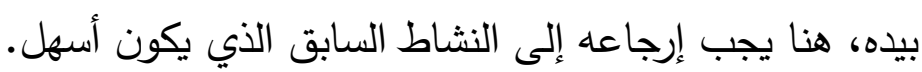

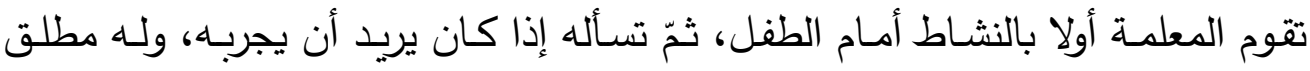
الحرية في اختيار الأنثطة. عدم القول للطفل أنه أخطأ في عمل النشاط أنها أو سحب النشاط منه في حالة الخطأ بل لابد من إعادة النشاط أمامه عدة مرات دون ملل. تعويد الطفل على النظام والترتيب في عمل الأنثطة. 


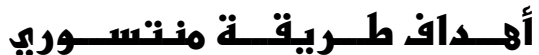

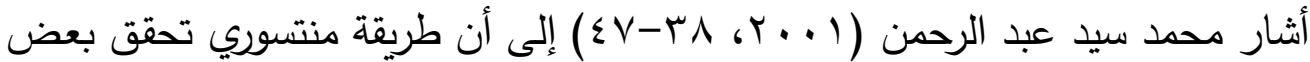

$$
\text { الأهداف والتي منها: }
$$

\section{ا- الاستقـــلاليــة والتركيـز}

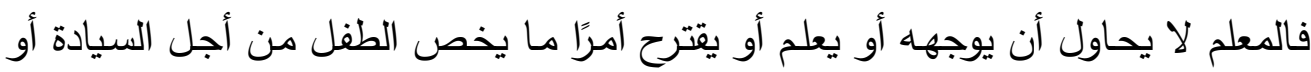

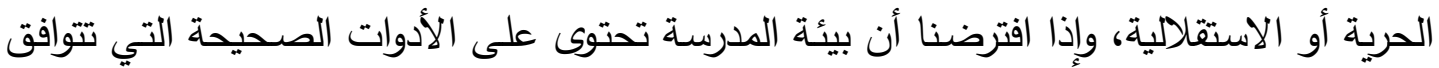

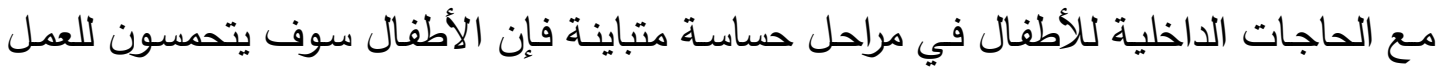
بهذه الأدوات من تلقاء أنفسهم بدون إثراف أو توجيه من الكبار، ولقد قضت منتسوري فترات

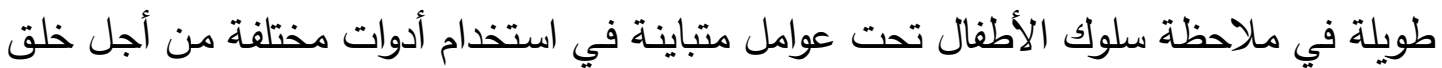

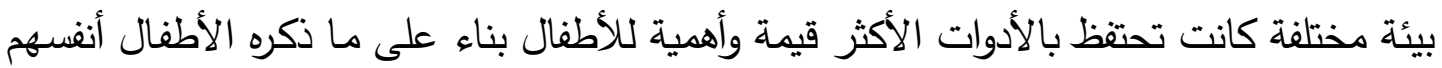

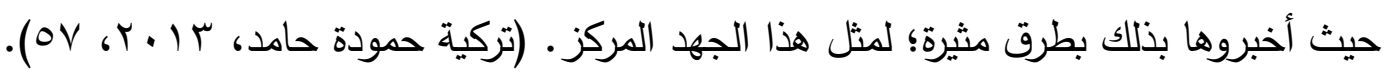

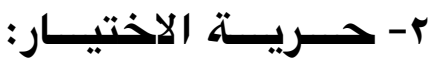

وقد توصلت منتسوري إلى معرفة هذه السمة في الطفل بطريقة لم تكن تتوقعها أبدًا، ففي أحد الأيام عادت المعلمة إلى بيتها ونسيت أن تغلق الأرفف التي تضع فيها المواد التعليمية، وعندما

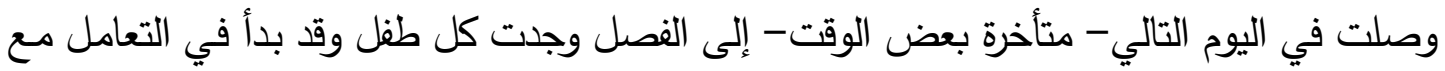

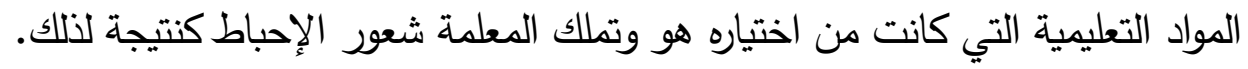

$$
\text { r- الثــــواب والعقــــاب: }
$$

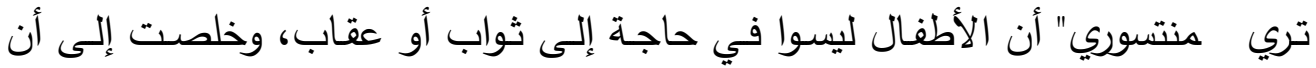
التنافس بين الأطفال أو إثابتهم أو إنزال العقاب بهم معوق لإختيار الطفل وحريته في تحديد

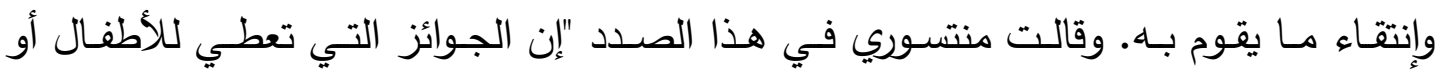

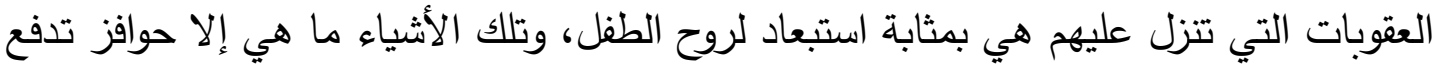
الطفل إلى بذل مجهود غير مطلوب أو تجبره عليه، لذا يجب الفصل تمائًا بين هذه الأشياء

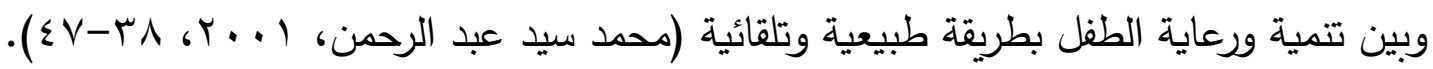

\section{ع- ســــوء السلـــــوك:}

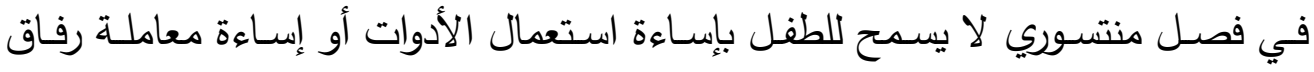
الدراسـة، لذذلك كان احترام الآخرين والحفاظ على أدوات الددرسـة ينمو نـوًا طبيعيًا فالأطفال 
يدركون كيف أن العمل مهم جدًا بالنسبة إليهم، فإذا قام طفل بمضايقة رفاقه الذين يعملون بتركيز عميق فإن هذا الطفل عادة ما يجبر على البقاء بمفرده، وبهذه الطريقة فهم يحترمون هذه الرغبة

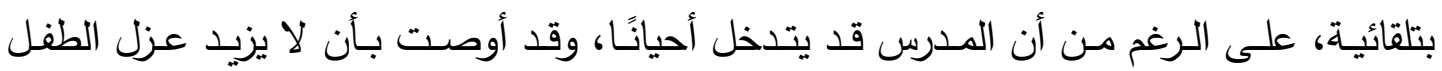

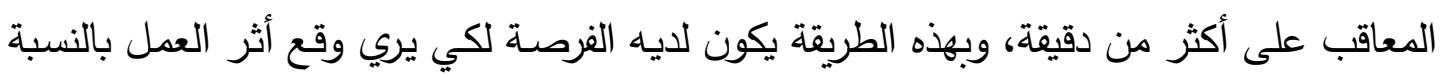

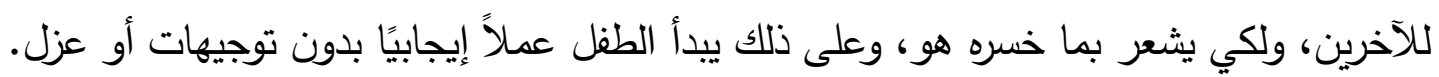

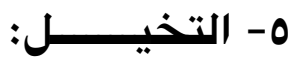

والتخيل هو عملية يتم فيها تكوين صور عقلية للأشياء في غياب المحفز المـادي

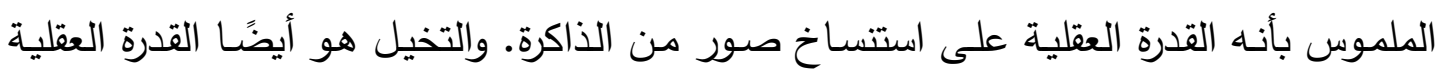
على تكوين صور أصلية ومفاهيم وذلك بربط نتاج الخبرات السابقة. وترى منتسوري أن التخيل هو "قوة إبداعية ذات فائدة عظيمة للجنس البشري لأنها مبنية على الواقع وتتبع منهاته، والتخيل يعمل على توليد تطبيقات عملية".

الأسسر النفسية الته بنيت عليما طريقة منتسورى فى تربية الطفل ذوى الإمتياجات الفاصة: وتتحصر هذه الأسس فى أربعة قوانين:

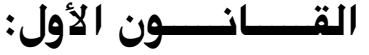

والذى يتمثل فى الطريقة التى تقوم عليها منتسورى حيث مخاطبة عقلية هؤلاء الأطفال من خلال الأنشطة المقدمة لهم والتى تكون أقل من الأنشطة التى يقوم بها الأطفال الأسوياء.

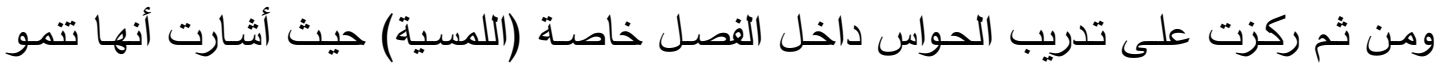

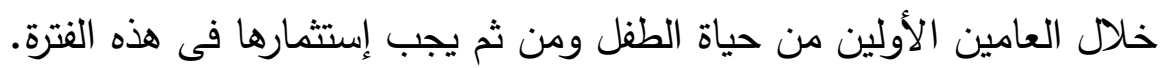

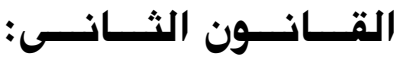

مراعاة التطور العقلى للأطفال ذوى الإحتياجات الخاصة ومراعاة ميولهم، لذلك يجب أن

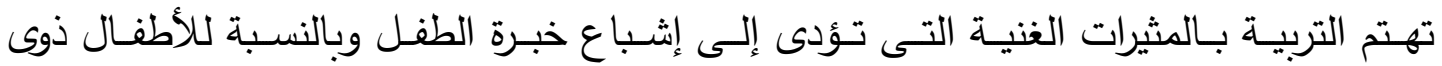
الإحتياجات الخاصة فهم يمروا بلحظات نفسية يكون إستعدادهم العقلى فيها أفضل من فترات أخرى، لذلك يجب إستثمار هذه الفترات. القـــانـــون الثـــالــث:

الذى يقوم على ترك الحريـة للطفل فى العهل بمفرده وإثباع ميولها، ولذلك أشـارت

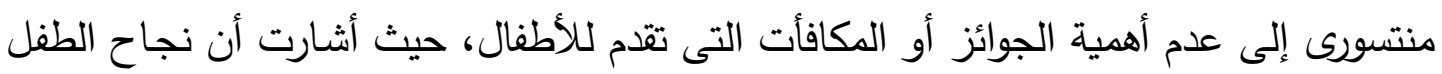

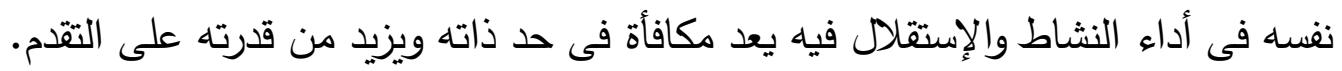




\section{القـــانــون الـــرابــع:}

يتمثل فى ترك الحرية للطفل ذوى الإحتياجات الخاصة بالحركة المنظمة داخل الفصل وعدم تقييد حركته لمراعاة حاجاته النفسية بما يساعد على تحقيق النمو الذاتى له.

\section{فصــول/ غــــ المــونتيســوري:}

الفصل الواحد يضم أطفالا تتراوح أعمارهم بين سن بـ إلى 7 سنوات ليتعلم الأطفال التعامل

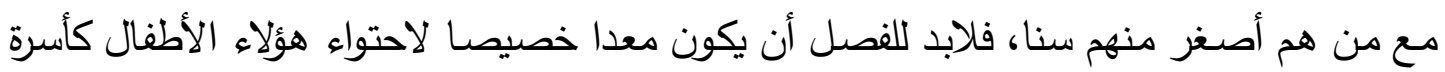
واحدة متعاونة تسودها الألفة والمحبة، لذا أصبح من المهح أن نغير مسمى الفصل فيصبح "غرفة" ليشعر الطفل بالحميمية والتقارب مع معلمته وأصدقائه في الفصل، لذلك لابد من تهيئة البيئة بشكل متكامل لتتيح للطفل كافة فرص التعلم الذاتي كما سمته "ماريا مونتيسوري" التي نجحت في تجريب وسائلها على الأطفال المعاقين كما سبق أن ذكرت مما دفعها إلى تطوير وسائلها وتقنينها بثكل كبير في رفع إنتاجية الأطفال العاديين واكتثاف قدراتهم بشكل مذهل، إذ يعتمد المنهج على قاعدة الخصوصية المطلقة والفروق الفرديـة، فالفصل ليس مكانـا نجبر على الجلوس فيـه فقط لتلقي المعلومات دون ممارستها بشكل حي، فممارسة كل ما يتلقاه الأطفال يضفي على التعليم متعة وإثارة لا مثيل لها أبدا. فالفصل الدراسي أو الغرفة الدراسية هو مكان الطفل الخاص الذي يتعلم فيه ولابد

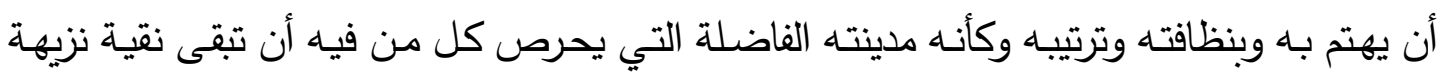

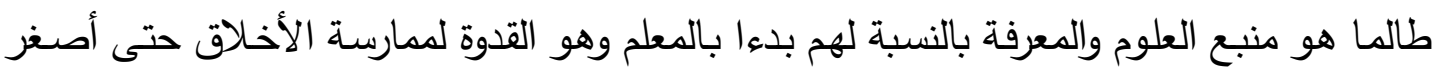

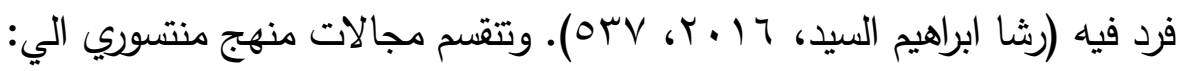

\section{1- مجــال الحيـاة العمليـة:}

وهو مجال قريب جدا من بيئة المنزل يتعلم الطفل فيها عدة مهارات نفتقد تعليمها للطفل

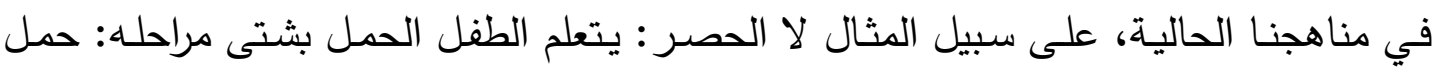

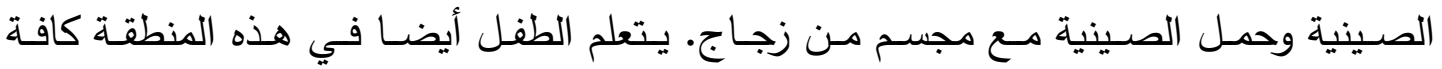
استخدامات الورق من قص وطي وتخريم وتدبيس. كما يتعلم الطفل عدة مهارات مثل عصر البرتقال، تلميع الزجاج، تلميع الأحذية، تلميع الفضيات، العناية بالنبات، إعداد المائدة، وكل المهارات يتعلمها الطفل بتسلسل دقيق تدرب عليه المعلمة مسبقا. 
وهو مجال يحتوي على كافة الوسائل والتمارين التي تساهم في تطوير وإثراء حواس الطفل الخمس ويتعداها إلى مرحلة الإبداع في استخدام حواسه، على سبيل المثال: يقوم الطفل بعمليات التصـيف والمقارنـة بين الكبير والصـغير ، الطويـل والقصير ، السميك والرفيع. يتعلم الطفل الفرق بين المر والمالح، الحلو...الخ، والفرق بين مختلف الروائح، كذلك يصنف الطفل بين مختلف الأصـوات الصـوت الحساد والنـاعم وغيـره، كمـا يتعدى كـل ذلك ليتعلم الأشكال الهندسية وتصنيفاتها وكيف أنه يمكنه صنع أشكال هندسية كبيرة من أثكال هندسية أصغر ، ويمكنه كذلك الإبداع في تصميم الأشكال الهندسية.

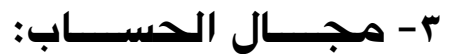

يـعلم فيـه الطفل الأرقام والقيـام بالعمليات الحسـابية البسيطة والصـعبة بـدءا بـالجمع والطرح والضرب والقسمة حتى الكسور • وكل ذلك بطريقة مدتعة وشيقة، ففي منطقة الحساب يوجد البنك الذي تعود فيه الطفل على عملية صرف الأرقام من كبيرة إلى صغير وتوزيعها على الوحدات العددية (أحاد، عشرات، مئات، ألوف).

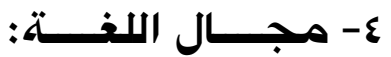

وهو مجال يتعلم الطفل فيـه صـوت الحرف وليس اسمه لسبب بسيط هو أنسه يتعلم الحرف ليقرأ الكلمة وليس للتعريف به. وبمجرد تعلم الطفل لعدد بسيط من الأحرف يمكنه صنع كلمات بسيطة ثم كلمات أكبر ... وهكذا حتى يصبح الطفل قادرا على كتابة الكلمات وقراءتها وإملائها ومن ثم ننتقل معه بعد ذلك إلى أنواع الكلمة: اسم، فعل، صفة، حرف، بطريقة مدتعة وباستخدام مجسمات خاصة بكل فئة ويمارس ذلك عن طريق عدة تمارين.

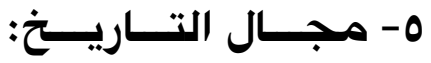

تهتم هذه المنطقـة بكل مـا يثري ثقافـة الطفل ويسـاهم في جعله طفـلا مطلعـا مستقلا باستطاعته المناقشة والإدلاء بمعلوماته المتنوعة.

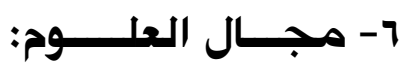

على سبيل المثال: الحي وغير الحي، والحواس الخمس، وأجزاء جسم الإنسان، وأجزاء جسم الحيوانات المختلفة، بالإضافة لأنواعها والتجارب العلمية المختلفة.

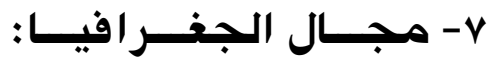
على سـبيل المثال: أجـزاء اليـابس والمـاء، الكـرة الأرضـية، القـارات، الـدول، الأعـلام

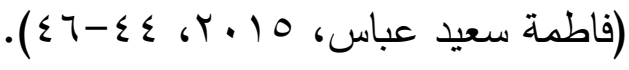




\section{السـدراســات الســابة}

\section{أولا: دراسات سابقة في مجال المفاهيم الزمنية}

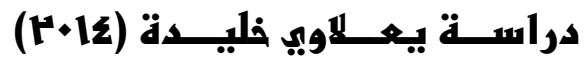

هدفت هذه الدراسة إلي التعرف على أثر الإدماج المدرسي في تحسين اكتساب مفهوم

الزمن المباشر • وقد تكونت عينة الدراسة من مجموعتين المجموعة التجريبية (• () أطفال ذوي متلازمة داون القابلين للتدريب تتراوح أعمارهم ما بين • ( و با سنة الملتحقين بمدارس الدمج

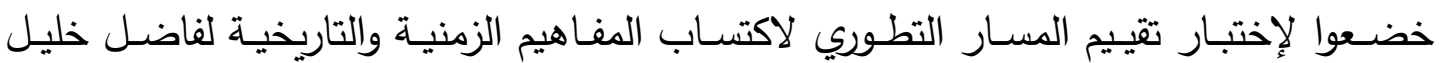

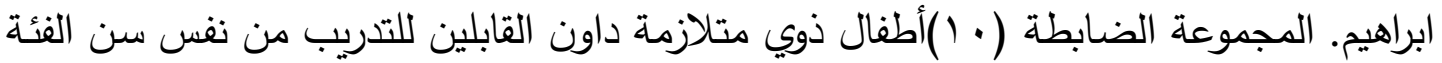

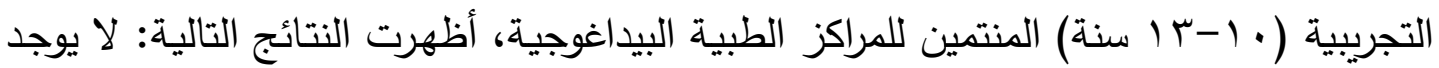
فرق بين الأطفال ذوي متلازمة داون القابلين للتدريب المدمجين في المدارس العادية والأطفال ذوي متلازمة داون القابلين للتدريب غير المدمجين في المدارس العادية في اكتساب مفهوم الزمن ومن تم فليس هناك أثر للإدماج المدرسي في تحسين اكتساب مفهوم الزمن.

\section{دراسة ماجدة محمود صالح \& رشا اسما عيل خليل ("N+1}

هدفت الدراسة الي فاعلية إكساب الأطفال المعاقين عقليا القابلين للتعلم بعض المفاهيم

الزمنية باستخدام الأنثطة التربوية. وتكونت عينة الدراسة (• () أطفال من مدرسة الرمل الميري

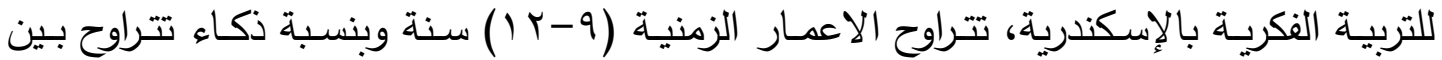

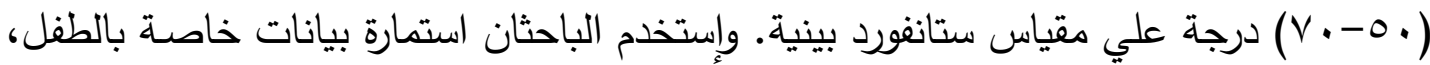
مقياس مفهوم الزمن المصور للأطفال المعاقين عقليا القابلين للتعلم. وتوصلت نتائج الدراسة الي وجود فروق دالـة إحصـائية بين التطبيق التبلي والتطبيق البعدي لمقياس مفهوم الزمن للأطفال المعاقين عقليا القابلين للتعلم لصالح التطبيق البعدى.

دراسـة جـابــر عيسـى (r+1r)

هـدفت الدراسـة الـي قياس فاعليـة برنـامج تـدريبى لتتميـة بعض المفـاهيم الرياضـية

(التصنيف - التسلسل، التناظر الأحادى) لاى عينة من الأطفال ذوى الإعاقة العقلية البسيطة ومقارنة أدائهم بمجموعة من الأطفال العاديين المتكافئين لهم فى العمر العقلى. وإستخدمت الإلى

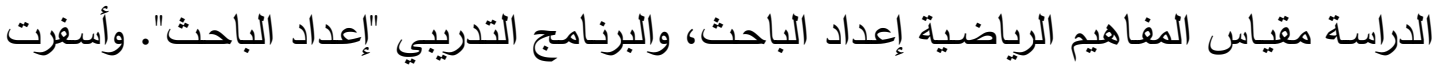
نتائج الدراسة عن عدم وجود فروق بين المجموعتين فى المفاهيم (التصنيف - التسلسل - 
التتاظر الأحادى) بين المجموعتين العاديين والمعاقين عقلياً بعد تطبيق البرنامج التدربيى مما يؤكد على إن الأطفال المعاقين عقلياً بإمكانهم تعلم المفاهيم مثل العاديين المكافئين لهم فى العمر العقلى وإن كان يحتاج إلى جهد ووقت أكثر .

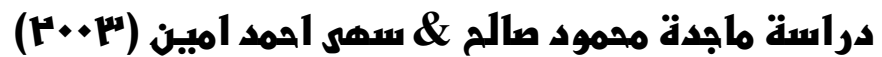

هدفت الدراسة الي قياس فاعليه برنامج مقترح باستخدام إستراتيجية تعليم الاقتران في تتمية

بعض المهارات الرياضية الحياتية لدي الأطفال المعاقين عقليا من الدرجة المتوسطة. وإستخدمت الدراسـة إختبار المهارات الحياتيـة إعداد الباحثتين، برنامجا قائم علي إستراتيجية تعليم الأقران من أجل إكسـاب الأطفال المعـاقين عقلياً بعض المهارات الرياضـية الحياتيـة الزمنيـة (الليلـ- النهار صيف-شتاء) وقد تعرف الأطفال من خلال أنشطة البرنـامج علي الأوقات المختلفة (صباحامسـاء-الليل-النهار)، وقد وجدوا بعض الصسعوبات في ربط الحدث بزمن وقوعـه، وكان للتدريب وللمران وتكرار الأنشطة المقترحة أثرها في ارتفاع هذه النسبة وخاصة فيما يتعلق بأيام الأسبوع.

\section{دراسة آمال علي مصطفى المنشاوي ("ب •+r)}

هدفت الدراسـة الـي دراسـة نمـو مفهوم الزمن والسببية لـدي الأطفـال المعـاقين عقليـا

والتعرف علي الفروق بين الأطفال المعاقين والأسوياء، وبين الإناث والذكور في نمو مفهومي الدراسـة. وتكونـت عينـة الدراسـة مـن عينـة مـن الأطفـال ذوي الاعاقـة العقليـة البسـيطة تتـراوح أعمارهم الزمنية V- ع ا عاما وتتراوح نسبة ذكائهم بين • V- . ه درجة، بالاضافة الي مجموعة من الاطفال العاديين في نفس العمر الزمني .توصلت النتائج إلي أن الأطفال المعاقين عقليا يتحسن إدراكهم لمفهوم الزمن مع تزايد العمر الزمني.

دراسـة مـاجـــة صـالـــم (1)

هدفت الدراسـة الي تنميـة مفهوم تسلسل الأحداث الزمنيـة لدي الأطفال ذوى الإعاقـة

العقليـة البسـيطة والمتوسـطة (9-9 - (3M) سـنه وفقـا لتقنيـة (3M) وإسـتخدمت الدراسـة مقيـاس المفاهيم الزمنية وأشارت نتائج الدراسـة إلي أن الذين استخدموا برنامج (3M) قد تحسن مفهوم تسلسل الإحداث الزمنية لديهم أكثر من أقرا نهم. وبرهنت النتائج أيضـا عن أن الأطفال من فئة ذوي الإعاقة العقلية البسيطة حققوا معدل درجات أعلي من أقرانهم ذوي التأخر العقلي المتوسط في فهم التسلسل الزمني للأحداث. 


\section{ثانياً: دراسات سابقة في مجال منهج مونتيسوري :}

\section{دراسة (Mustafa Kaya1\& Kadir Yildiz,2019)}

هدفت الدراسـة إلي معرفة أثر برنـامج قائم علي منهج منتسوري في تتميـة المهارات الحركية ومهارات الإدراك البصري لاي المعاقين عقليا القابلين للتدريب. وتكونت عينة الدراسة من گr ذكرا من المعاقين عقليا القابلين للتدريب وقد قسمت عينة الدراسـة إلي مجموعتين: إحداهما تجريبية (Y T) تعرضو الي برنامج تدريبي قائم علي منهج منتسوري، وأخري ضابطة

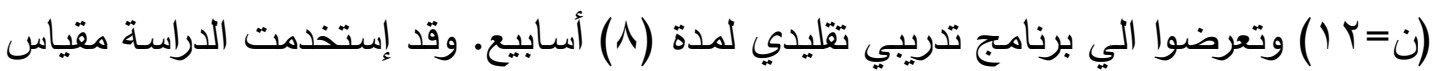
المهارات الادراك البصري والحركية. وقد أسفرت النتائج عن عدم وجود فروق بين لفردئ المجموعتين التجريبية والضابطة في مهارات الادراك الحركي، بينما وجدت فروق طفيفة بين المجموعتين في مهارات الادراك البصري لصالح المجموعة التجريبية التي تلقت تدريبا باستخدام منهج منتسوري.

\section{دراسة (Sema Ongoren \& Derya Ozlem Yazlik,2018)}

تهدف هذه الدراسة إلى فحص أثر التدربب بطريقة منتسوري علي المهارات الدفاهيمية

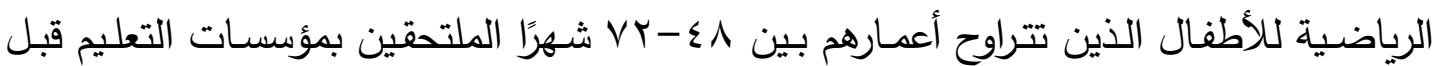

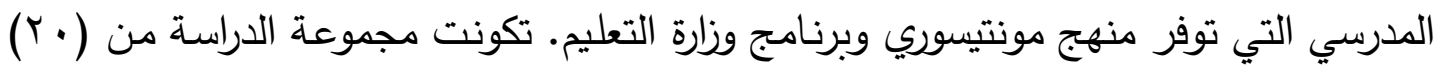

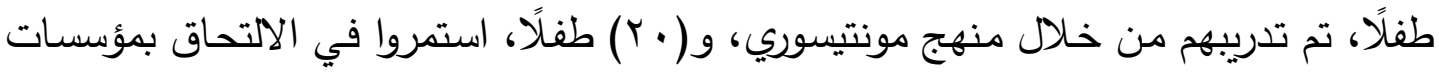
التعليم قبل الدرسي التي تطبق خطة وزارة التربية والتعليم،، وتم جمع بيانات الدراسة بطريقة الملاحظة المنظمة في وقت اللعب الحر / العمل الفردي في مراكز التعلم للأطفال الذين يشكلون مجموعة الدراسة. تم استخدام نموذج مراقبة منظم كأداة لجمع البيانات، وتم تضمين مهارات المفهوم الرياضي مثل العد، والمطابقة، والتجميع، والمقارنة، وإنشاء رسم بياني. تم تحليل بيانات البحث بطريقة التحليل الوصفي، وتم حساب التكرار والنسبة المئوية للبيانات التي تم الحصول

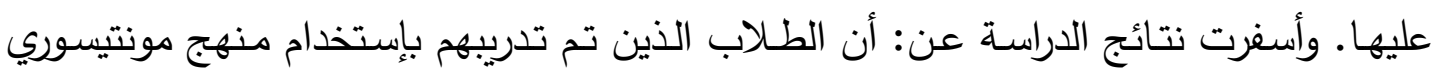
ووزارة التربية والتعليم لم يتمكنوا من إنشاء رسومات في كلا المجموعتين بينما كانت مهارات العد هي أكثر المهارات التي تمت ملاحظتها في الأطفال الذين تم تدريبهم بإستخدام منهج مونتيسوري بالكامل، مقارنة بالأطفال الذين تم تدريبهم مع وزارة التعليم والرياضة والتعليم. 
دراسـة فاطهـة سعيـــ عبـاسر (r) (H)

هدفت الدراسة إلى إعداد برنامج قائم على بعض أنشطة مونتيسوري لتحسين التوافق النفسي

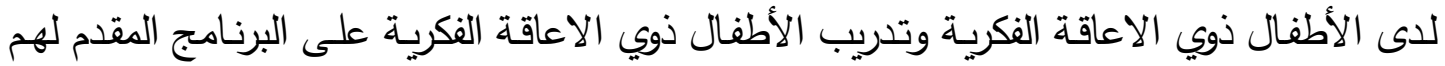

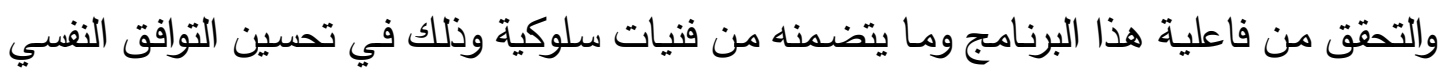

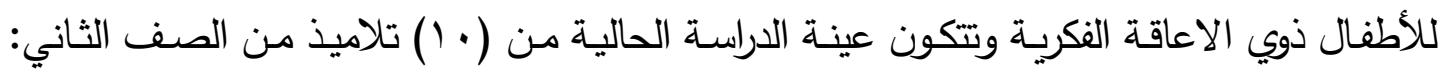

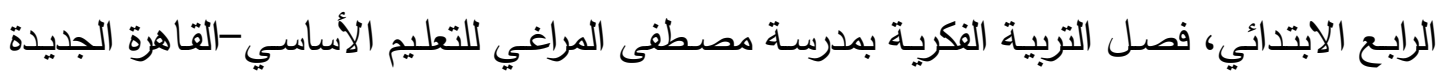

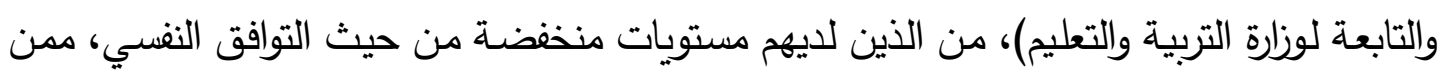

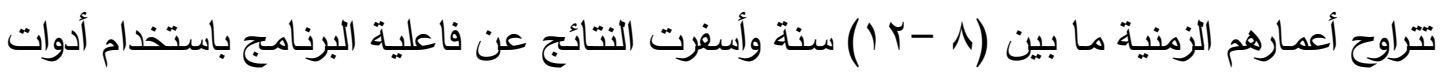

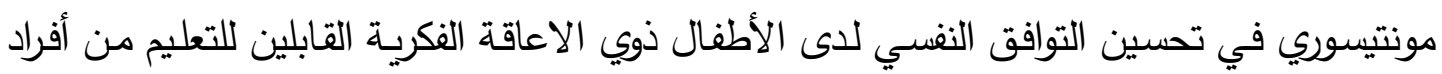

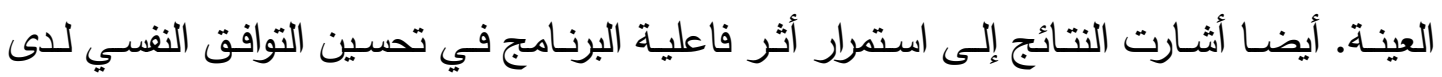

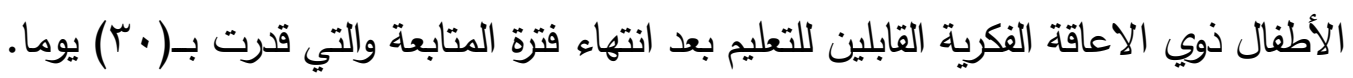

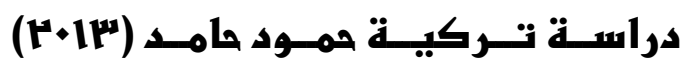
هدفت الدراسة الي قياس فاعلية برنامج تدريبي باستخدام أدوات مونتيسوري المطورة في

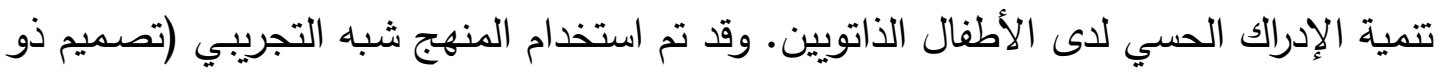

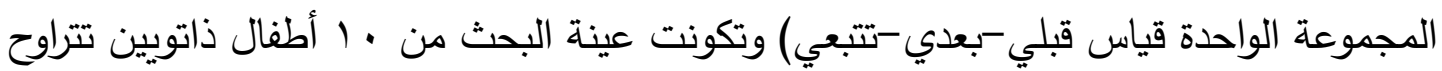

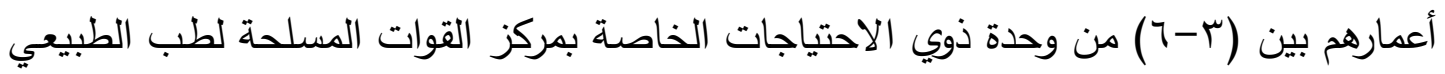
والتأهيلي بالعجوزة-جمهورية مصر العربية وتكون الأدوات من: مقياس الإدراك الحسي الحسي للأطفال

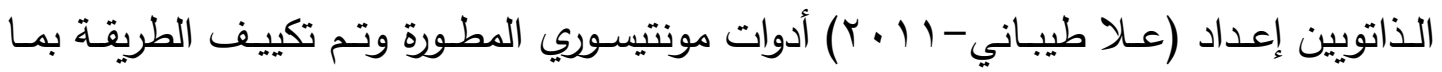
يتناسب مع الأطفال الذاتويين.

\section{دراســة (sema ongoren,2009)}

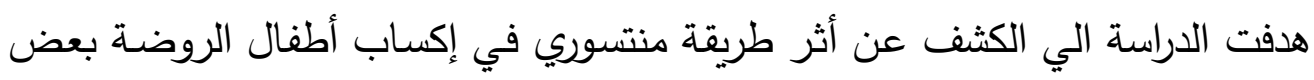

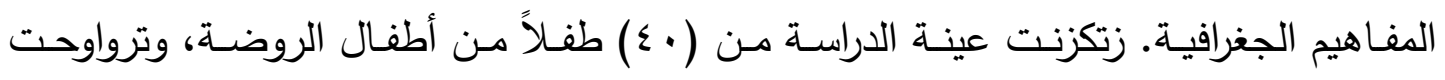

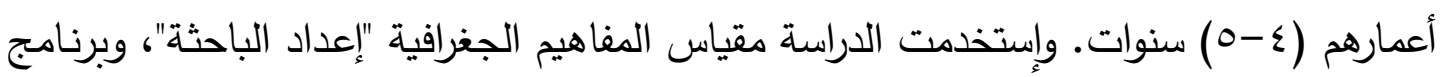

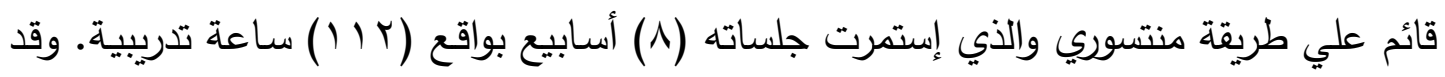

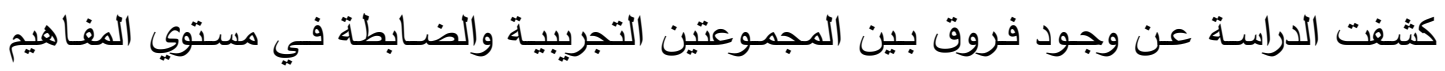

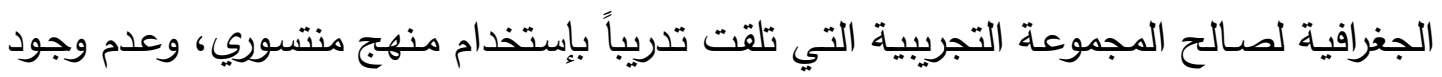

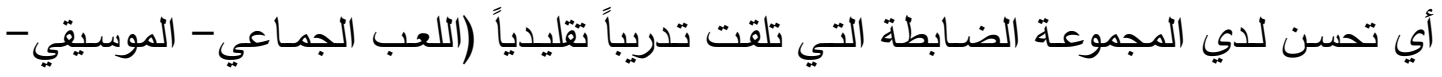
القصة- الدراما- بعض الانثطة المتعلقة بالمفاهيم الجغرافية) والذي إستمر (؟) أسابيع. 
ومــن خــلال العـرض السـابق للدراســات الســابقة، لاحظـــت الباحثــة أن بعـض الدراسات" إقتصرت علي دراسة مفهوم الزمن عند المعاقين عقليا كدراسة أمسال مصطفي المنشاوي

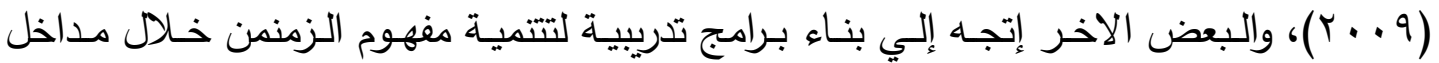

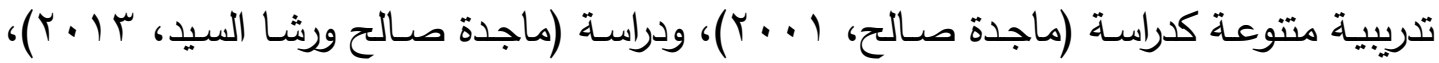
دراسة (يعلاوي خليدة، 10 • ب)، بينما إستخدمت دراسات أخري منهج ماريا منتسوري في تتيمة بعض المفاهيم الأخري لدي المعاقين عقليا وتحسين السلوك التوافقي لديهر كدراسة (فاطمة سعيد،

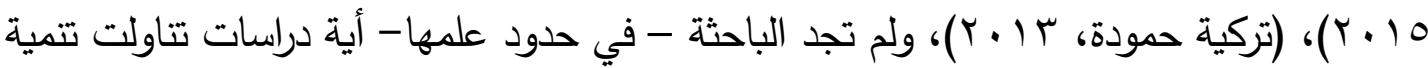
المفاهيم الزمنية لاي المعاقين عقليا من الدرجة المتوسطة بإستخدام منهج ماريا منتسوري.

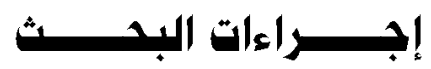

\section{أولاً : المنهج المستخلدم في البحث}

اقتضى البحث الحالي في ضوء أهدافه استخدام المنهج شبه التجريبي؛ والتجريب هو تغيير متعدد ومضبوط للشروط المحددة لواقعـة معينة، وملاحظة للتغيرات الناتجـة في هذه الواقعـة ذاتهـا وتقسـيرها. والبحـث التجريبـي يتضــن محاولــة الباحـث لضـبط كـل العوامـل (المتغيرات) الأساسية المؤثرة في المتغير أو المتغيرات التابعة في التجربة ماعدا عاملاً واحداً يتحكم فيه ويغيره على نحو معين بقصد تحديد وقياس تأثيره على المتغير أو المتغيرات التابعة

$$
\text { (جابر عبد الحميد، أحمد خيرى كاظم، (1) • ب:؛ } 9 \text { (1). }
$$

ومن التصميمات التجريبية المستخدمة التصميم ذو القياس القبلي والبعدي للمجموعتين التجريبية والضـابطة، ثم القياس التتبعي للمجموعـة التجريبية بعد مرور شهرين من القياس البعدي الأول والذى تم بعد المعالجة المباشرة. والهدف من هذا الإجراء التأكد من استمرارية أثر المتغير المستقل (البرنامج التتريبي) على المتغير التابع (مفهوم الزمن)، ويوضح الثكل التالي التصميم التجريبي المستخدم في البحث. 


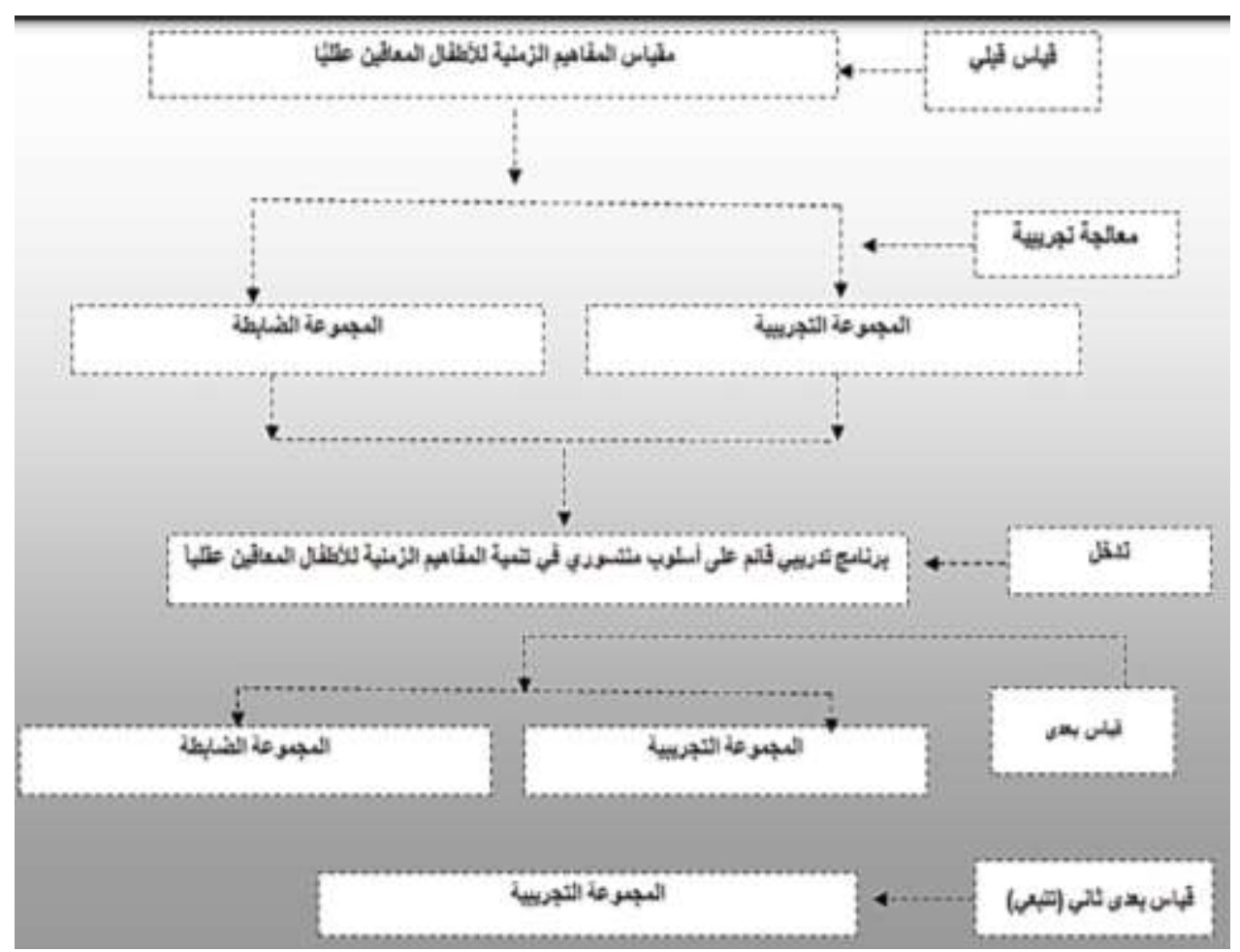

شكل ( ) يوضح التصميه التجريبي المستخله في البحث

ثانياً : عينـة البحـثـ وخطـوات انتقــائهـا

انقسمت عينة البحث إلى قسمين:

1- عينة التحقق من الخصائص السيكومترية.

r- العينة الأساسية (الخاصة بالثق التجربي من البحث).

1- عبنة التصقة من الفمائم السبكومتربة

تكونت عينة التحقق من الخصائص السيكومترية في صورتها النهائية من ( • ب) طفلاً وطفلة من الأطفال المعاقين عقليًا، ونلك بنطاق محافظة بني سويف خلال الفصل الدراسي الثاني من العام

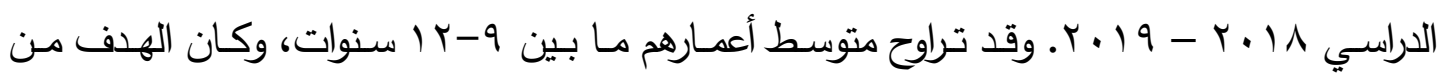
إختيار هذه العينة هو التحقق من الخصائص السيكومترية لأدوات البحث (الصدق، والثبات).

\section{ب}

تكونت عينـة البحث الأساسية من (·r) طفلاً وطفلـة من الأطفال المعاقين عقليًا بنطاق

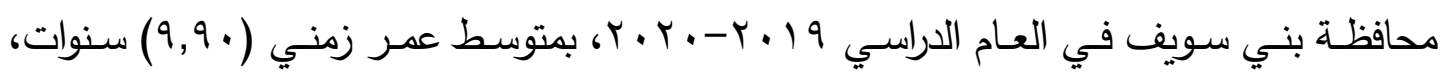

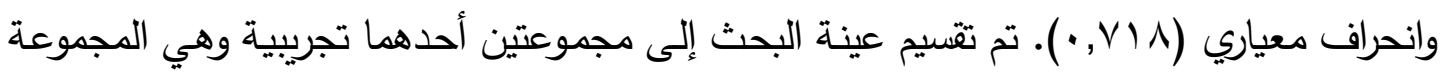


التي تعرضت للبرنامج التتريبي وذلك لتتمية المهارات الزمنية وقوامها ( • ( ) أطفال، ومجموعة أخري ضـابطة وهـي المجموعـة التي لـم تتعرض للبرنـامج التـدريبي ولهـا نفس خصـائص التكافؤ مـع المجموعـة التجريبية وقوامها (• ( ) أطفال، وقد راعت الباحثة تحقيق التكافؤ بين أفراد العينـة مـن حيث (العمر الزمني، نسبة الذكاء، المستوى التعليمي للأب والأم، مستوى المفاهيم الزمنية).

\section{• التحقق من تكافؤ المجموعتين (الضابطة والتجريبية)} لمـا كانت نتائج البحث مرتبطة بطبيعـة العينـة وخصائصها؛ فقد كان من الضـروري الحصول على عينتين متكافئتين من حيث المتغيرات الاخيلة (الوسيطة)، ويذكر (على ماهر

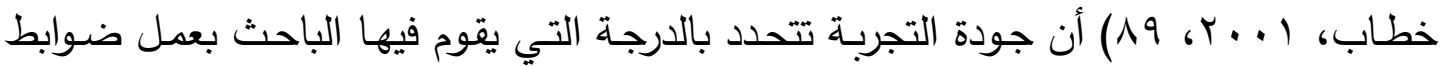
صارمة للمتغيرات الدخيلة من أغراض دراسته، وأن التصميمات التجرببية الحقيقية توفر درجة عالية من الضبط للمتغيرات الدخيلة. وقد تحققت الباحثة من تكافؤ المجموعتين في كل من متغيرات العمر الزمنى، نسبة الذكاء، المستوى التعليمي للأب والأم، ومستوى المفاهيم الزمنية. أ) التكافؤ بين مجموعتي البحث في العمر الزمني

تراوح العمر الزمني لأفراد عينة البحث ما بين (9- Y ( ) سنوات، وقد تم التحقق من تكافؤ مجموعتي البحث (التجريبية والضابطة) في متغير العدر الزمني باستخدام اختبار مان ويتتي، ويوضح الجدول رقم (1) متوسط الرتب وقيمة U وقيمة Z ودلالتها الاحصائية لمتغير العمر الزمني. جلول رقمـ (1) يوضح دلالات الفروق في العمر الزمني لدى عينة البحث باستخداه اختبار مان-ويتني

\begin{tabular}{|c|c|c|c|c|c|c|c|c|}
\hline الدلالة الاحصائية & قيمة Z & قيمة W & قيمة U & مجموع الرتب & متوسط الرتب & |المتوسط الحسابي & j & | المجموعات \\
\hline$\cdot, 07 \xi$ & \multirow{2}{*}{ •, Ory- } & \multirow{2}{*}{$9 \Lambda, \cdots$} & \multirow{2}{*}{$\varepsilon r, \cdots$} & lir,•• & $11, r \cdot$ & \multirow{2}{*}{$9,9}$. & 1. & | الضابطة \\
\hline غير دالة & & & & $9 \Lambda, \cdot \bullet$ & $9, \wedge$. & & 1. & |التجريبية | \\
\hline
\end{tabular}

يتضــح مـن الجـدول (1) عـدم وجـود فـروق دالـة إحصــائياً بـين متوسـطات رتـب

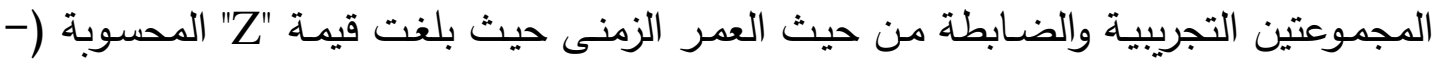
OVV إحصائياً، وهذا يشير إلى تكافؤ المجموعتين (التجريبية، والضابطة) في العدر الزمني. ب) التكافؤ بين مجموعتي البحث في نسبة الذكاء تراوحت معاملات ذكاء أطفال عينة البحث ما بين (00 - هب) درجة على مقياس ستانفورد بينيه للذكاء الصورة الخامسة من واقع اختبارات الذكاء الواردة في سجلات المدرسـة، 
وهم يعانون من قصور في المفاهيم الزمنية، ويقعون ضمن فئة القابلين للتدريب، ويتراوح عمرهم العقلي من (r-7) سنوات، وتم التحقق من تكافؤ مجموعتي البحث (التجربيية والضـابطة) في

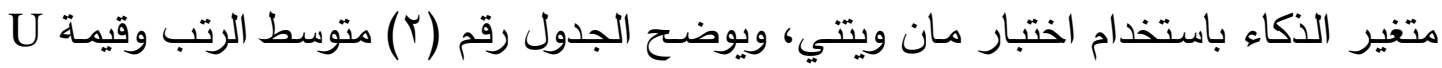
وقيمة Z ودلالتها الاحصائية لمتغير نسبة الذكاء.

جلول رقم (r) يوضح دلالات الفروق في نسبة الذكاء للى عينة البحث باستخلاه اختبار مان-ويتني

\begin{tabular}{|c|c|c|c|c|c|c|c|c|}
\hline الدلالة الاحصائية & قيمة Z & قيمة w & قيمة U U & مجموع الرتب & متوسط الرتب & المتوسط الحسابي & ن & المجموعات \\
\hline •,rqA & \multirow{2}{*}{$\cdot, \wedge \leqslant \eta_{-}$} & \multirow{2}{*}{$\leqslant 9, \cdots$} & \multirow{2}{*}{$r q, \cdots$} & $117, \cdot \cdot$ & $11,7$. & \multirow{2}{*}{$r, 0}$. & 1. & الضابطة \\
\hline غير دالة & & & & $9 \xi, \cdot \bullet$ & 9,8 & & 1. & التجريبية \\
\hline
\end{tabular}

يتضــح مـن الجـدول (r) عـدم وجـود فـروق دالــة إحصــائياً بـين متوسـطات رتب

المجموعتين التجربيية والضـابطة من حيث نسبة الذكاء حيث بلغت قيمـة "Z" المحسوبة (-

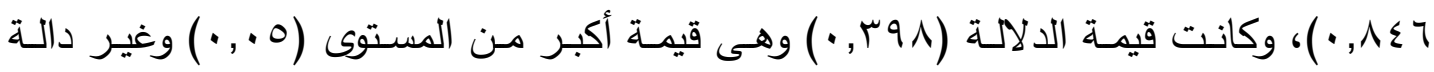
إحصائياً، مما يعنى تكافؤ المجموعتين التجربيية والضابطة في نسبة الذكاء.

\section{ج) التكافؤ بين مجموعتي البحث في المستوى الثقافي الإجتماعي للأب والأم} 1 - بالنسبة للمستوى الثقافي الإجتماعي للأب

تم التحقق مـن تكافؤ مجموعتي البحث (التجريبيـة والضـابطة) في المستوى الثقافي الإجتماعي للأب علي مقياس المستوي الاجتماعي الثقافي اعداد حمدان فضة لو99 19 من خلال تطبيق اختبار مربع كاي (كا؟)، كما يتضح في جدول (r). جلول رقم (r) يوضح دلالات الفروق في المستوى الثقافي الإجتماعي الأب باستخلام اختبار مربع كاي

\begin{tabular}{|c|c|c|c|c|c|c|c|c|}
\hline الدلالة الاحصائية & درجة الحرية & قيمة مربع كاي & مؤهل متوسط & | إعدادية| & يقرأويكتب & أمي & ن & المجموعات \\
\hline \multirow{2}{*}{ •, rir } & \multirow{3}{*}{$r$} & \multirow{3}{*}{$\xi, 0 .}$. & r & $r$ & $r$ & r & 1. & الضابطة \\
\hline & & & 1 & - & 0 & $\varepsilon$ & 1. & التجريبية \\
\hline غير دالة & & & $r$ & $r$ & $\wedge$ & 7 & r. & المجموع \\
\hline
\end{tabular}

بحساب قيمة كا` للمستوى الثقافي الإجتماعي للأب وجد أنها تساوى ( . . ؛, )، وأنها غير دالة حيث بلغت قيمة الدلالة با ب, • •. وهي قيمة أكبر من المستوى (0 . . •) وغير دالة احصائياً، مما يعني تكافؤ المجموعتين التجربية والضابطة في المستوى الثقافي الإجتماعي للأب. 
r - بالنسبة للمستوى الثقافي الإجتماعي للأم

تم التحقق من تكافؤ مجموعتي البحث (التجريبية والضـابطة) في المستوى الثقافي الإجتماعي للأم علي مقياس المستوي الاجتماعي الثقافي اعداد حمدان فضـة لو9 19 من خلال

تطبيق اختبار مربع كاي (كا؟)، كما يتضح في جدول (ع). جدول رقه (§) يوضح دلالات الفروق في المستوى الثقافي الإجتماعي للأمر باستخدام اختبار مربع كاي

\begin{tabular}{|c|c|c|c|c|c|c|c|c|}
\hline الللالة الاحصائية & درجة الحرية & قيمة مربع كاي & مؤهل متوسط & | & يقرأويكتب & أمي & j & المجموعات \\
\hline \multirow{2}{*}{$\cdot, \Lambda \cdot V$} & \multirow{3}{*}{$r$} & \multirow{3}{*}{ - , 9v7 } & 1 & 1 & 0 & $r$ & 1. & الضابطة \\
\hline & & & 1 & $r$ & $r$ & $\varepsilon$ & 1. & التجريبية \\
\hline غير دالة & & & $r$ & $r$ & $\wedge$ & $v$ & r. & المجموع \\
\hline
\end{tabular}

بحساب قيمة كا' المستوى الثقافي الإجتماعي للأم وجد أنها تساوى (דVY9, •)، وأنها غير

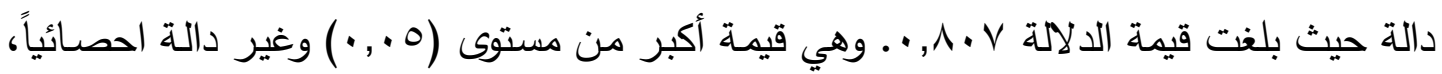
مما يعني تكافؤ المجموعتين التجريبية والضابطة في المستوى الثقافي الإجتماعي للأم.

\section{د) التكافؤ بين مجموعتي البحث في المفاهيم الزمنية}

تم التحقق من تكافؤ مجموعتي البحث (التجريبية والضـابطة) في المفاهيم الزمنية من خلال تطبيق مقياس المفاهيم الزمنية في القياس القبلي على المجموعتين، وحساب متوسط الرتب وقيمة U وقيمة Z ودلالتها الاحصائية باستخدام اختبار مان ويتتي، والجدول (0) يوضح ذلك. جلدول رقـ (0) يوضحدلالات الفروق في المفاهيم الزمنية للى مجموعتي البحث باستخذاه اختبار مان-ويتني

\begin{tabular}{|c|c|c|c|c|c|c|c|c|}
\hline الدلالة الاحصائية & قيمة Z & قيمة w & قيمة U U & مجموع الرتب & متوسط الرتب & المتوسط الحسابي & ن & |المجموعات \\
\hline 促, & \multirow{2}{*}{ •, } & \multirow{2}{*}{$99, \cdots$} & \multirow{2}{*}{$\llbracket \&, \cdots$} & $111, \cdot \cdot$ & $11,1$. & & 1. & الضابطة \\
\hline غير دالة & & & & $99, \cdot \cdot$ & १, १. & & 1. & التجريبية \\
\hline
\end{tabular}

يتضـح مـن الجـول (0) عـدم وجـود فـروق دالــة إحصـائياً بـين متوسـطات رتـب

"Z" المجموعتين التجريبية والضـابطة في الدرجـة الكليـة للمفـاهيم الزمنيـة، حيث بلغت قيمـة

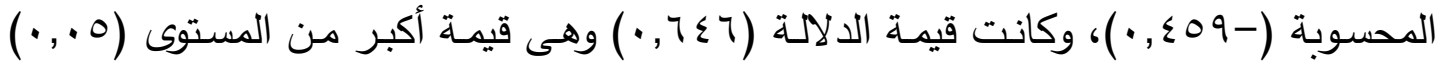

وغير دالة إحصائياً، وهذا يعنى تكافؤ المجموعتين التجريبية والضابطة في المفاهيم الزمنية. 
ثالثاً : أدوات البحث ووصفها وتشمل : • مقياسر المستوى الاجتما عى الاقتصادى والثقافىى، إعداد حمدان فضه (199V):

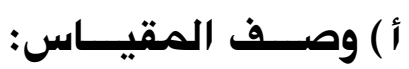
يهـف المقياس إلى تحديد المستوى الاجتمـاعى الاقتصـادى، والمستوى الاجتمـاعى الثقافى للفرد، كمستويين اجتماعيين مستقلين، وذلك فى ضوء إجابته على المقياس.ويتضمن المقياس "هץ" مفردة، لكل منها "§" استجابات اختياريـة. ويتضـمن المقيـاس ككل مقياسين

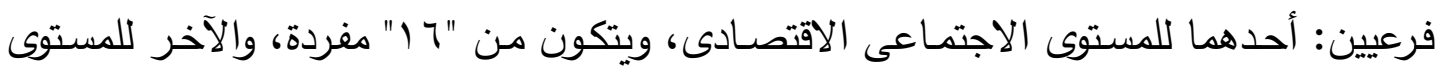
الاجتماعى الثقافى، ويتكون من "و" مفردات.

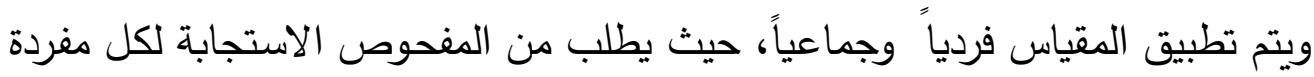

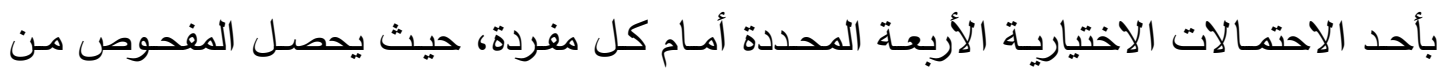

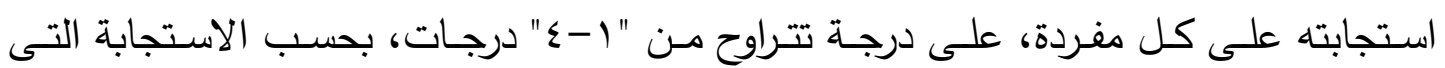

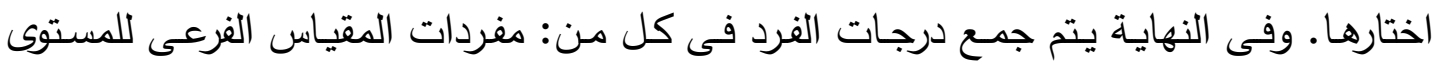

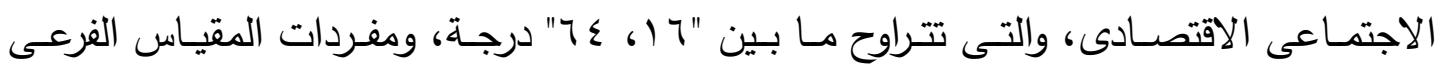

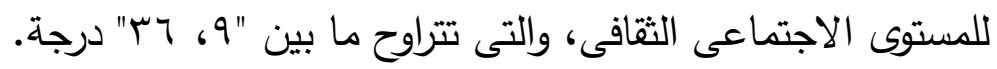

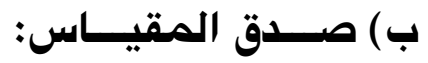

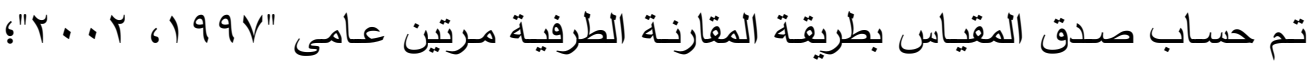

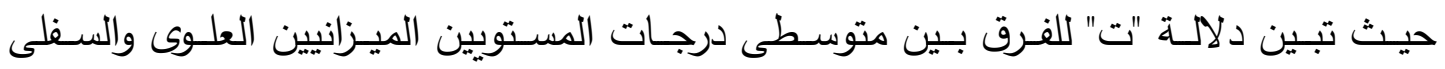
للمقياسين "الاقتصادى، والثقافى". كما حسب صدق مفردات المقياس بطريقة المقارنة الطرفية؛ حيث تبين دلالة معاملات صدقها جميعاً.

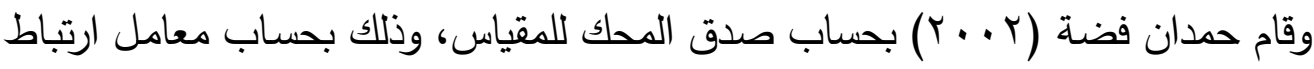

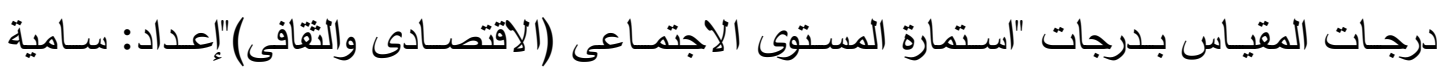

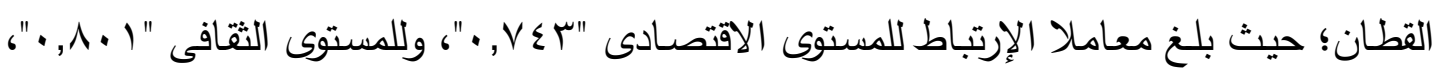

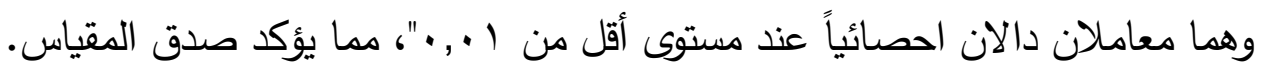

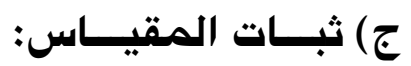

قام حمدان فضـة (997 (199 ) بحساب ثبات المقياس بطريقة التجزئة النصفية، وباستخدام معادلة "سبيرمان - براون"، ومعادلة "رولون"، حيث بلغت معاملات الثبات، بنـاءً على هاتين

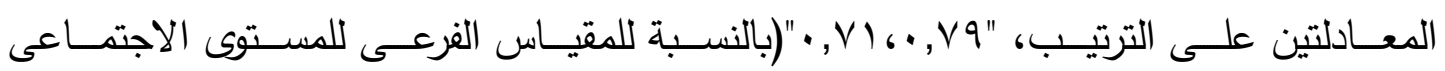




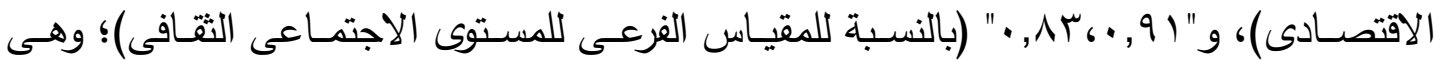

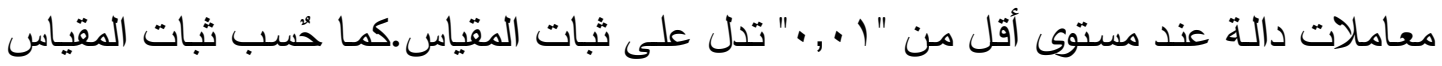

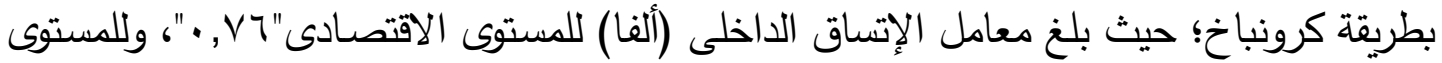
الثقافى "ANA, • ". كما حُسب الثبات بطريقة الاحتمال المنوالى وتبين دلالة معاملات ثباتها جميعاً.

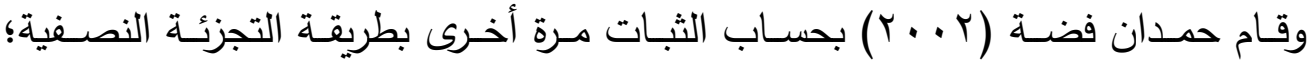
وباستخدام معادلات: "سبيرمان -براون، ورولون، وجتمان"، حيث بلغت معاملات الثبات للمستوى

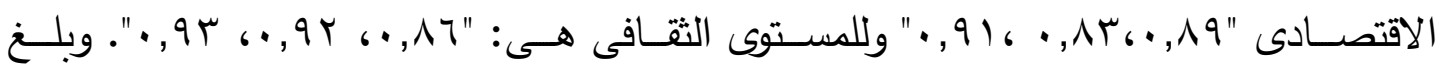
معاملا الاتساق الداخلى للمقياسين الاقتصادى والثقافى على الترتيب هما: " • 9, ، ، 9, • "وهما معاملان دالان احصائياً على ثبات المقياسين الاقتصادى والثقافى.

\section{• مقياس المفاهيم الزمنية للأطفال المعاقين عقليًا (إعداد الباهثة).}

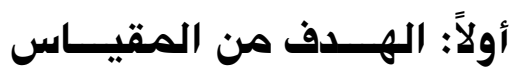

يهدف المقياس الحالي إلى الوقوف على مستوى المفاهيم الزمنيـة للأطفال المعاقين عقلياً من الدرجة المتوسطة من سن 9-1 ا سنوات، والعمل على تحسينها من خلال تقديم

$$
\text { ثرنامجاً تدريبي قائم على أسلوب منتسوري في التدريب. }
$$

من خلال إطلاع الباحثة على ما توفر لها من مفاهيم نظرية ودراسات سابقة وعلى

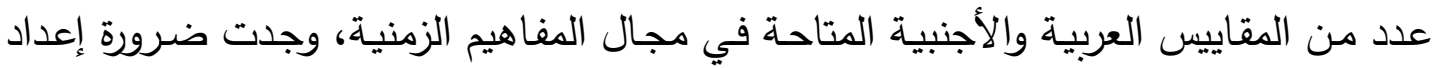

$$
\text { المقياس الحالي للاعتبارات الآتية: }
$$

1- عدم وجود مقياس-في حدود علم الباحثة- يقيس المفاهيم الزمنية للأطفال ذوي الإعاقة العقلية المتوسطة.

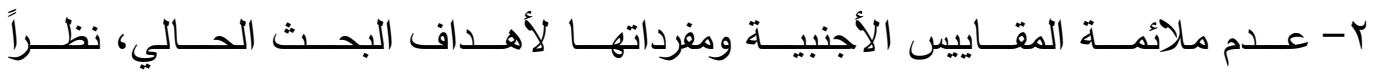
لاختلاف البيئة والثقافة.

r- توافر مقياس مقنن للمفاهيم الزمنيـة إنمـا يُسـهم في إثراء المكتبـة السيكولوجية بأداة تثخيصية علاجية تعمل على تحسين البيئة التعليمية والمناخ النفسي المدرسي للأطفال المعاقين عقلياً داخل مدارس التربية الفكرية. 


\section{ثالثاً: وصف المقياس في صورته الأوليتة}

يتكون مقياس المفاهيم الزمنية في صورته الأولية من (؟Y) عبارة موزعة على أربعة

محاور افترضتها الباحث في ضوء إطلاعها على أدبيات البحث التي تتاولت المفاهيم الزمنية لدى الأطفال ذوي الإعاقة العقلية المتوسطة، وهذه المحاور تشمل: (الزمن العضوي، والزمن إلزئ الاجتماعي، والزمن البيولوجي، والزمن الشخصي). والجدول (آ) يوضـح توزيع العبارات على المحاور الرئيسية للمقياس.

جلدول ( ) يوضح توزيع عبارات مقياس المفاهيم الزمنية على المحاور ( في صورته الأولية)

\begin{tabular}{|c|c|c|c|}
\hline \multicolumn{2}{|c|}{ 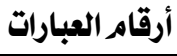 } & \multirow{2}{*}{ التعريف الإجرائي } & \multirow{2}{*}{ 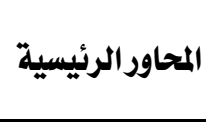 } \\
\hline إلى & من & & \\
\hline 9 & 1 & يقصل به الزمن الذي نستطيع ان نتحكم فيله ، من خلال استعمالنا للوقت بواسطة الساعة | & 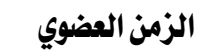 \\
\hline Ir & $r$ & والاعياد الوطنية والدينية الزمن ملدرك من خلال المجتمعات من نفس الحضـارة، كالمناسبات الخاصة & الزمن الاجتماعي \\
\hline 11 & ir & 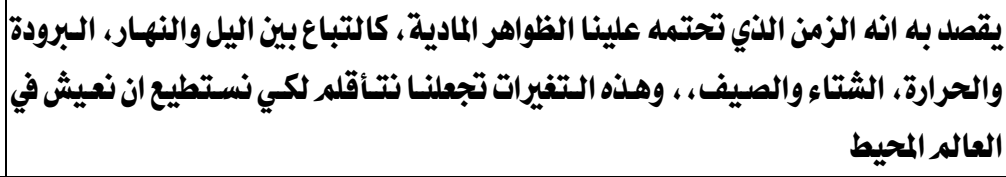 & الزمن البيولوجي \\
\hline rz & 19 & الطريقة التي يدرك بها الشخص الزمن في مجالات مختلفة & الزمن الشخصي \\
\hline
\end{tabular}

\section{رابعاً: خطــوات بنــاء المقيـاس}

تـتلخص خطــوات إعـداد مقيــاس المفــاهيم الزمنيــة للأطفــال ذوي الإعاقــة العقليــة

$$
\text { المتوسطة فيما يلي: }
$$

ا-بدايـةً قامت الباحثة بتحديد الهدف من إعداد هذا المقياس؛ وهو التعرف على مستوى المفاهيم الزمنية للأطفال المعاقين ذوي الإعاقة العقلية المتوسطة بمدارس التربية الفكريـة

$$
\text { بنطاق محافظة بني سويف. }
$$

ץ- قامـت الباحثـة باسـتقراء الأدبيـات السـيكولوجية التي تتاولت المفـاهيم الزمنيـة للأطفـال العاديين، والأطفال المعاقين عقليا على وجه الخصوص كدراسة (فاضل خليل، . . . ؟ )،

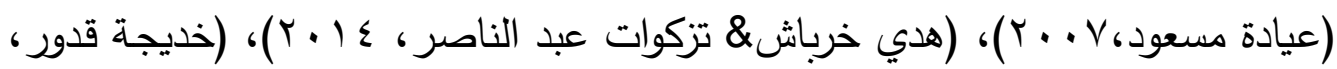
10 (GranrielavNelson, 2006), (Reynolds, 2003), (boehem, 2010, 3022, 1990, 1991, 2001, 2008), (Martin A., 1983), (Driot-Volels, 2003, 2016), (You Wang, 2015), (Marvin D. Wyne, 1967), (Sunddenfort, 2010), (Busby Grant \& Suddenfort, 2009, 2015, 2010), (Busby Grant, 2011), (Bucher pans, 2007), (Helayan Hershhom, 2015), 
(James B, Pace, 1971), (Mash Brakely, 2003), (Lovell k. slater, ؛1960), (Martins \& Jambaque, 2006), (Janeslatt \& lottorple, 2008) مـع إجراء تحليل للنظريات والبحوث المرتبطة بها؛ مما يساعد الباحثة في استخلاص أبعاده وتحديد التعريف الإجرائي لكل بعد.

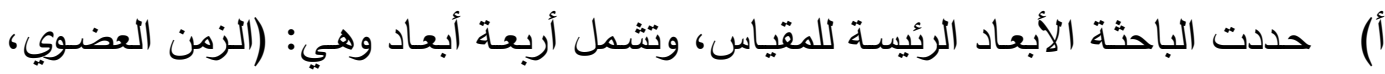

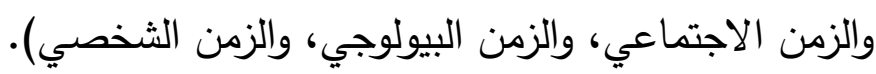

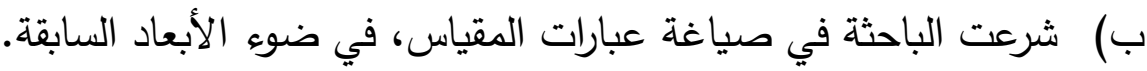

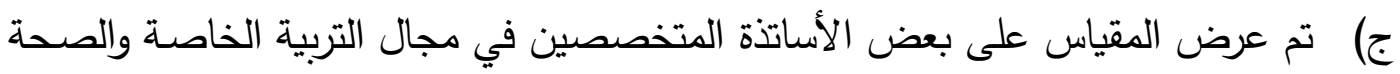
النفسية لإبداء الرأي في مدى ملائهة المقياس لها أعد لقياسه، وارتباط العبارات بالأبعاد

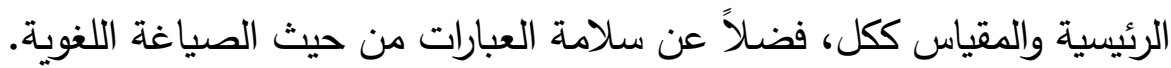
د) هضعت العبارات لميزان تقدير ثلاثي (دائماً، أحياناً، نادراً).

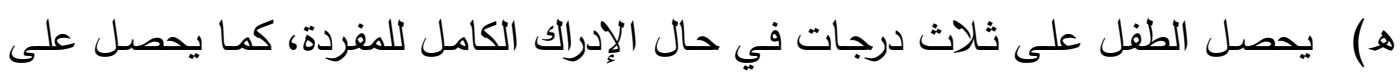

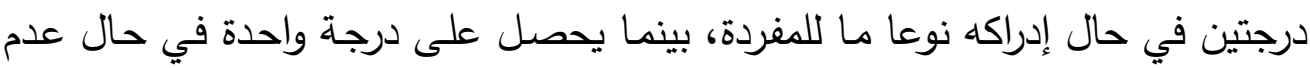
إدراكه علي الإطلاق.

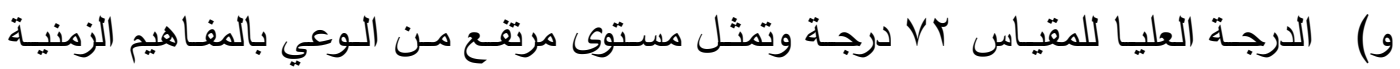

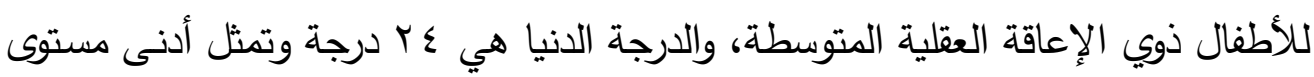
ضعيف من الوعي بالمفاهيم الزمنية لدي الأطفال ذوي الإعاقة العقلية المتوسطة.

\section{رابعاً : الخصائص السيكومترية لمقياس المفاهيم الزمنية}

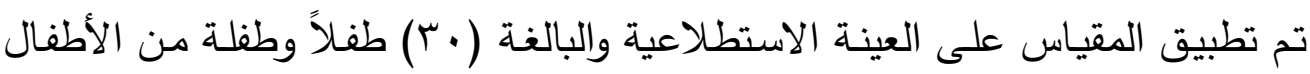
المعاقين عقليًا القابلين للتدرب بمدارس التربية الفكريـة بنطاق محافظة بنـي سويف ومراكزهـا (بوش- الواسطي - إهناسيا)، وذلك للتحقق من الخصائص السيكومترية للمقياس (مؤشرات

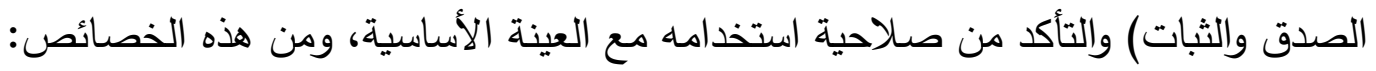

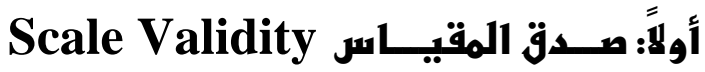

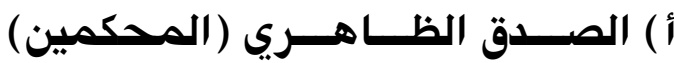

ويقوم هذا النوع من الصدق على فكرة مدى مناسبة المقياس لما يقيس، ولمن يُطبق الفق الفيق

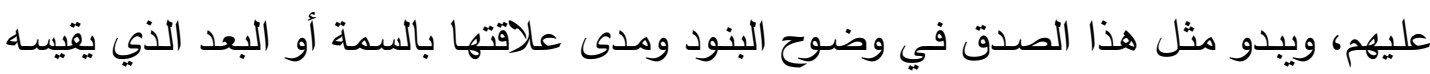

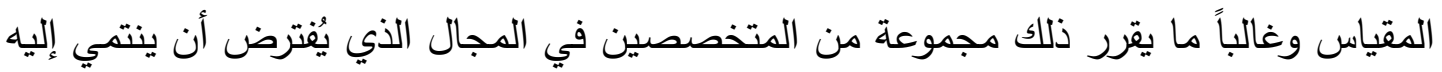

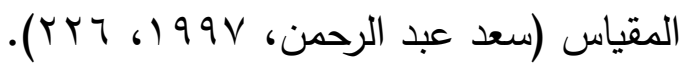


وقد قامت الباحثة في المراحل البنائية للمقياس بعرض عباراته على مجموعة من الأساتذة المتخصصين في مجال التربية الخاصـة والصحة النفسية، ولاقت معظم عبارات المقياس قبول المحكمين بنسبة تتعدي ال .9 \% مما يجعل المقياس يقيس ما أعد لقياسه.

\section{ب) صـدق الاتسـاق الـداخلـي}

وهو نوع من الصدق يتم فيـه حساب معامل الارتباط بين درجـة العبارة ودرجـة البعد

المنتمية إليه، وكذلك الدرجة الكلية للمقياس بعد استبعاد درجة العبارة من درجة البعد حتى لا لا لهوبل تؤثر في معامل الاتسـاق الناتج، وهنـا يجب أن تكون معاملات الارتباط دالة ومرتفعة (على

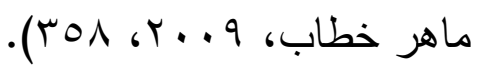

\section{ا - ارتباط العبارات بالماور الرئيسية للمقياس}

قامـت الباحثـة بحسـاب قيمـة معـاملات الارتبـاط بين كل عبـارة مـن عبـارات مقيـاس المفاهيم الزمنية للأطفال المعاقين عقلياً القابلين للتدريب والدرجة الكلية لكل بعد من الأبعاد الرئيسية للمقياس، والجدول (V) يوضح ذلك.

\section{جلول (v) يوضح معاملات الارتباط بين كل عبارة من عبارات}

مقياس المفاهيه الزمنية والأبعاد الرئيسية للمقياس

\begin{tabular}{|c|c|c|c|c|c|c|c|}
\hline \multicolumn{2}{|c|}{ الــزمــن الشخصـــي } & \multicolumn{2}{|c|}{ الــزمــن البيــولــوجــي } & \multicolumn{2}{|c|}{ الــزمــن الاجتمــاعـي } & \multicolumn{2}{|c|}{ الــزمــن العضــوي } \\
\hline الارتبـــاط & البنـــلد & الارتبـــاط & البنــــلد & الارتبـــاط & البنـــلد & الارتبـــاط & البنـــــ \\
\hline$* * \bullet, 091$ & 19 & $* * \bullet, 7 \leqslant 1$ & ir & $* * \bullet, 017$ & $\checkmark$ & $* * \bullet, \vee \wedge \cdot$ & 1 \\
\hline$* * \bullet, Y r Y$ & r. & $* *, Y \cdot r$ & 18 & $* * \bullet, \wedge 0$ & $\Lambda$ & $* * \bullet, \wedge \circ \wedge$ & r \\
\hline$* * \bullet, V Y V$ & YI & $* *, r \circ q$ & 10 & **•, $\wedge \wedge \mathrm{r}$ & 9 & $* *, \Lambda \leqslant r$ & $r$ \\
\hline$* *, 700$ & rr & $* *$, १ & 17 & $* * \bullet\rceil , V \wedge$ & 1. & $* *$ *Arr & $\varepsilon$ \\
\hline$\cdot, \cdot 10$ & rr & $* *,, 701$ & IV & $* *, \Lambda \leqslant \Lambda$ & 11 & $* * \bullet, \wedge \mid$ & 0 \\
\hline$* * \bullet, \leqslant 7 V$ & Yร & $* * \bullet, 0, r$ & M & $* * \bullet, \Lambda Y r$ & ir & $* * \bullet, \wedge 9$. & 7 \\
\hline
\end{tabular}

تشير نتائج الجدول (V) إلى إرتفـاع قيم معـاملات إرتبـاط عبـارات مقيـاس المفـاهيم الزمنية بالدرجة الكلية للأبعاد الرئيسية، حيث تراوحت قيم معاملات الارتباط ما بين (Y •0, •،

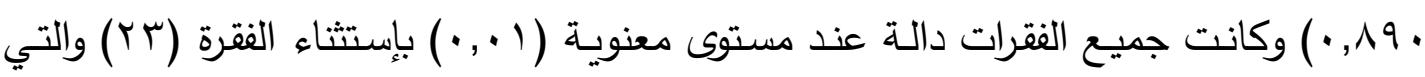
إنخفضت قيم معاملات ارتباطها وغير دالة إحصـائياً، مما يستدعى على الباحثة حذفها من المقياس ليصبح عدد عباراته النهائية (rr) عبارة. 


\section{r - إرتباط الأبعاد بالدرجة الكلية للمقياس}

قامت الباحثة بحساب قيمة معاملات الارتباط بين كل محور من محاور مقياس المفاهيم

الزمنية للأطفال المعاقين عقلياً القابلين للتدريب والدرجة الكلية للمقياس، والجدول (^) يوضح ذلك.

جلول ( ( ) يوضح معاملات الارتباط المحاور الرئيسية والدرجة الكلية لمقياس المفاهيم الزمنية ولية

\begin{tabular}{|c|c|}
\hline معـــامــلـل الارتبـــــاط & المححــــاور الــــئيسيــــــة \\
\hline$* * \bullet, \vee \vee q$ & الزمن العضوي \\
\hline **•, YAr & الزمن الاجتماعي \\
\hline$* * \bullet, 7 \Lambda$ & الزمن البيولوجي \\
\hline$* * \bullet, 7 \leqslant 0$ & الزمن الشخصي \\
\hline
\end{tabular}

يتضـح من خلال الجدول (^) ارتفاع معاملات إرتباط الأبعاد الرئيسية لمقياس المفاهيم

الزمنية للأطفال المعاقين عقلياً القابلين للتدربب بالدرجة الكلية للمقياس، حيث تراوحت قيم معاملات

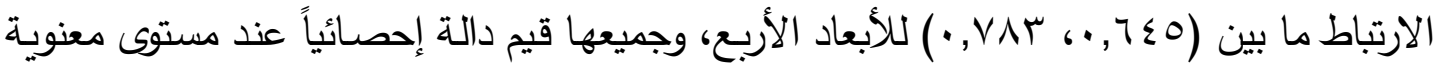
( ( • • ). ممـا يشير إلى صـدق الاتسـاق الداخلي لمقياس مقياس المفاهيم الزمنية للأطفال ذوي الإعاقة العقلية المتوسطة من سن 9 - r ا سنوات والذي أعدته الباحثة خصيصاً لهذا البحث.

\section{ج) صدق المقارنتة الطرفيته}

هو نوع من أنواع الصدق يقوم على فكرة تقسيم أفراد العينـة إلى مجموعتين (الإرباع

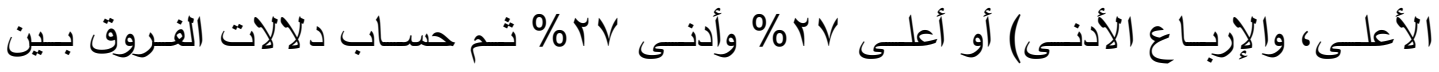
مجموعتين مستقلتين، ويتضح ذلك من خلاعل الجدول التالي:جلول (9 ) يوضح دلالات الفروق بين المجموعتين الدنيا والعليا

على مقياس المفاهيم الزمنية للأطفال المعاقيز عقليا

\begin{tabular}{|c|c|c|c|c|c|c|c|c|}
\hline \multirow{2}{*}{ الدلالة } & \multirow{2}{*}{ قيمة Z } & \multirow{2}{*}{ قيمة W } & \multirow{2}{*}{ قيمة U } & \multicolumn{2}{|c|}{ المجموعة العليا (ن= A) } & \multicolumn{2}{|c|}{ المجموعة الدنيا (ن=^) } & \multirow{2}{*}{ |المفاهيم الزمنية| } \\
\hline & & & & مجموع الرتب| & متوسط الرتب & مجموع الرتب & متوسط الرتب| & \\
\hline$\cdot, \cdot 1$ & $r, r q \Lambda-$ & rq, $\cdots$ & $\bullet, \cdots$ & $1 \cdot \cdot, \cdot \cdot$ & Ir,o. & rq,•• & $\xi, 0$. & المقياس ككل \\
\hline
\end{tabular}

يتضـح مـن خـلال الجدول (9) وجـود فروق ذات دلالـة إحصـائية بـين متوسطات رتب المجموعتين الدنيا والعليا على مقيـاس المفاهيم الزمنيـة للأطفال المعـاقين عقلياً القابلين للتدريب

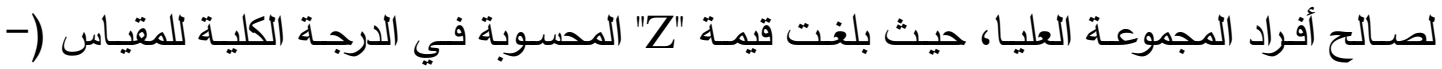

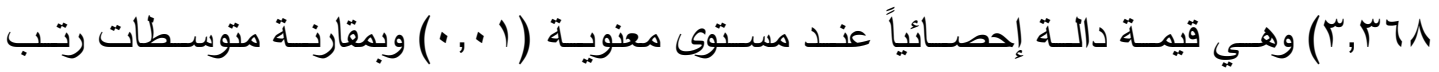
المجموعتين نجد أن الفرق لصالح المجموعة العليا، مما يؤكد على صدق المقارنة الطرفية للمقياس. 


\section{ثانياً: ثبات مقياسر المغاهيم الزمنية للأطفال المعاقين عقليًا}

قامت الباحثة بحساب معاملات الثبات للأبعاد الرئيسية للمقياس، وكذلك الدرجة الكلية

للمقياس بطريقتي ألفا كرونباخ، والتجزئة النصفية.

جلول (•1) يوضح معاملاتثبات الأبعادواللدرجة الكلية للمقياس بطريقتي ألفا كرونباخوجتمان للتجزئة النصفية

\begin{tabular}{|c|c|c|c|c|}
\hline معامل سبيرمان براون & معامل جتمان & معامل ثبات ألفا & عدد العبارات & الأبعــــــــــاد \\
\hline •,AY. & $\cdot, \wedge 19$ & •, q14 & 7 & الزمن العضوي \\
\hline$\cdot, 9 \cdot 1$ & $\cdot, 9 \cdot \cdot$ & $\cdot, \wedge 0 \wedge$ & 7 & الزمن الاجتماعي \\
\hline$\cdot, \mathrm{Yl}$. & $\cdot, 979$ & $\cdot, \mathrm{M} A \mathrm{~A}$ & 7 & الزمن البيولوجي \\
\hline •, $7 \leqslant 0$ & $\cdot, 009$ & $\cdot, 770$ & 0 & الزمن الشخصي \\
\hline •, rro & •, YrT & •, rrr & rr & المقياس ككل \\
\hline
\end{tabular}

يثير جدول (· () إلى أن جميع قيم معاملات الثبات بطريقتي ألفا كرونباخ، وجتمان

للتجزئة النصفية مرتفعة، حيث بلغت قيم معاملات الثبات في الدرجة الكلية لمقياس المفاهيم الزمنية للأطفال المعاقين عقلياً القابلين للتدريب بطريقة ألفا كرونباخ (VVT, • ) بينما بلغت قيمة معــاملات الثبـات بطريقــة التجزئسـة النصــفية (VYY, • )، وباســتخدام معادلــة التصــحيح لكيـودر ريتشاردسـون بلـغ معامـل ثبات للدرجـة الكليـة (VV0, • ) ممـا يشـير إلى ثبـات مرتفع لاستجابات الأطفال على المقياس.

الصورة النهائية لمقياس المفاهيم الزمنية للأطفال المعاقين عقلياً

تكونـت الصـورة النهائيـة للمقيـاس مـن (Tr) عبـارة تقـيس مسـتوى المفـاهيم الزمنيـة

للأطفال المعاقين عقلياً القابلين للتدريب من سن 9 - r ا سنوات، يحصل الطفل على ثلاث درجـات في حسال إدراكهـ التام للمفردة، بينمـا يحصل على درجتين في حالـه ادراكهـ نوعـا مـا للمفردة، ويحصل على درجة واحدة في حال عدم إدراكه علي الإطلاق للمفردة؛ وبالتالي تصبح الدرجة العليا للمقياس هي 97 درجة وهي تعبر عن مستوى مرتفع من المفاهيم الزمنية للأطفال المعاقين عقلياً القابلين للتدريب، بينما الدرجة المتوسطة للمقياس هي بr درجة وهي تعبر عن مستوى منخفض من المفاهيم الزمنية للأطفال المعاقين عقلياً القابلين للتدريب. 
جدول (11) يوضح الصورة النهائية لقياس المفاهيم الزمنية للأطفال المعاقين عقلياً

\begin{tabular}{|c|c|c|c|}
\hline أرق قــــــاه العبــــــــارات & عدد العبارات & الأبعــــــاد & مر \\
\hline $7,0,8,4,4,1$ & 7 & الزمن العضوي & 1 \\
\hline$\|r\|,, 1+, a ، \wedge, r$ & 7 & الزمن الاجتماعي & $r$ \\
\hline $11,18 \cdot 17,10 \cdot 18,14$ & 9 & الزمن البيولوجي & $r$ \\
\hline Y\&, rY, rI, r., 19 & 0 & الزمن الشخصي & $\xi$ \\
\hline
\end{tabular}

ج) برنامج بإستخدام أنثطة منتسوري (إعداد/ الباحثة) اعداد مهتوي البرنامج/ الإطار النظري للبرنامه:

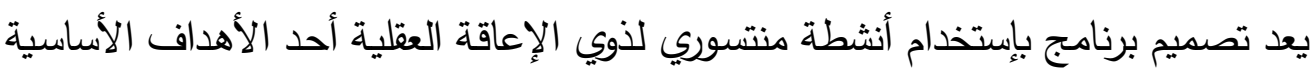
لهذه الدراسة، ولتصميم هذا البرنامج إستعانت الباحثة بعدد من البحوث والدراسات التي إستخدت

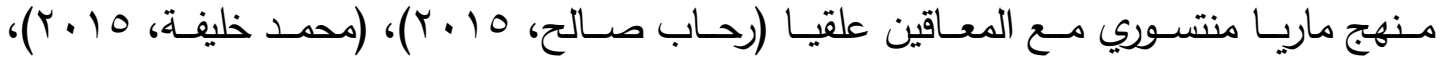

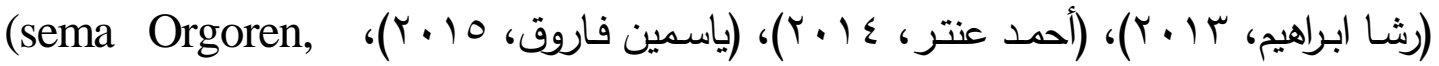
(2009), (montessory, 1995) ، وبعض الدراسات الأخري التي إرتكزت علي تتمية مفهوم الزمن لدي الأطفال العاديين بكثل عام والمعاقين عقليا وفئات أخري من ذوي الإحتياجات

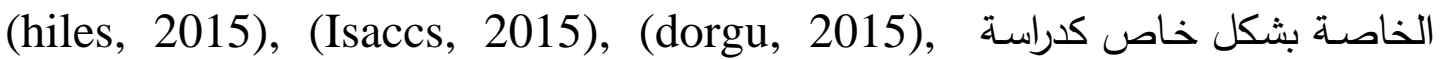
(Janes Lath Kottorp, 2013), (penny low-Ziegen fuss, 1972) (يعلاوي خليدة،

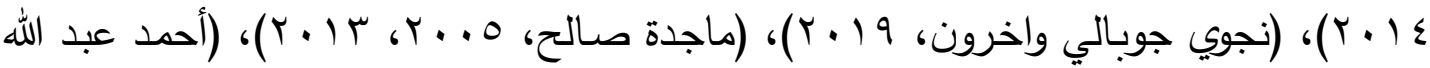

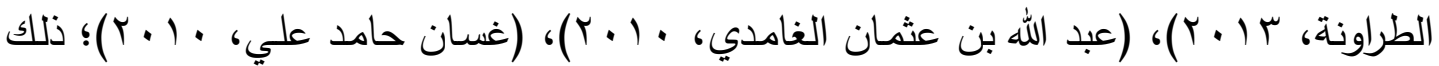

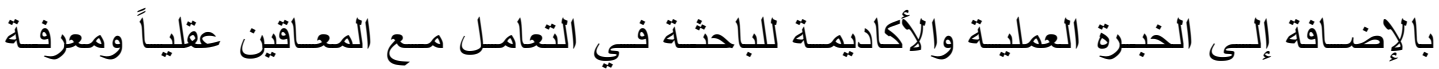
إحتياجاتهم المختلفة.

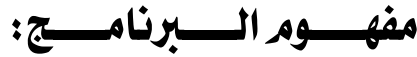

"هو برنامج منظم ومخطط يستند الي مبادئ منهج ماريا منتسوري من خلال مجموعة من

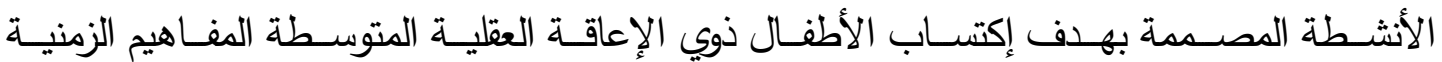
(كالمناسبات الإجتماعية، مفهوم الساعة، الإيقاع الزمني، الزمن الثخصي، المصطلحات الدالة علي الزمن)، وقد صمدت هذه الادوات بثكل يعطي الطفل الفرصة للتعلم بحرية ووفقا لمستواه النمائي. 


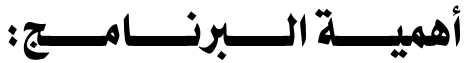

يحتاج الأفراد المعاقون عقلياً فئة القابلون للتعلم إلي برامج إرشادية وتدربية خاصـة بهم

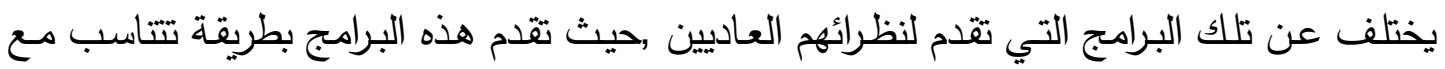

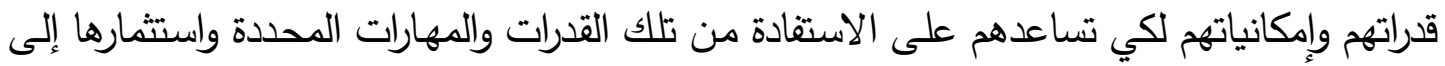

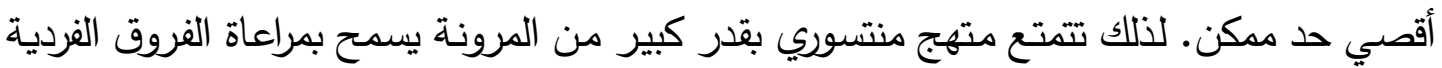

الموجودة بين هؤلاء الأفراد، ولا بد أن تتوافر عدة عوامل أساسية لنجاح البرنامج كان من أهمها:

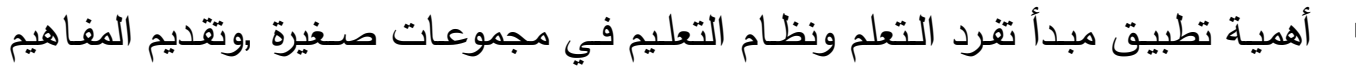

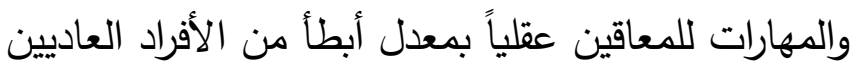

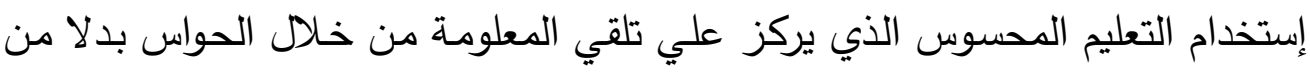
التذكر والحفظ اعطاء الطفل مطلق الحريـة في إختيار الادوات التي يستخدمها والتعلم وفقا لقدراته وسرعته الخاصة مراعاة تسهيل وتبسيط إجراءات تعليم هؤلاء الأطفال وتدريبهم واختيار أساليب تتلاءم مع قدراتهم وإمكاناتهم المحدودة.

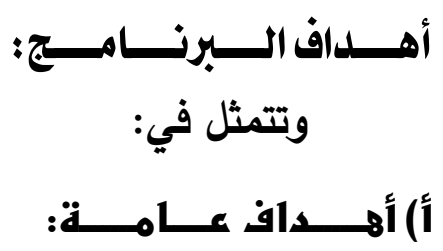

"الان الهدف الرئيسي من البرنامج هو تنمية مستوي الوعي بالمفاهيم الزمنية لدي الأطفال

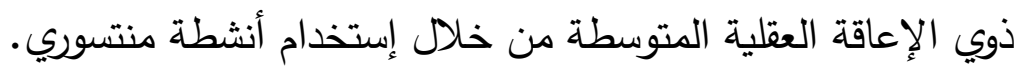

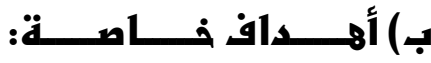

$$
\begin{aligned}
& \text { تدريب الأطفال علي ادرالك مفهوم الزمن الثخصي } \\
& \text { تدريب الأطفال علي ادرالك مفهوم الزمن البيولوجي الألي الئي }
\end{aligned}
$$

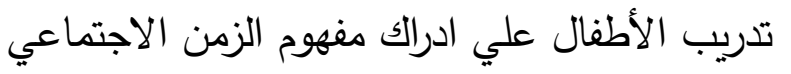

$$
\begin{aligned}
& \text { تدريب الأطفال علي ادرالك مفهوم الزمن العضوي التعن الآناعي }
\end{aligned}
$$

وتقوم الباحثة بمراعاة ما يلي من أجل العمل علي تحقيق هذه الاهداف ومن أهمها:

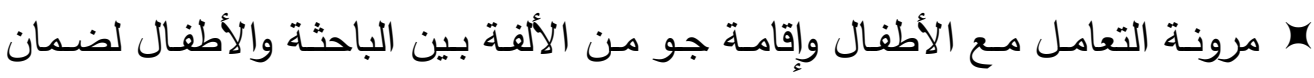

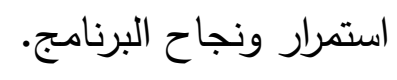

مراعاة خصائص الأطفال ذوي الاعاقة العقلية ومستوي قدراتهم، والفروق الفردية بينهم. 
× التأكيد علي احترام الدور وإعطاء الطفل الحرية في اختيار الانثطة (الاعتماد على استخدام الحواس فى أنثطة البرنامج. (المتخدام عبارات وألفاظ واضحة ومفهومة للأطفال هـ أن يتميز البرنامج بالبساطة والتنوع. (إعطاء الطفل الوقت الكافي للطفل للممارسة والتطبيق.

\section{أسـس الـبرنامـج الإرشــادي التــلـيبـي للـدراسـة:}

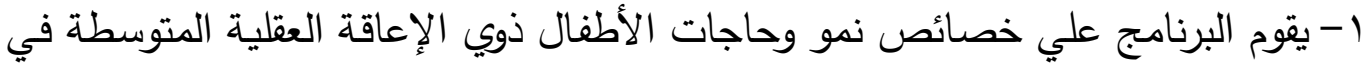

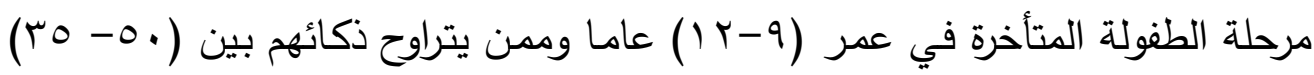
علي مقياس استانفورد بنيه للذكاء.

r- أن يكون البرنامج مرحا ومتقبلا ومريحا للنفس عند هؤلاء الاطفال في هذاء هذه المرحلة.

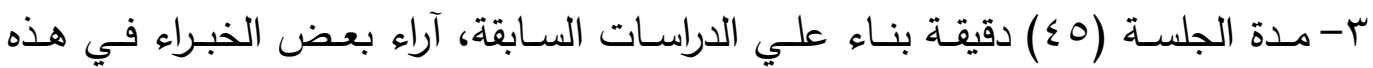

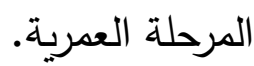
؟ - طبقت الجلسات بشكل فردي مع كل طفل.

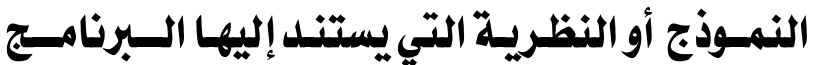

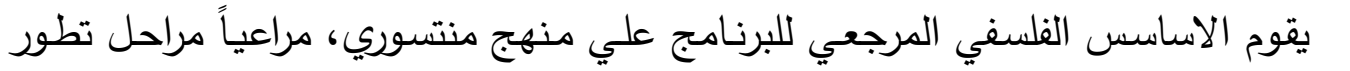
النمو العقلي وتطور مفهوم الزمن عند الأطفال ذوي الاعاقة العقلية المتوسطة كما أثار

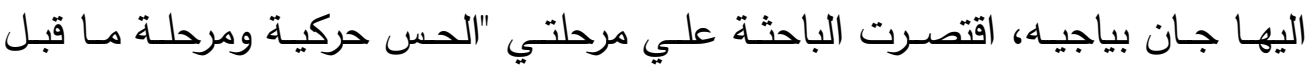

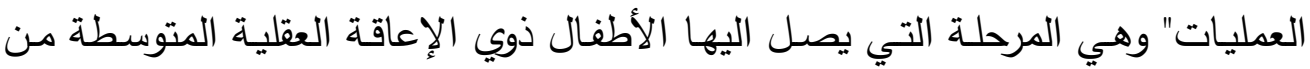

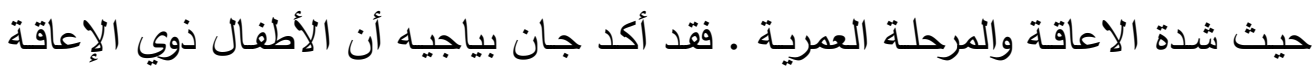
العقلية المتوسطة يقفون عند مرحلة ماقبل العمليات (lovell\&slatter, 1960, 40).

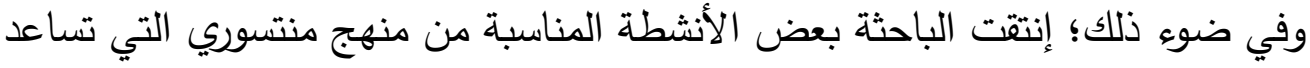

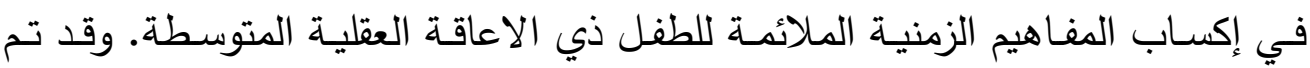

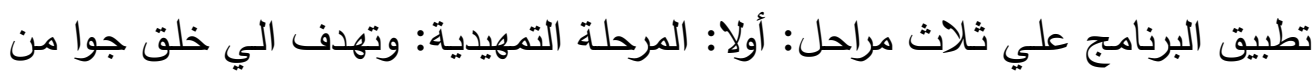

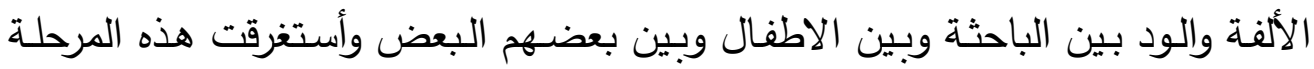

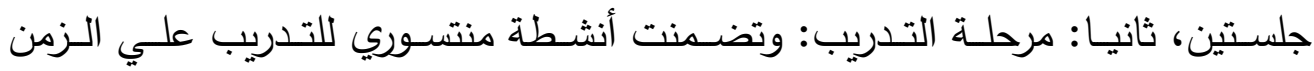

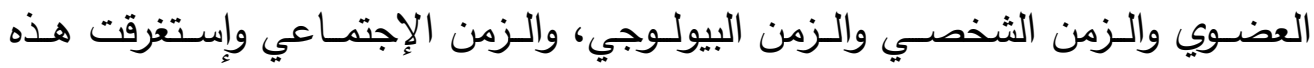

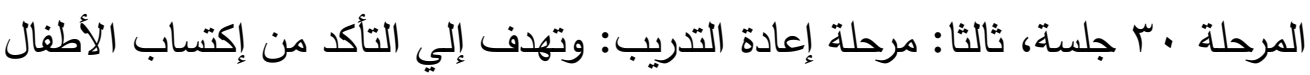
للمفاهيم الزمنية من خلال تطبيق الأنشطة بشكل حر مع متابعة أداؤهم ومراقبته. 


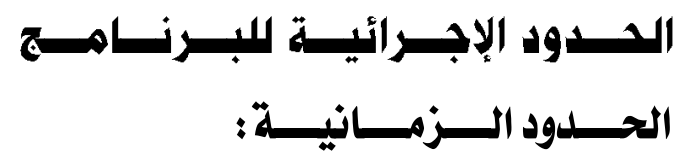

وهى فترة إجـراء الدراسـة على العينـة السـابق الإشـارة إليها، مـن خـلال إجراء جلسـات

برنامج قائم علي أنثطة منتسوري؛ والتي تبلغ (بس) جلسة تدريبية لمدة ثلاثة أشهر، وبمعدل r جلسات أسبوعياً، وكل جلسـة (0ء) دقيقة، ثم تقوم الباحثة بتتبع العينـة بعد مرور شهران من إنتهاء تطبيق البرنامج.

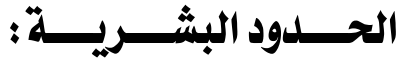

يتتم تطبيق البرنـامج علي ( • ب) طفـلاً من ذوي الإعاقـة العقلية المتوسطة من تلاميذ

مدرسة التربية الفكريـة - بمحافظة المنيا (أعضاء المجموعة التجريبية) والمقيمين إقامة داخلية بالمدرسـة؛ ولديهم درجـة عالية (الإرباع الأدني) علي أبعاد مقياس المفاهيم الزمنية، ويتراوح

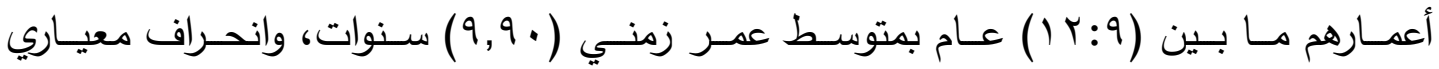

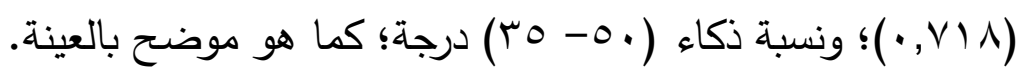

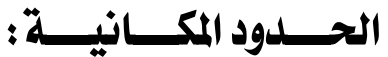

تم تطبيق البرنامج علي عينة من مدرسة التربية الفكريـة بيني سويف، حيث تم تطبيق

الجلسات بغرفة بالمدرسة تم تجهيزها بأدوات منتسوري.

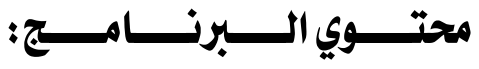

جلول (r) مخطط بجلسات البرنامج التدريبي القائم علي أنشطة منتسوري

\begin{tabular}{|c|c|c|c|c|c|}
\hline تقييم الجلسة & زمن الجلسة & | الفنيات المستخدمة | & 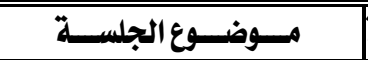 & رقمر الجلسة & المـرحلــة \\
\hline \multirow{10}{*}{ التصحيح } & so & | النمذجة - لعب الدور| & |جلسة تمهيلية & $r-1$ & المرحلة الأولي : المرحلة \\
\hline & $\$ 0$ & |النملججة- لعب الدور|| & |تحلديل فصول السنة. & $r: 1$ & \multirow{8}{*}{ المرحلة الثاني : مرحلة } \\
\hline & $\$ 0$ & |النملججة- لعب الدور|| & | المناسبات الاجتماعية & $r: 9$ & \\
\hline & 80 & |النملججة- لعب الدور|| & |الانشطة اليومية. & $1 \cdot: 14$ & \\
\hline & $\$ 0$ & |النملججة- لعب الدور|| & |تحليد مفهور قبل- بعد. & $18: 10$ & \\
\hline & \$o & |النمذجة - لعب الدور & تمييز بيزمفاهيه امس واليوروغل & $17: 18$ & \\
\hline & $\$ 0$ & |النملججة- لعب الدور|| & |دراك الساعة كاملة & $1 A: r r$ & \\
\hline & \$o & |النمذجة- لعب الدور | لعبةر & أنصاف الساعة. & $r T: r \Lambda$ & \\
\hline & so & |النمذجة - لعب الدور | & أيساه الاسبوع. & $r q: r r$ & \\
\hline & r. & | العب الدور & | إعادة التدريب & rT:rq & الثالثة : مرحلة إعادة \\
\hline
\end{tabular}




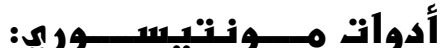

تضـنت الأدوات المستخدمة في الدراسـة الحالية ورقـة وقلم -عجلـة فصـول السنة عجلة فصول أيام الاسبوع - عجلة شهور السنة - كروت أيام الاسبوع - كروت فصول السنة - كروت شهور السنة - صور فصول السنة - مجسم الساعة الخشبية- ختم الساعة الكاملة نص الساعة - قصص لتطور العمر - كروت لامس واليوم وغد قصص لحياة الطفل اليوميةكروت قبل وبعد -كروت للمناسبات الاجتماعية- اغاني تستخدم للدائرة الافتتاحية.

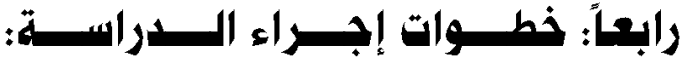

1- تطبيـق أدوات الدراسـة السيكومترية (مقيـاس المفـاهيم الزمنيـة للأطفـال ذوي الإعاقـة

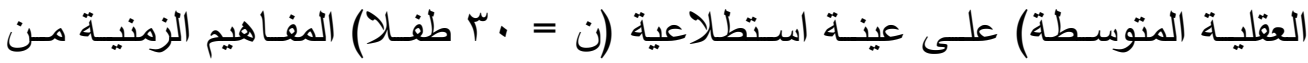

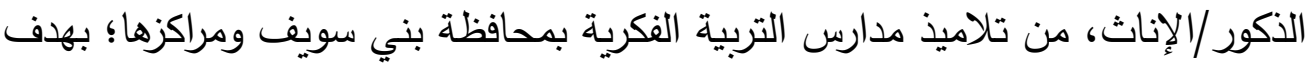

تقتينها "حساب ثباتها وصدقها". r- تطبيق أدوات الدراسـة السيكومترية (مقيـاس المفـاهيم الزمنيـة للأطفـال ذوي الإعاقــة

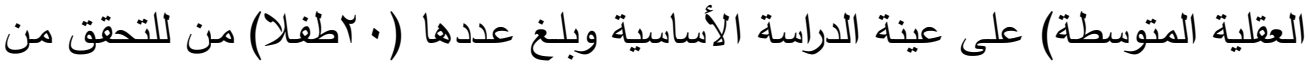
فروض الدراسة.

r- تقسيم عينة الدراسة الأساسية إلى مجموعتين: أ) مجموعة تجريبية: تخضع لتطبيق لبرنامج أنثطة منتسوري، وعددها (· ل (1) أطفال.

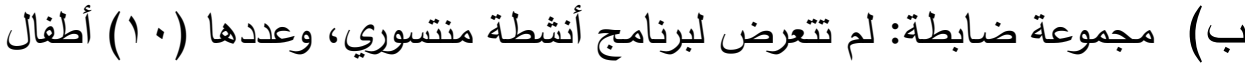
ع - تطبيق البرنامج ( ب ج جلسة) على أفراد المجموعة التجريبية بصورة جماعية وفردية، بواقع ثلاث جلسات أسبوعياً. 0- بعد الانتهاء من تطبيق البرنامج، يتم تطبيق مقياس المفاهيم الزمنية للاطفال ذوي

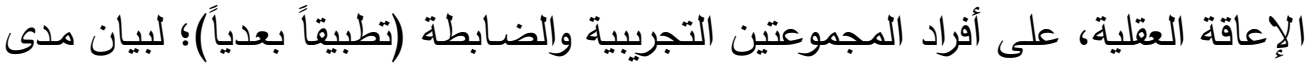

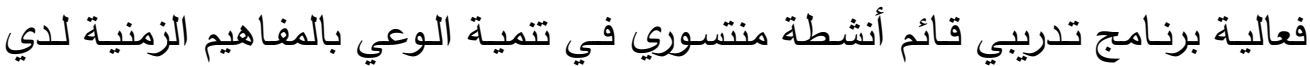
الأطفال ذوي الإعاقة العقلية المتوسطة. 7- تطبيق مقياس المفاهيم الزمنية للأطفال ذوي الإعاقة العقلية المتوسطة مرة أخرى بعد الإسطة

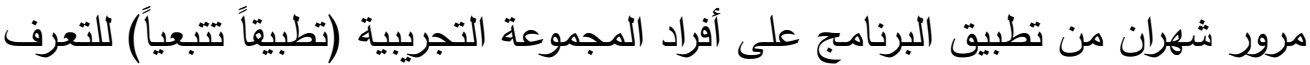
مدى استمرارية فعالية البرنامج بإستخدام أنشطة منتسوري في تنمية بعض مشكلات الانضباط السلوكي لدي الأطفال ذوي الإعاقة العقلية المتوسطة. 


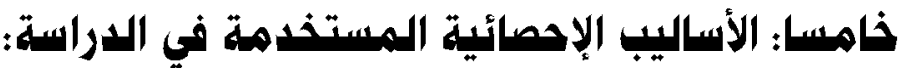

للتحقق من كفاءة أدوات الدراسة السيكومترية، وصحة الفروض، استخدمت الباحثة عدداً من الأساليب الإحصائية اللابارامترية منها:

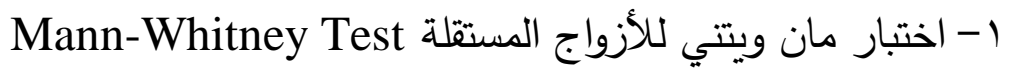

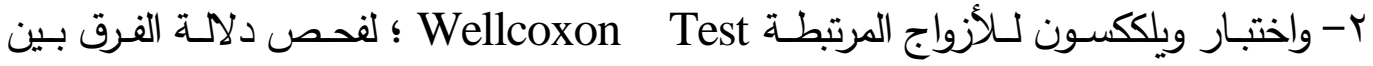
متوسطي رتب درجات المجموعة التجرببة والضابطة كل على حدة، أو المجموعتين التجريبية والضابطة معاً قبل / بعد تطبيق البرنامج لمعرفة مدى فعالية برنامج تدريبي قائم علي أنشطة

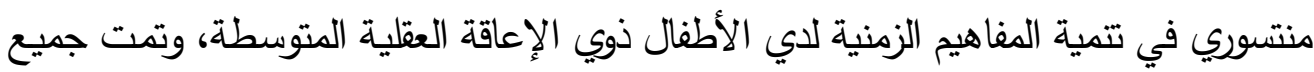

المعالجات للإحصائية بواسطة الحزمة الإحصائية للعلوم الاجتماعية (SPSS, V.20).

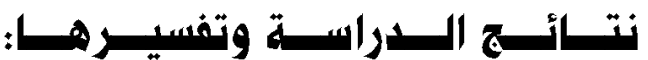

\section{نتيجــة الفــرض الأول وتفسـيره}

ينص الفرض الأول على أنـه: "يوجد فرق دال إحصائياً بين متوسطي رتب المجموعة

التجريبية والمجموعة الضابطة في القياس البعدي على مقياس المفاهيم الزمنية وأبعاده الفرعية للأطفال ذوي الإعاقة العقلية المتوسطة".

للتحقق من صحة هذا الفرض قامت الباحثة بحساب دلالات الفروق بين متوسطات رتب المجموعتين التجرببية والضابطة على مقياس المفاهيم الزمنية وأبعاده الفرعية للأطفال ذوي Mann Whitney الإعاقة العقلية المتوسطة. باستخدام اختبار مان ويتتي لعينتين مستقلتين

$$
\text { Test }
$$

جلدول (\&1) الفروق بين متوسطات رتب المجموعتين التجريبية والضابطة في القياس البعدي لمقياس المفاهيه

\begin{tabular}{|c|c|c|c|c|c|c|c|c|c|c|}
\hline مربع إيتا & 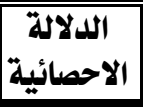 & قيمة Z & قيمة W & قيمة & مجموع الرتب & متوسط & الحسابي & | العدد | العد & المجموعة & 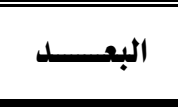 \\
\hline \multirow{2}{*}{$\cdot, 7+1$} & \multirow{2}{*}{$\cdot, \cdot 1$} & \multirow{2}{*}{ r, $\{Y \xi-$} & \multirow{2}{*}{$7 \cdot, 0 \cdot \cdot$} & \multirow{2}{*}{$0,0 . \cdot$} & $1 \leqslant 9,0$ & 18,90 & $11, \cdot \bullet$ & 1. & تجريبية & \multirow{2}{*}{ الزمن العضوي } \\
\hline & & & & & $7 \cdot, 0 \cdot$ & $7, \cdot 0$ & $v, v$. & 1. & ضابطة & \\
\hline \multirow{2}{*}{ •, rrr } & \multirow{2}{*}{$\cdot, \cdot 0$} & \multirow{2}{*}{ r,ror- } & \multirow{2}{*}{ Vo,o.. } & \multirow{2}{*}{$r_{\bullet}, 0 \cdot \cdot$} & $1 r \varepsilon, 0$. & $17, \leqslant 0$ & $1 \cdot, r$. & 1. & تجريبية & \multirow{2}{*}{ الاجتماعي الزمن } \\
\hline & & & & & vo,o. & $v, 00$ & $v, v$. & 1. & ضابطة & \\
\hline \multirow{2}{*}{ •, VIr } & \multirow{2}{*}{$\cdot, \cdot 1$} & \multirow{2}{*}{$r, \Lambda \cdot r-$} & \multirow{2}{*}{$\Delta 0, \cdots$} & \multirow{2}{*}{$\bullet, \cdots$} & $100, \cdots$ & 10,0 & ir,o. & 1. & تجريبية & \multirow{2}{*}{ زمن البيولوجي } \\
\hline & & & & & $\Delta 0, \cdot \cdot$ & 0,0 & $\Lambda, r \cdot$ & 1. & ضابطة & \\
\hline \multirow{2}{*}{ •,Arq } & \multirow{2}{*}{$\cdot, \cdot 1$} & \multirow{2}{*}{$r, \wedge \cdot \xi-$} & \multirow{2}{*}{$\Delta 0, \cdots$} & \multirow{2}{*}{$\bullet, \cdot \bullet \cdot$} & $100, \cdots$ & 10,0 & $10, r$ & 1. & تجريبية & \multirow{2}{*}{ لزمن الشخصي } \\
\hline & & & & & $\Delta 0, \cdots$ & 0,0 & $\Lambda, 1$. & 1. & ضابطة & \\
\hline \multirow{2}{*}{$\cdot, \wedge \mid \wedge$} & \multirow{2}{*}{$\cdot, \cdot 1$} & \multirow{2}{*}{$r, r \mid r-$} & \multirow{2}{*}{$07, \cdots$} & \multirow{2}{*}{$1, \cdots$} & $10 \xi, \cdot \cdot$ & $10, \xi$. & $0 ., 0$. & 1. & تجريبية & \multirow{2}{*}{ المقياس ككل } \\
\hline & & & & & $07, \cdots$ & 0,7 . & rI, A. & 1. & ضابطة & \\
\hline
\end{tabular}
الزمنية وأبعاده الرئيسية للأطفال ذوي الإعاقة العقلية المتوسطة باستخداه اختبار مان ويتني

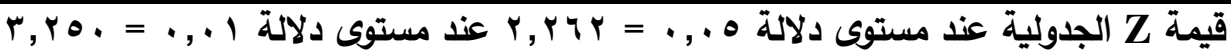




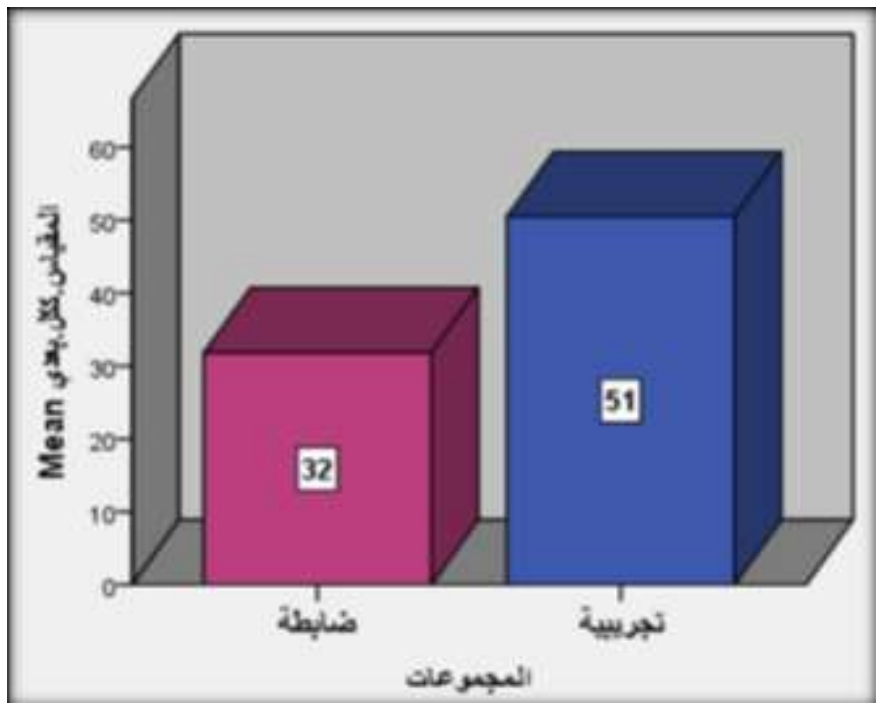

شكل (1) الفروق بين متوسطات درجات المجموعتين التجريبية

\section{والضابطة في القياس البعدي لمقياس المفاهيم الزمنية}

يتضح من خلال جدول (ع () وجود فروق بين متوسطات رتب درجات المجموعتين التجريبيـة والضـابطة في القيـاس البعدي لمقيـاس الهفـاهيم الزمنيـة وأبعـاده الفرعيـة للأطفـال

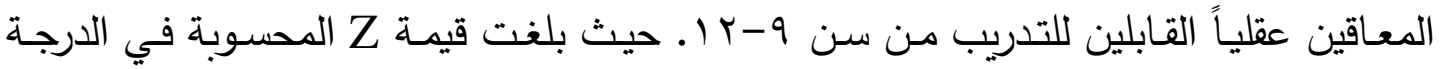

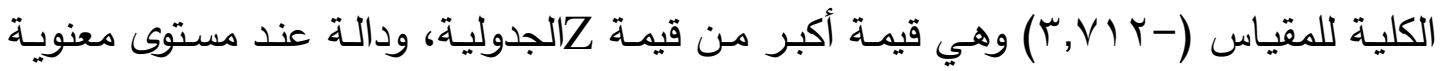
( ( , ·)، ولمعرفة اتجاه الفرق يتم مقارنة متوسط رتب المجموعتين الضابطة والتجريبية. فقد بلغ

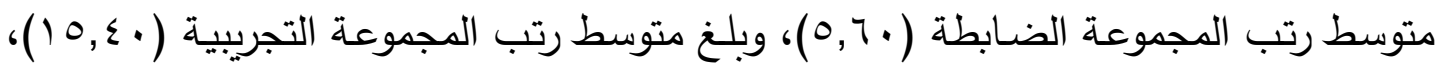

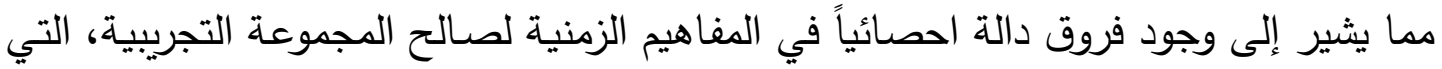

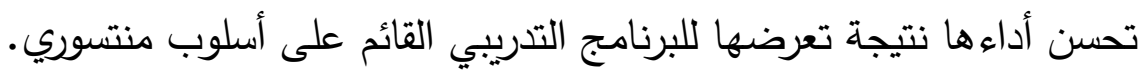
وبالنسبة للأبعاد الفرعية لمقياس المفاهيم الزمنية يتضح وجود فروق دالة إحصائياً بين

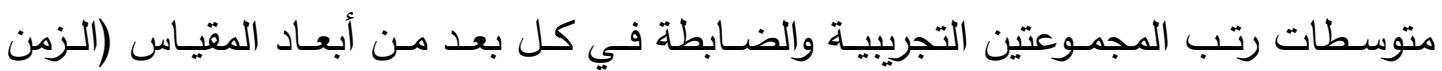

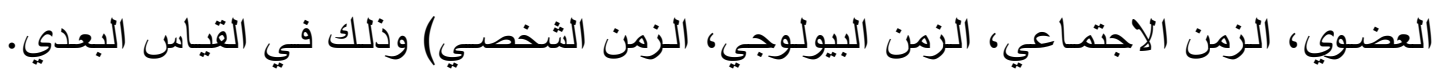

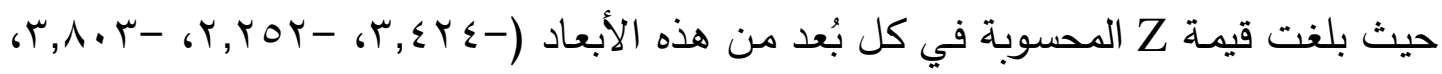

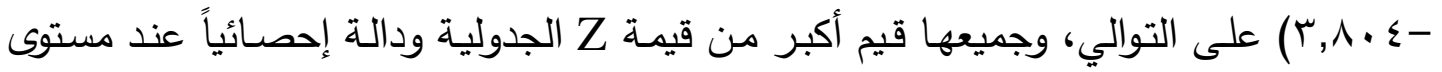

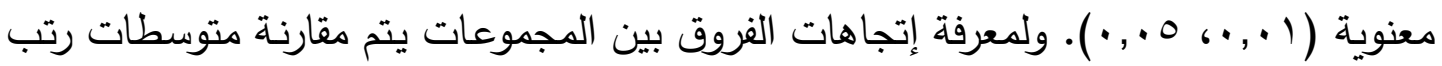

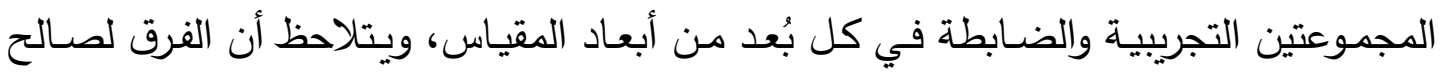
المجموعة التجريبية التي تعرضت للبرنامج التدريبي. 
هذا ولم تكتفي الباحثة بحساب دلالات الفروق بين متوسطات رتب درجات المجموعتين

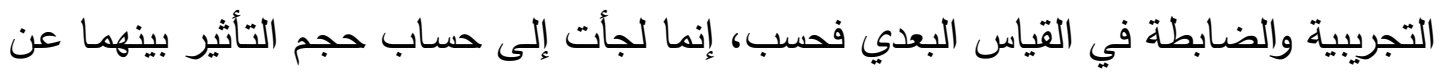

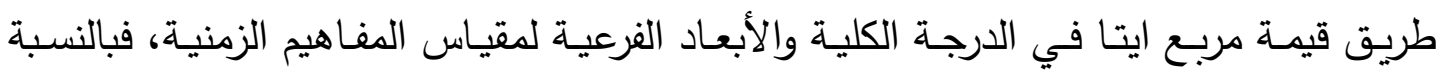

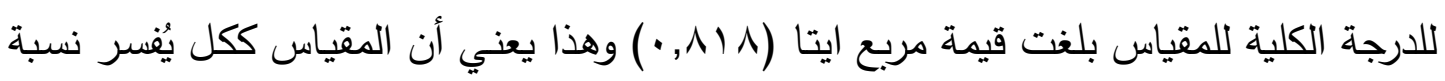

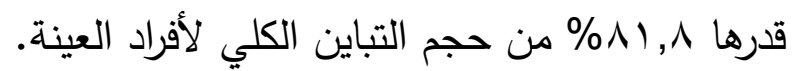

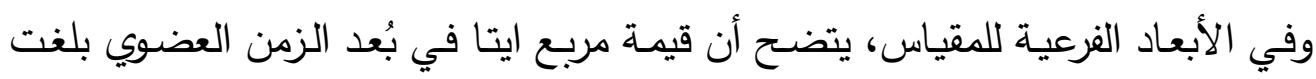

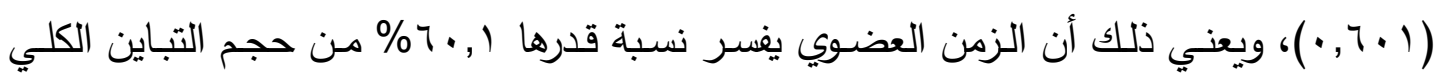

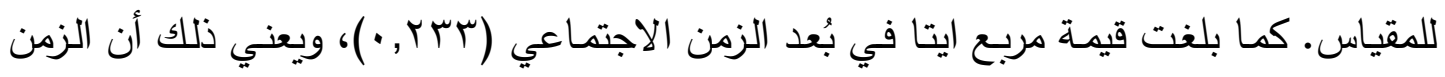

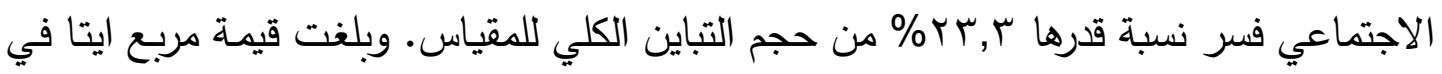

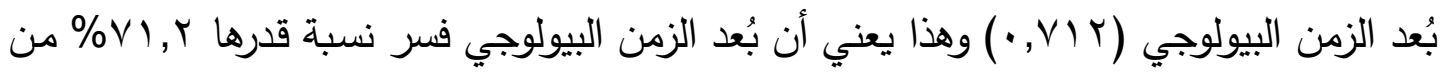

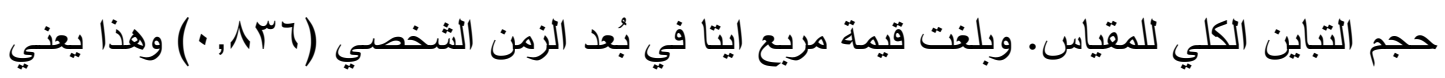

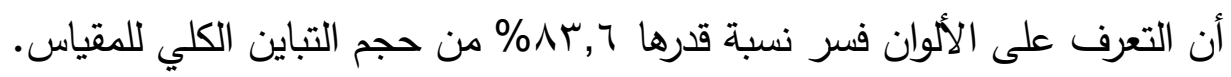

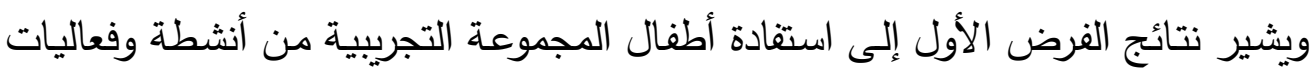

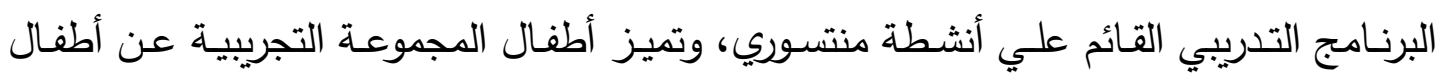

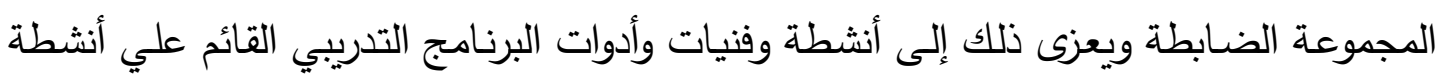

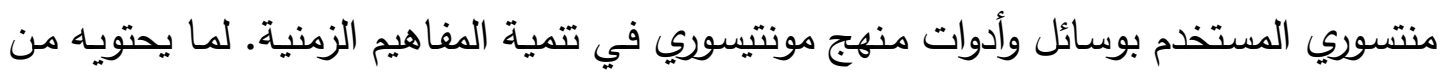

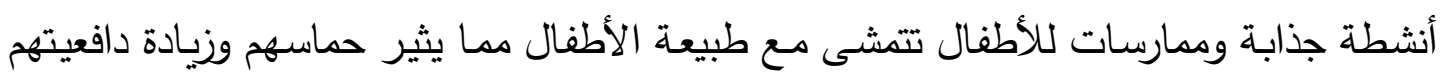

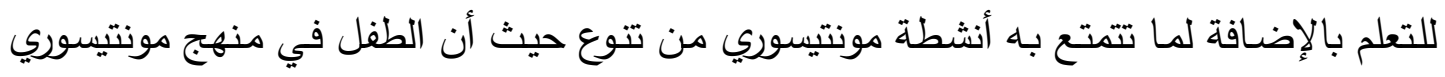

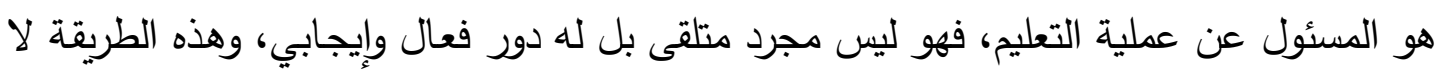

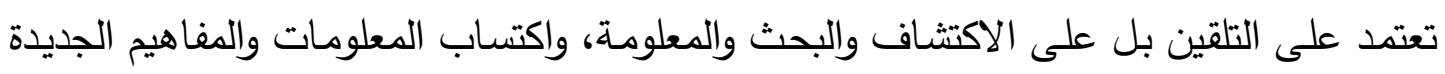

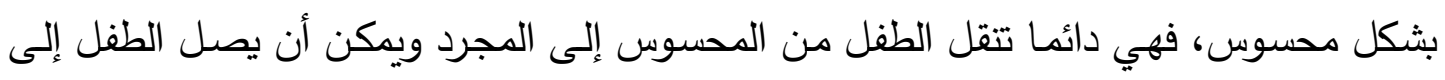

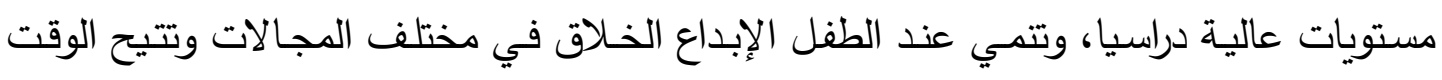

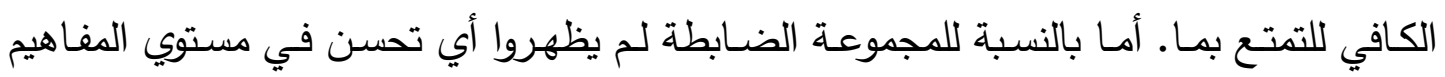
الزمنية وذلك لأنهم لم يتعرضوا لنفس الانثطة التي تعرض لها لها أطفال المجموعة التجريبية.

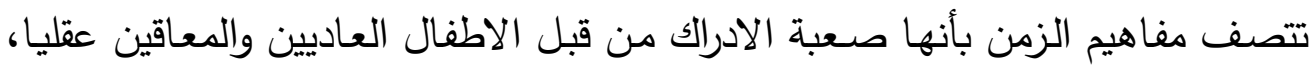

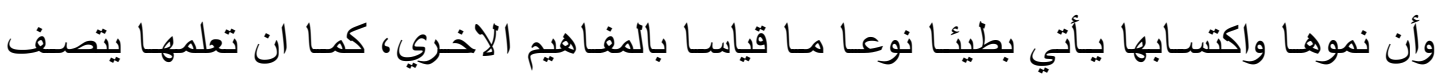

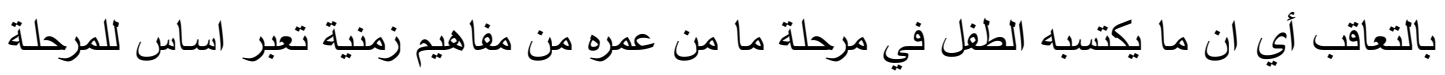

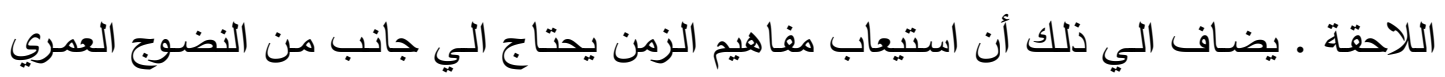


واكتساب خبرات معرفية واجتماعية معينة (فاضل خليل ابراهيم، 999 1، (Y)؛ وهو ما يفتقده

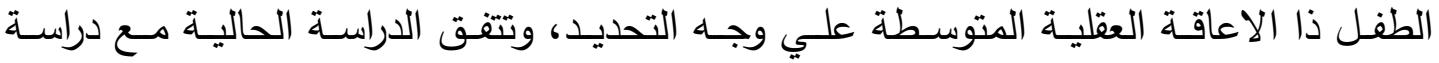
(Busby \& Suddendorf, 2005; Suddendorf, Nielsen, \& Von Gehlen, 2011; ،(2005 ،Busby \& Suddendorf) ،Schacter, Addis, \& Buckner, 2007) (Busby Grant\& Suddendorf, 2011)، (Suddendorf,2010). لذلك تكون الطرق

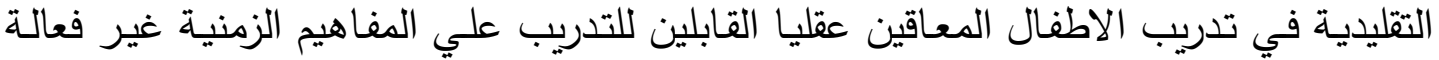

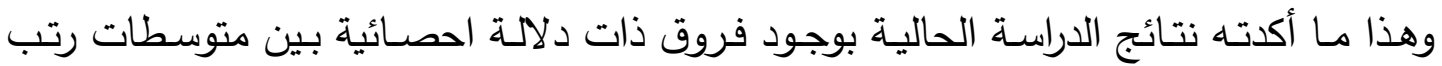
أطفال المجموعتين التجريبية والضابطة في القياس البعدي على مقياس المفاهيم الزمنية لصالح

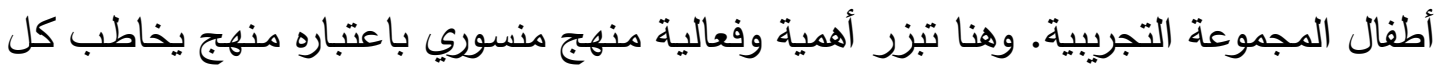

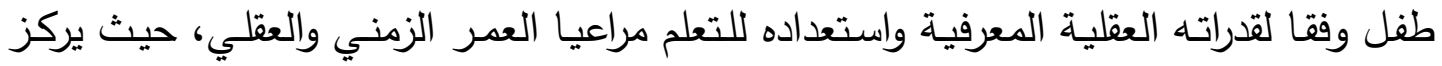
علي فردية الطفل في التعلم من خلال ادوات جذابة تتدرج من المحسوس الي المجرد. فالطفل

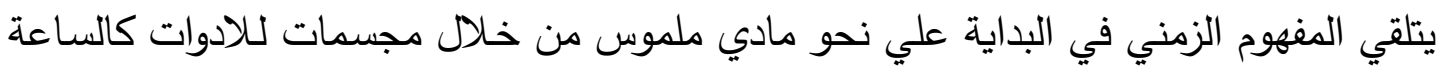

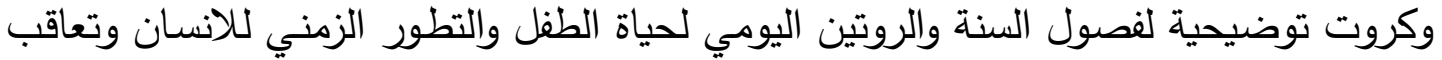

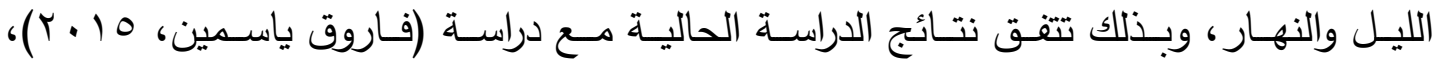

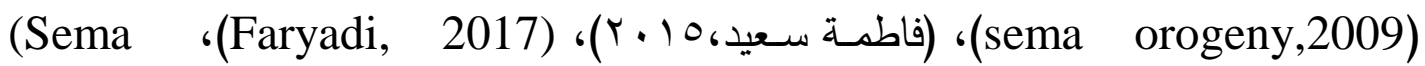
(Kayili, G.,\& Ari, R. 2011) ، (Ongoren \& Derya Ozlem Yazlik, 2018)

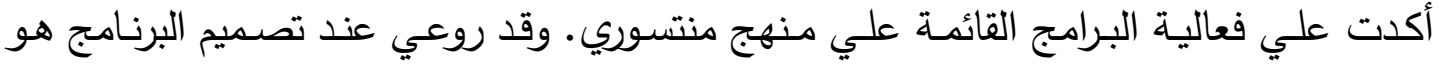

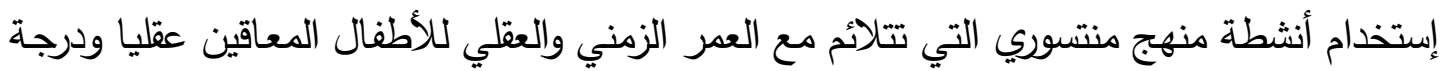

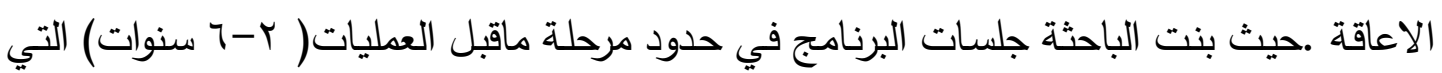
حددها بياجيه في تصنيفه لمراحل النمو العقلي، وهي المرحلة التي يصل اليها المعاقين عقليا من الدرجة المتوسطة، وفي ضوء الدراسات التي قام بها (Boehem, 2008, 1991, 2001).

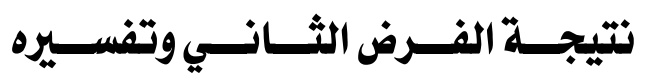
ينص الفرض الثاني على أنسه: "يوجد فرق دال إحصائياً بين متوسطي رتب القياس الفياس

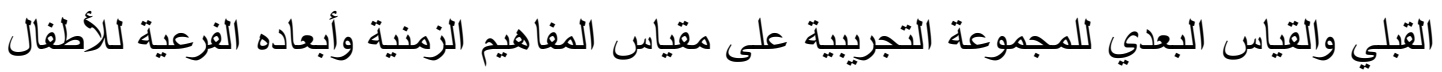
ذوي الإعاقة العقلية المتوسطة".

للتحقق من صحة هذا الفرض قامت الباحثة بحساب دلالات الفروق بين متوسطات رتب القياسين القبلي والبعدي للمجموعة التجريبية على مقياس المفاهيم الزمنية وأبعاده الفرعية

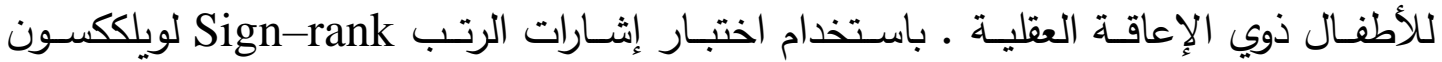
Wilcoxon لحساب دلالات الفروق بين مجموعتين مرتبطتين، والجدول (10) يوضح ذلك. 
جدول (10) الفروق بين متوسطات رتب القياسين القبلي والبعدي للمجموعة التجريبية على مقياس المفاهيم الزمنية للأطفال المعاقين عقليا باستخلاهر اختبارويلككسون

\begin{tabular}{|c|c|c|c|c|c|c|c|c|c|}
\hline حجم التأثير & الدلالة & | Zيمة & الرتمبع & متوسط الرتب| & العدد | & اتجاه فروق & المتوسط الحسابي & |القياسات & البعد \\
\hline \multirow{4}{*}{$\cdot, \mathrm{V} \leqslant 7$} & \multirow{4}{*}{$\bullet, \cdot 1$} & \multirow{4}{*}{ Y,Alr- } & •,• & $\bullet, \cdot \bullet$ & - & سلبي & \multirow{2}{*}{$7,1}$. & \multirow{2}{*}{ قبلي } & \multirow{4}{*}{ لزمن العضوي } \\
\hline & & & $\Delta 0, \cdot \cdot$ & $0,0$. & 1. & إيجابي & & & \\
\hline & & & & & - & محايل & \multirow{2}{*}{$11, \cdot \cdot$} & \multirow{2}{*}{ بعدي } & \\
\hline & & & & & 1. & كلي & & & \\
\hline \multirow{4}{*}{ •, 111 } & \multirow{4}{*}{$\cdot, \cdot 0$} & \multirow{4}{*}{$r$, osq- } & $\bullet, \cdot \bullet$ & $\bullet, \cdot \bullet$ & - & سلبي & \multirow{2}{*}{$\Lambda, \vee$. } & \multirow{2}{*}{ قبلي } & \multirow{4}{*}{ الزمن الاجتماعي } \\
\hline & & & $r q, \cdot \cdot$ & $\xi, 0$. & $\Lambda$ & إيجابي & & & \\
\hline & & & & & $r$ & محايل & \multirow{2}{*}{$1 \cdot, \mathrm{V}$. } & \multirow{2}{*}{ بعدي } & \\
\hline & & & & & 1. & كلي & & & \\
\hline \multirow{4}{*}{ - YYO } & \multirow{4}{*}{$\cdot, \cdot 1$} & \multirow{4}{*}{$\mathbf{r}, \Lambda \mid \xi-$} & $\bullet, \cdot \bullet$ & •,••• & - & سلبي & \multirow{2}{*}{$\Lambda, 1}$. & \multirow{2}{*}{ قبلي } & \multirow{4}{*}{ الزمن البيولوجي } \\
\hline & & & $\Delta 0, \cdot \cdots$ & $0,0$. & 1. & إيجابي & & & \\
\hline & & & & 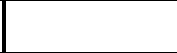 & - & محايل & \multirow{2}{*}{$1 \%, 0}$. & \multirow{2}{*}{ بعدي } & \\
\hline & & & & & 1. & كلي & & & \\
\hline \multirow{4}{*}{ •, $17 \xi$} & \multirow{4}{*}{$\bullet,+1$} & \multirow{4}{*}{$r, \Delta r^{r}-$} & $\cdot, \cdot \bullet$ & $\bullet, \cdot \bullet$ & • & سلبي & \multirow{2}{*}{$\Lambda, \cdot \bullet$} & \multirow{2}{*}{ قبلي } & \multirow{4}{*}{ الزمن الشخصي } \\
\hline & & & $\Delta 0, \cdot \cdot$ & $0,0$. & 1. & إيجابي & & & \\
\hline & & & & & - & محايل & \multirow{2}{*}{$10, r}$. & \multirow{2}{*}{ بعدي } & \\
\hline & & & & & 1. & كلي & & & \\
\hline \multirow{4}{*}{ •,AFE } & \multirow{4}{*}{$\bullet,+1$} & & $\cdot, \cdot \bullet$ & •,••• & - & سلبي & \# & ق & \\
\hline & & " & $00, \cdot \cdot$ & $0,0$. & 1. & إيجابي & , & تبي & \\
\hline & & & & & - & محايل & & & \\
\hline & & & & & 1. & كلى & $0 u, \infty$ & بتدي & \\
\hline
\end{tabular}

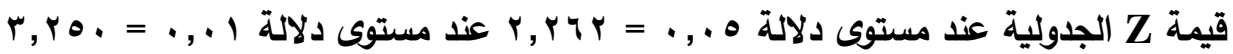
شكل (r) الفروق بين متوسطات درجات القياسين القبلي والبعدي للمجموعة التجريبية على مقياس المفاهيم الزمنية متونية درجاتياسين

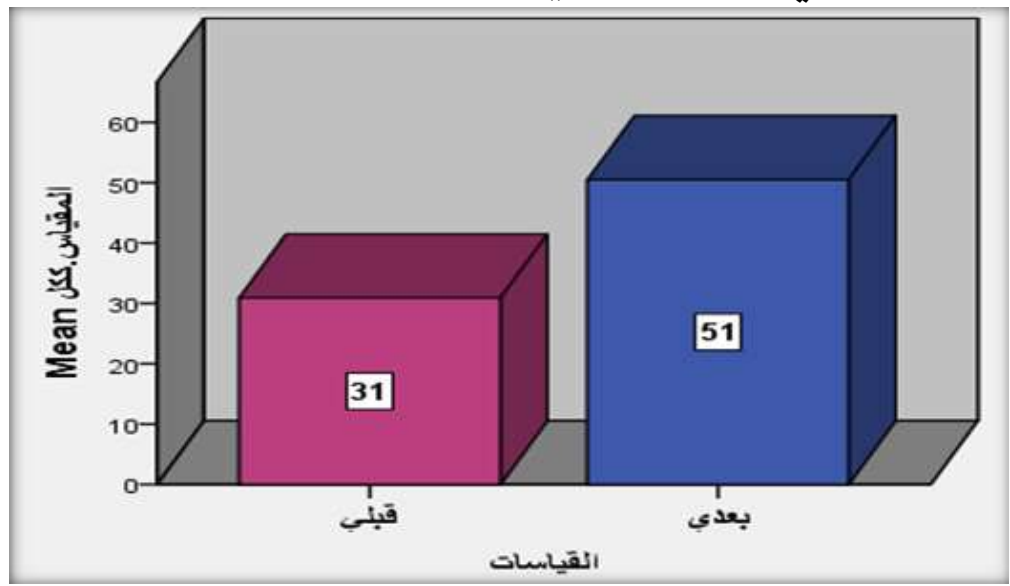


يتضح من خلال جدول (0 1) وجود فروق بين متوسطات رتب درجات القياسين القبلي والبعدي للمجموعة التجريبية على مقياس المفاهيم الزمنية وأبعاده الفرعية للأطفال المعاقين

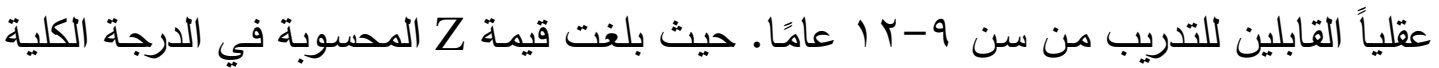

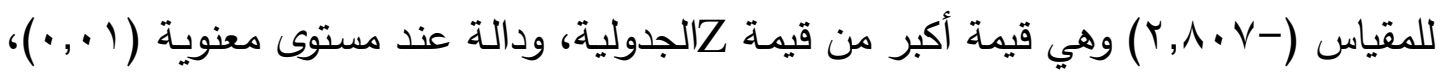
ولمعرفة اتجاه الفرق يتم الدقارنة بين مجموع الرتب الموجبة والرتب السالبة في الدرجة الكلية

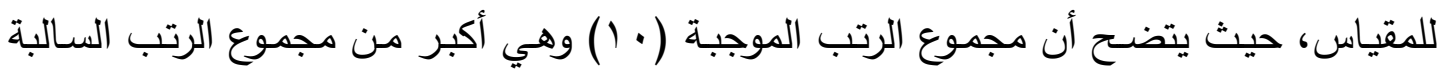

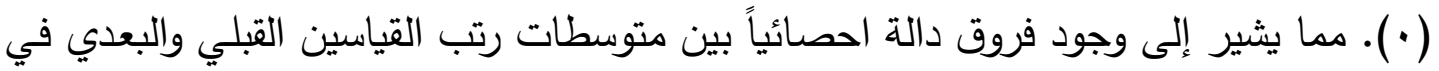
المفاهيم الزمنية للمجموعة التجريبية لصالح القياس البعدي.

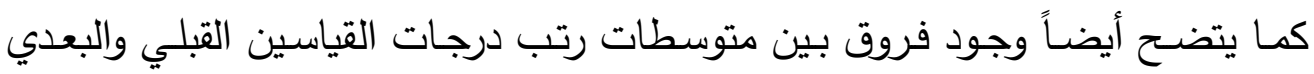

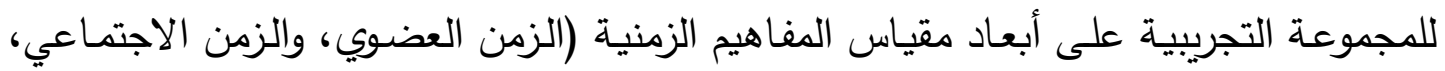

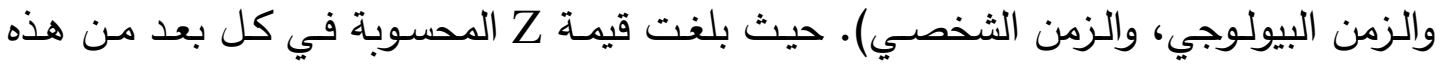

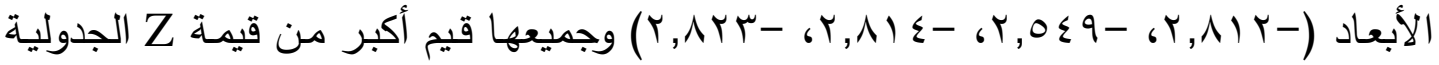

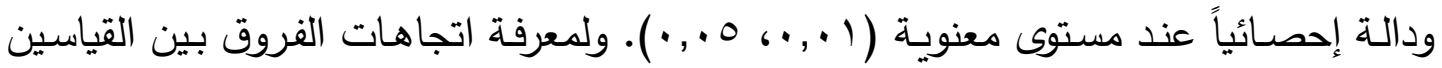

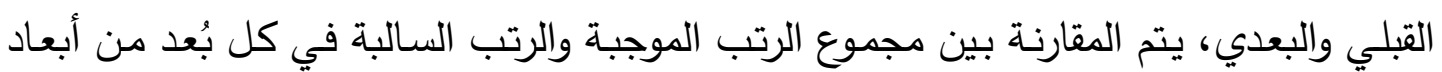

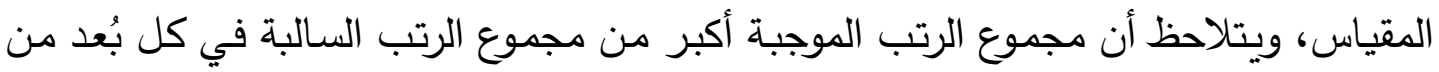

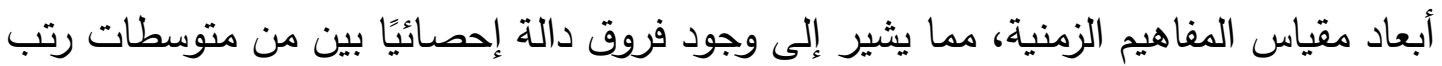
القياسين القبلي والبعدي للمجموعة التجريبية لصالح القياس البعدي. كما قامت الباحثة بحساب حجم الأثر عن طريق تطبيق معادلة معامل الارتباط الثنائي

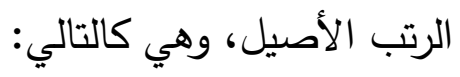

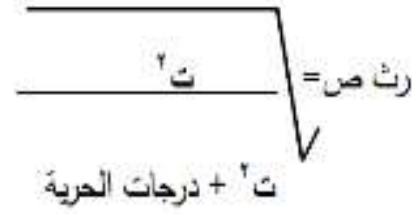

وبتطبيق المعادلة نجد أن حجم تأثير البرنامج التدريبي في أفراد المجموعة التجريبية

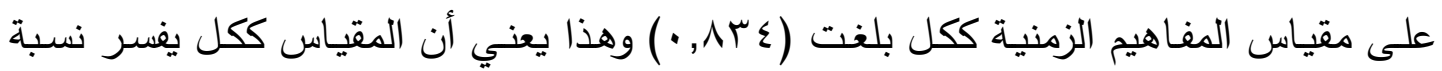

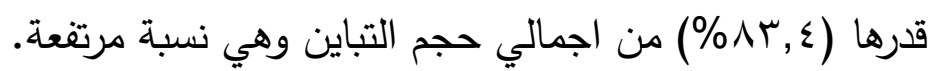

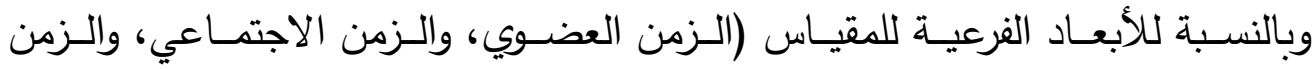

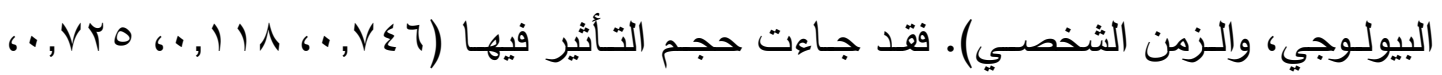


ع ام, • ) على الترتيب، وهي قيم كبيرة وفقاً لمحكات حجم التأثير لكوهين (Cohen, 1988).

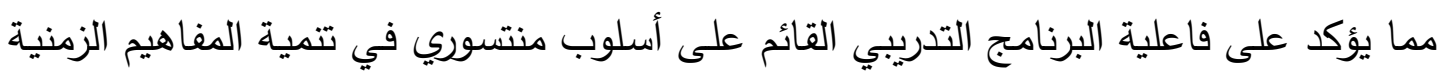

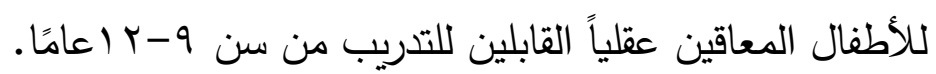

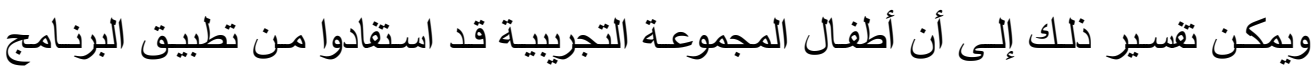

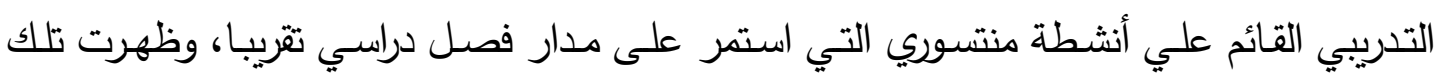

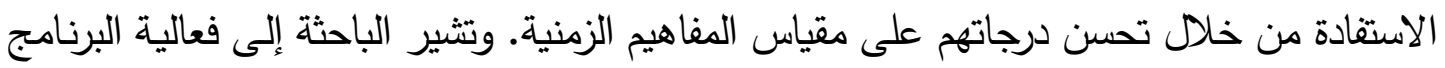

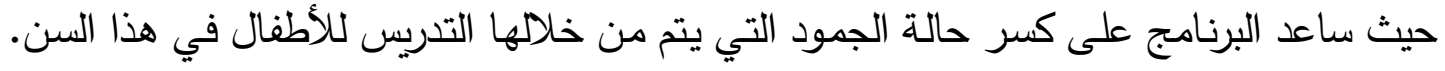

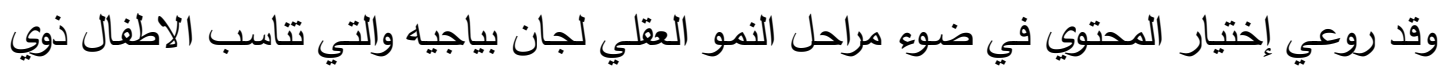

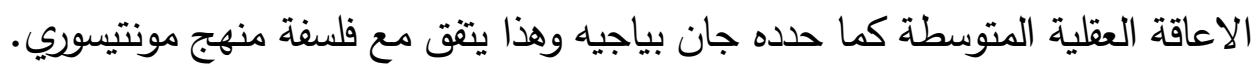

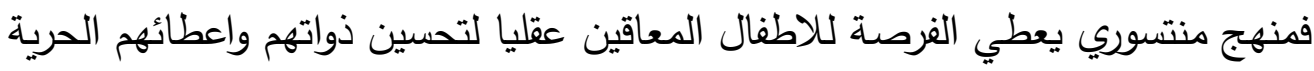

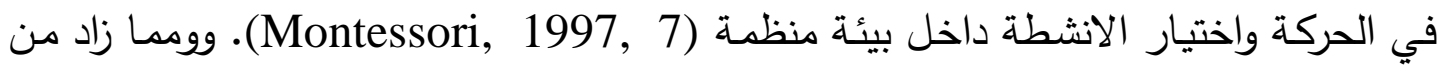

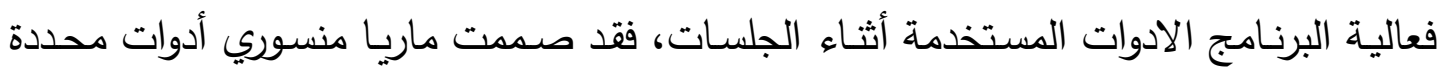

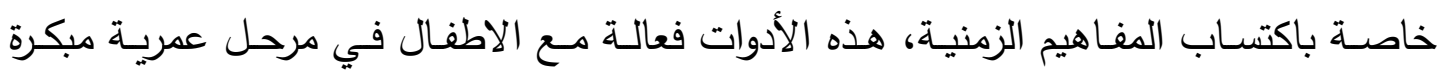

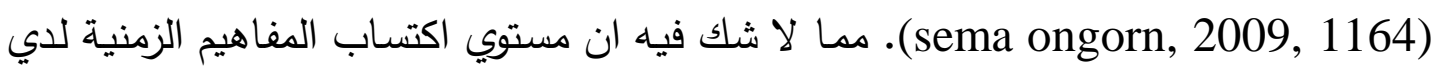

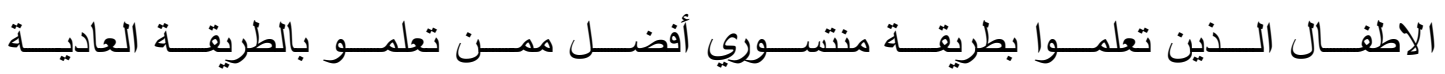
(Asfuroglu,1990). ففي ضوء القياس البعدي لأبعاد مقياس الهفاهيم الزمنية؛ تبين أن أطفال

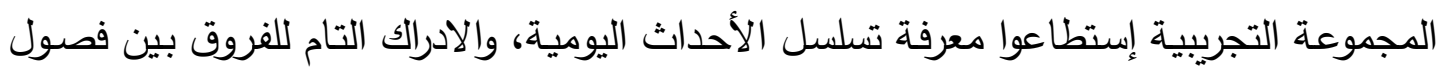

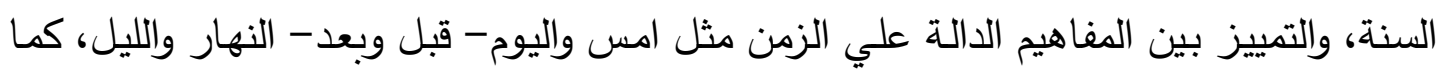

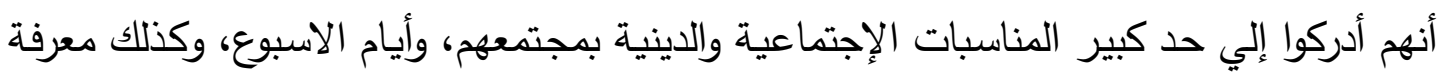

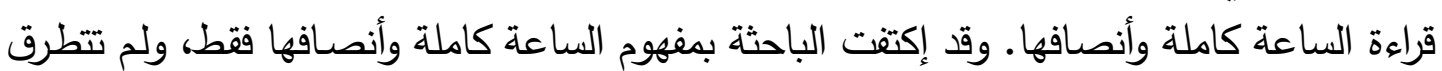

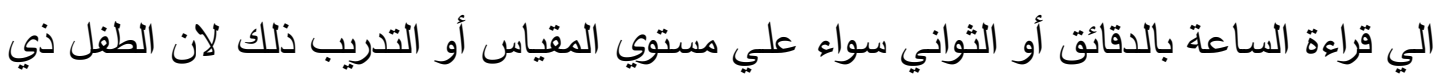

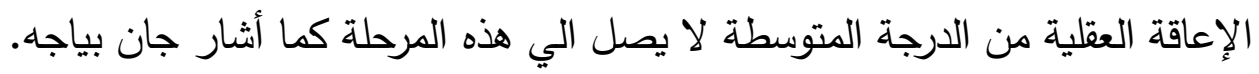

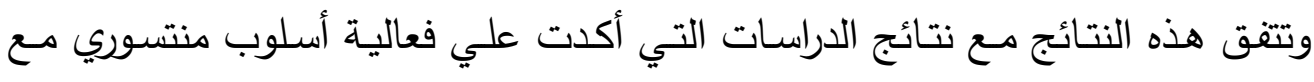

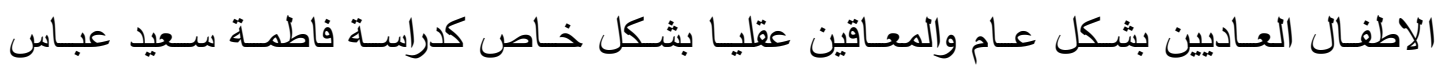

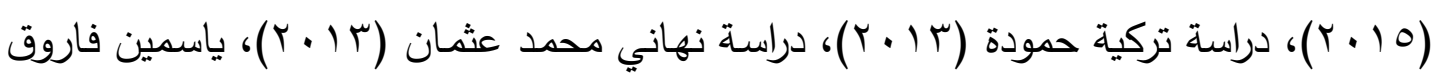

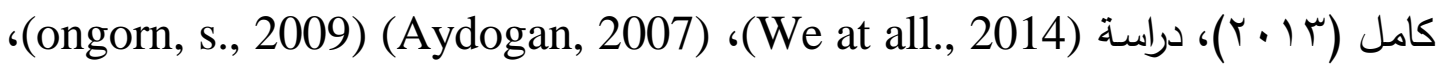

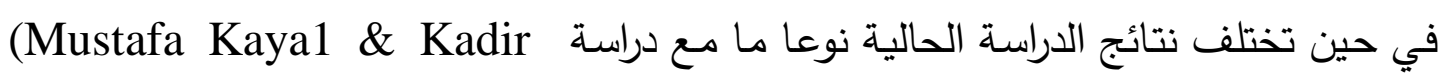

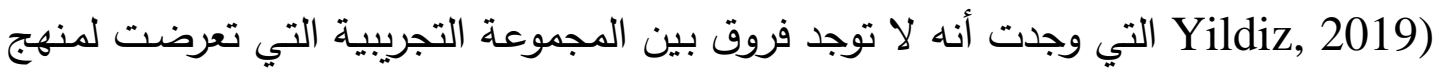
منتسوري والمجموعة الضابطة التي تلقت تدريباً تقليدياً. 
وتختلف البرامج التدريبية المقدمة للمعاقين عقليا بثكل عام عن تلك البرامج التي تعتمد

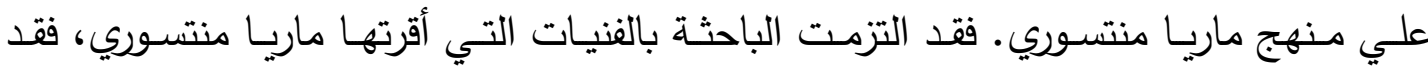

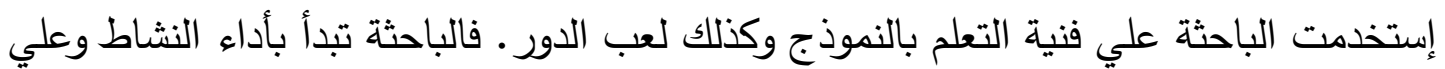

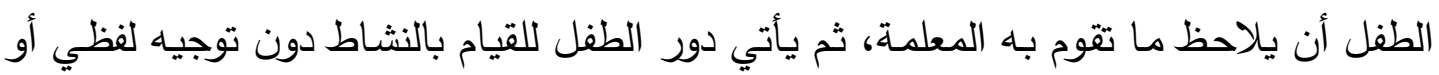

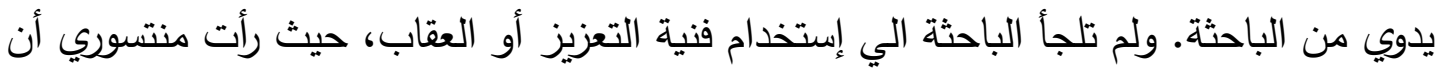

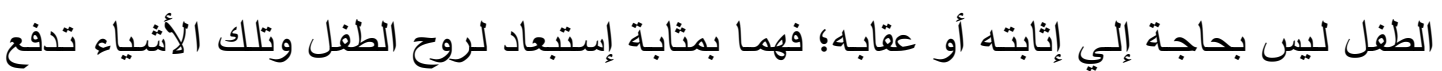

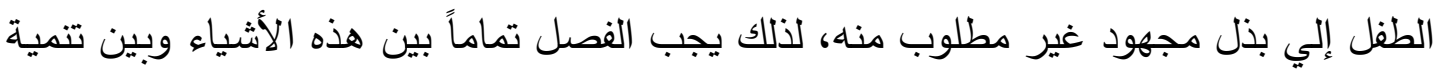
ورعاية الطفل بطريقة طبيعية وتلقائية. كما أن الباحثة لم توجه الأطفال في حال إخفاقهم في أداء المهـة تاركة لهم الوقت الكافي لأداء المهمة، فالطفل يكتثف بنفسه الخطأ التي وقع فيه وهو مال التها تسميه ماريا منتسوري

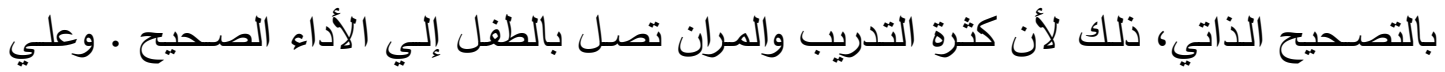

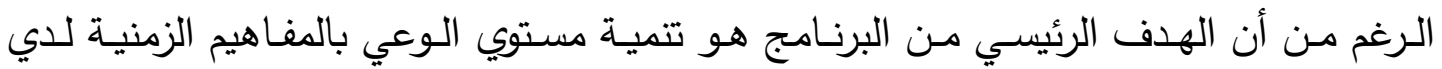
الأطفال ذوي الإعاقة العقلية، إلا أن الباحثة لاحظت إكتساب الكثير من السلوكيات الإيجابية

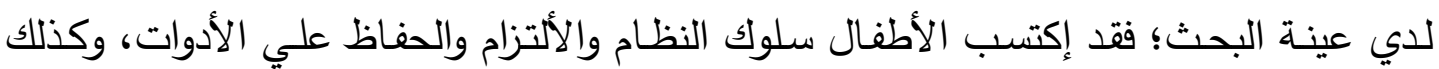

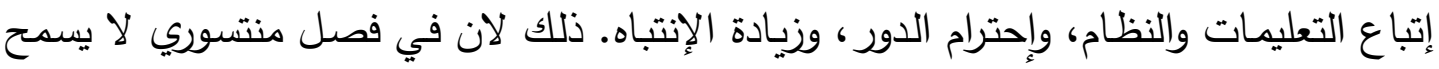

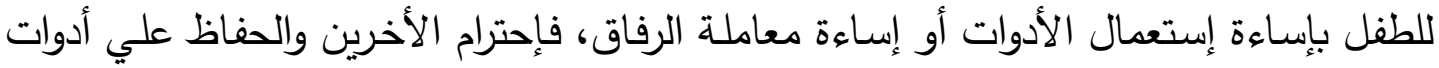

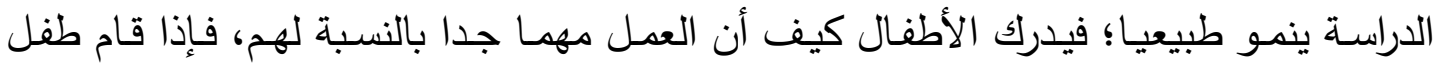
بمضايقة رفاقه الذين يعملون بتركيز عميق فإن هذا الطفل عادة ما يجبر على البقاء بمفرده، وبهذه الطريقة فهم يحترمون هذه الرغبة بتلقائية، على الرغم من أن المدرس قد يتدخل أحيانًا،

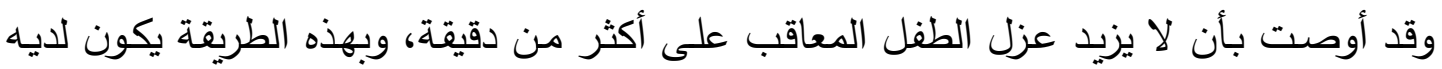

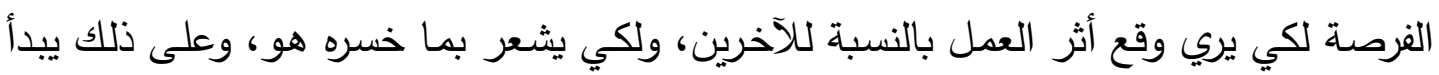

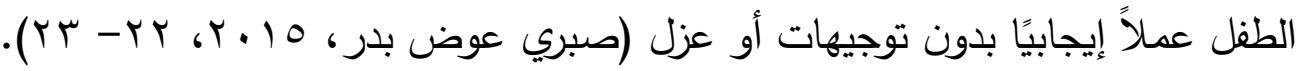
هذا وتختلف الدراسة الحالية عن الدراسات التي إستخدت منهج منتسوري مع المعاقين

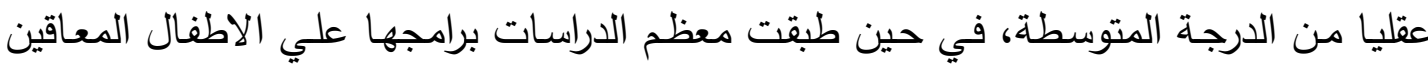
عقليا من الدرجـة البسيطة كدراسة (عزة سيف البريدي، 9 ( ـ ب)، غير أن الدراسـات الأخري

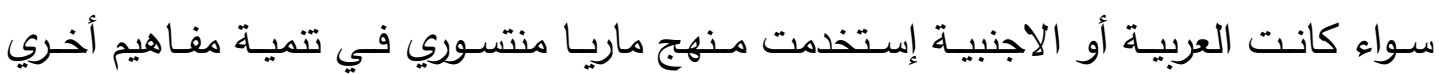

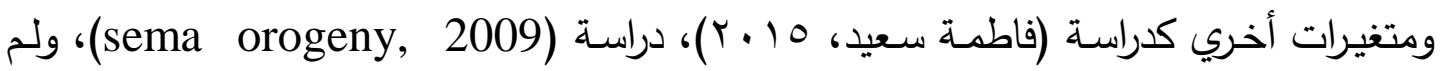
تتطرق أي دراسة منهم إلي تتمية المفاهيم الزمنية من خلال منهج منتسوري. 


\section{نتيجـــة الفـــرض الثــالــث وتفســيره}

ينص الفرض الثالث على أنه: "لا يوجد فرق دال إحصائياً بين متوسطي رتب القياس التهاس القياس البعدي والقياس التتبعي للمجموعة التجريبية على مقياس المفاهيم الزمنية وأبعاده الفرعية ذوي الإعاقة العقلية المتوسطة". للتحقق من صحة هذا الفرض قامت الباحثة بحساب دلالات الفروق بين متوسطات رتب القياسين البعدي والتتبعي للمجموعـة التجريبية على مقيـاس الدفـاهيم الزمنيـة وأبعـاده الفرعيـة للأطفال المعاقين عقلياً القابلين للتتريب. باستخدام اختبار إثارات الرتب Sign-rank لويلككسون Wilcoxon

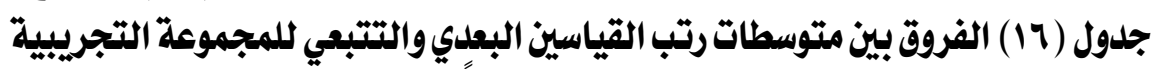

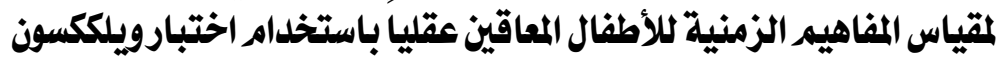

\begin{tabular}{|c|c|c|c|c|c|c|}
\hline مستوى الللالة & قيمة & مجموع الرتب | & متوسط الرتب | & العدد & اتجاه فروق الرتب | & البعل \\
\hline \multirow{4}{*}{ غير دالة } & \multirow{4}{*}{ 1, $7 \%$} & १,.• & $r, \cdot \cdot$ & $r$ & سلبي & \multirow{4}{*}{ الزمن العضوي } \\
\hline & & $\bullet, \cdot$ & $\bullet, \cdot$ & . & إيجابي & \\
\hline & & & & $\mathrm{r}$ & محايد & \\
\hline & & & & 1. & كلي & \\
\hline \multirow{4}{*}{ غير دالة } & \multirow{4}{*}{ •,977- } & $11, \cdot \cdot$ & $r$, ro & $\xi$ & سلبي & \multirow{4}{*}{ الزمن الاجتماعي } \\
\hline & & $\xi, \cdot \cdot$ & $\mathfrak{\xi}, \cdot$ & 1 & إيجابي & \\
\hline & & & & 0 & محايد & \\
\hline & & & & 1. & كلي & \\
\hline \multirow{4}{*}{ غير دالة } & \multirow{4}{*}{$1, \wedge \xi 1-$} & $1 \cdot, \cdot \cdot$ & $r, \Delta \cdot$ & $\xi$ & سلبي & \multirow{4}{*}{ الزمن البيولوجي } \\
\hline & & $\cdot, \cdot \bullet$ & $\cdot, \cdot \cdot$ & . & إيجابي & \\
\hline & & & & 7 & محايد & \\
\hline & & & & 1. & كلي & \\
\hline \multirow{4}{*}{ غير دالة } & \multirow{4}{*}{$\cdot, 00 \mathrm{Y}-$} & $7,0$. & r,IV & $r$ & سلبي & \multirow{4}{*}{ الزمن الشخصي } \\
\hline & & $r, \Delta$. & $r, \Delta$. & 1 & إيجابي & \\
\hline & & & & 9 & محايد & \\
\hline & & & & 1. & كلي & \\
\hline \multirow{4}{*}{ غير دالة } & \multirow{4}{*}{ 1, Irr- } & $r q, 0$. & $\xi, q r$ & 1 & سلبي & \multirow{4}{*}{ |المقياس ككل } \\
\hline & & 7,0. & r, ro & $r$ & إيجابي & \\
\hline & & & & $\frac{r}{r}$ & محايد & \\
\hline & & & & 1. & كلي & \\
\hline
\end{tabular}

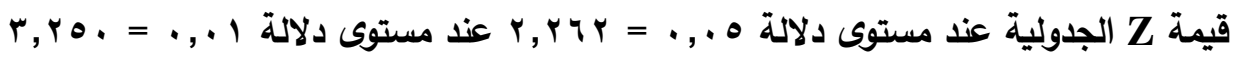


يتضح من خلال جدول (7 () عدم وجود فروق بين متوسطات رتب درجات القياسين البعدي والتتبعي للمجموعـة التجريبية على مقياس المفـاهيم الزمنية وأبعاده الفرعيـة للأطفال

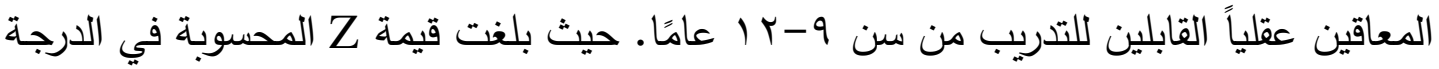

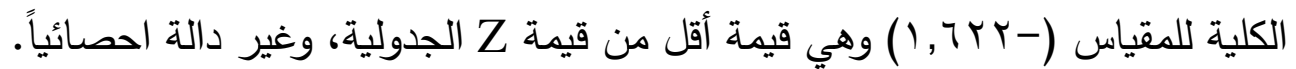

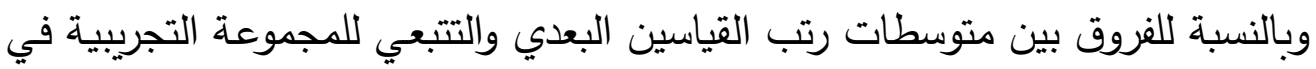

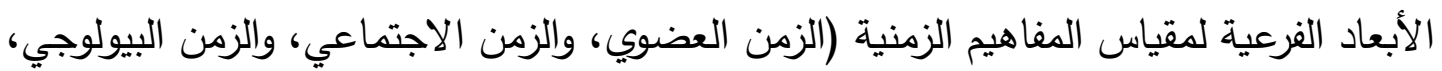

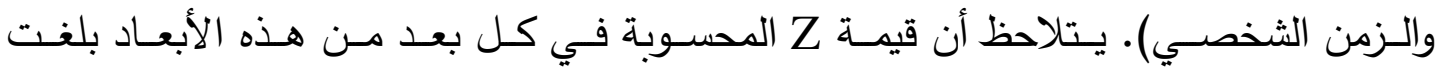

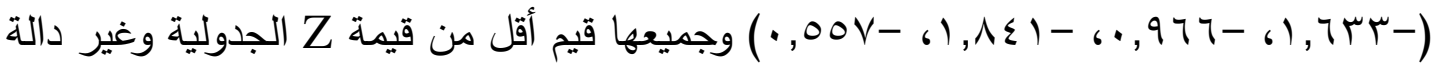

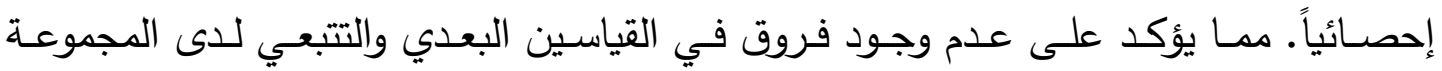
التجريبية على مقياس المفاهيم الزمنية وأبعاده الفرعية للأطفال المعاقين عقلياً القابلين للتدريب.

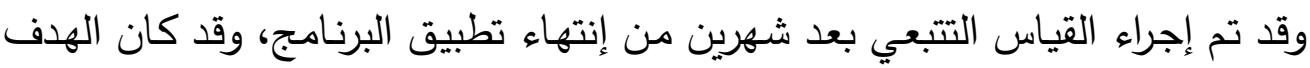
من القياس التتبعي هو التحقق من مدى إستمرار أثر التدريب الذي تلقهاء أطفال المجموعة التهاء

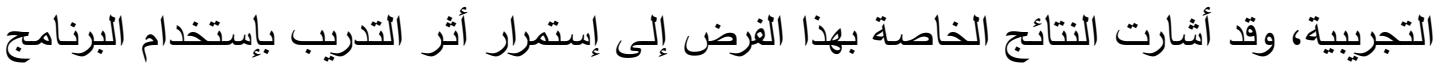

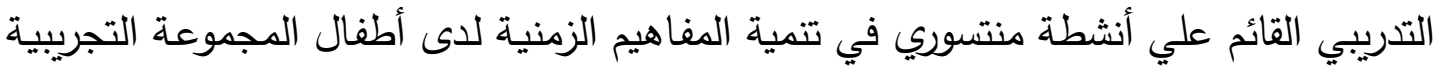

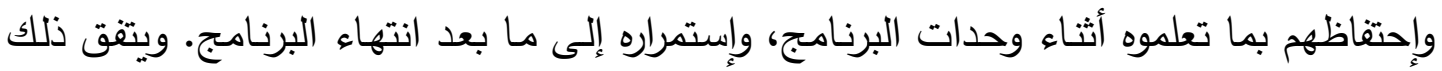

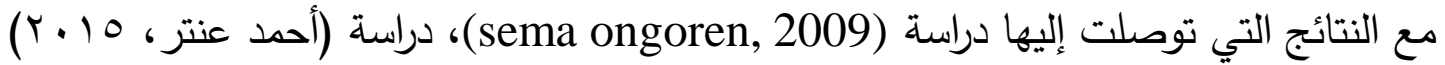

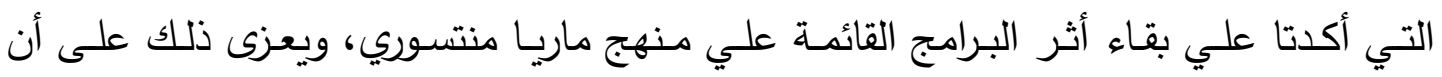

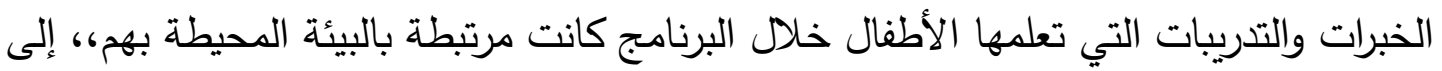

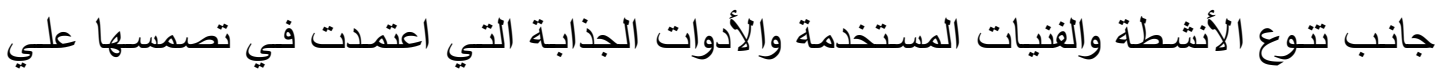
التعلم المحسوس الذي يخاطب جميع الحواس مما كان لها الأثر الإيجابي في إكتساب الدفاهيم الزمنية إستمرارها إلى ما بعد البرنامج.

وتبـين إيجابيـة التـدريب والتتدريس عـن طريـق البرنـامج التـدريبي القـائم علـي أنثـطة

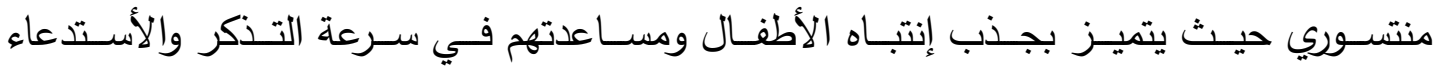

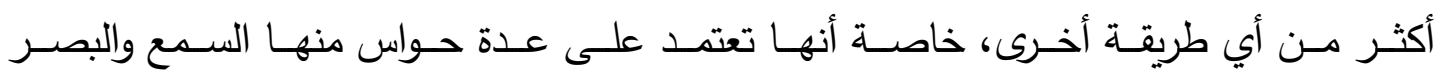

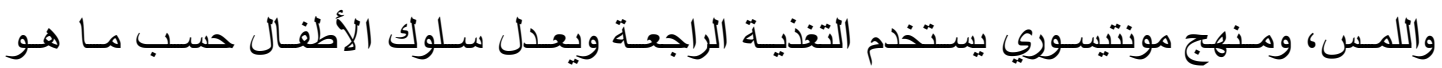

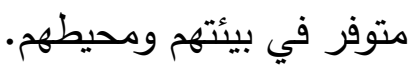


ومما زاد من بقاء أثر البرنامج التسريبي القائم علي أنثطة منتسوري هو عدم إستخدام

الباحثة لفنية التعزيز، فتري منتسوري أن الطفل ليس في حاجة الي ثواب أو عقاب بل تميل إلي أن يتعلم الطفل بثكل تلقائي، فوصول الطفل للأداء الصحيح هو المعزز الحقيقي له، كما أن لفنية

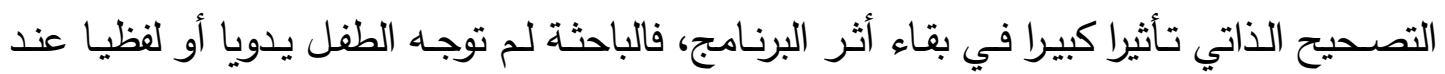

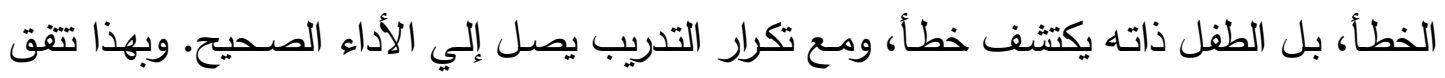
(Muijs, D \& Reynold, D., 2001), (sema ongoren \& نتائج البحث الحالي مع دراسة Ali Ishan, 2009, 1163), (Montessory, 1997, 7) مما سبق يتضـح أن البرنامج التدريبي القائم علي أنشطة منتسوري بما تضدنها من أساليب وفنيات واستراتيجيات وأدوات وأنشطة متنوعة كان لله فعالاً في تتمية المفاهيم الزمنية لاي أطفال المجموعـة التجريبية ذوي الإعاقة العقلية المتوسطة كما وردت في نتائج البحث، على عكس المجموعة الضابطة التي لم تتعرض لأنشطة البرنامج وفعالياته.

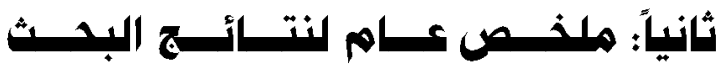

تتلخص نتائج البحث الحالي في النقاط التالية:

1-توجد فروق ذات دلالـة احصـائية بـين متوسطي رتب درجـات أطفـال المجـوعتين

التجريبية والضـابطة في القياس البعدي علي أبعاد مقياس المفاهيم الزمنيـة وأبعاده

الفرعيـة للأطفـال ذوي الإعاقـة العقليـة المتوسطة؛ وذلك لصـالح المجموعـة التجريبـة

وبمعامل تأثير كبير • بان.

ץ-توجد فروق ذات دلالة احصائية بين متوسطي رتب درجات القياسين القبلي والبعدي لأطفال المجموعة التجربية على أبعاد مقياس المفاهيم الزمنية وأبعاده الفرعية للأطفال

ذوي الإعاقة العقلية المتوسطة ؛ وذلك لصالح القياس البعدي وبمعامل تأثير كبير . r- لا توجد فروق ذات دلالــة احصـائية بـين متوسطات رتب درجـات القياسين البعدي والتتبعي لأطفال المجموعة التجريبية على أبعاد مقياس المفاهيم الزمنية وأبعاده الفرعية للأطفال ذوي الإعاقة العقلية المتوسطة. 


\section{تسوصيسات الـدراسـة}

في ضوء إجراءات الدراسة وما توصلت اليه الباحثة من نتائج وما قدمته من تفسير لهذه النتائج؛ توصي الباحثة بالتالي:

1- تعميم منهج ماريـا منتسوري بمدارس التربية الفكرية، ومدارس الدمج كمنهجية منظمـة

وفعالة في تعليم ذوي الإعاقة العقلية.

ץ- إجراء نفس الدراسة علي الاطفال ذوي الاعاقة العقلية الثديدة، وعلي فئات أخري من ذوي الإحتياجات الخاصة.

r- عمل دورات تدريبية لمعلمي التربية الفكرية عن منهج منتسوري وكيفية إستخدام أدواته.

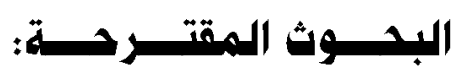

1- فعاليـة برنـامج قائم علي منهج منتسوري في تتميـة المفاهيم العلميـة والجغرافيـة لدي الأطفال ذوي الإعاقة العقلية.

r- أثر استخدام مدخل منتسوري في تتمية الوعي بالجسد لاي الأطفال ذوي الإعاقة العقلية. r- فعالية برنامجي نفس حركي في تتمية المفاهيم الزمنية لدي المعاقين عقليا. ع- دور الوسائط التكنولوجية في تتمية مفهوم الزمن للأطفال المعاقين عقليا. 


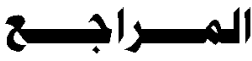

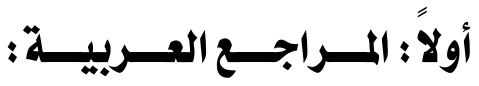
أحمد طالب(ع ـ ـ ؟). مفهوم الزمان ودلالته في الفلسفة والادب - بين النظريـة والتطبيق-، دار العرب للنشر والتوزيع، الجزائر.

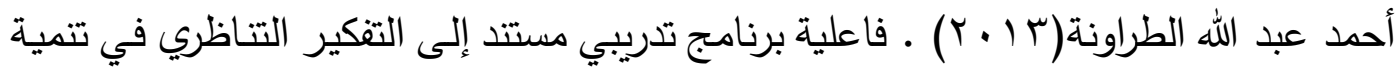

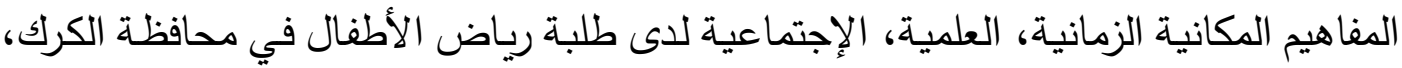

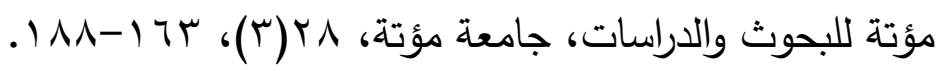

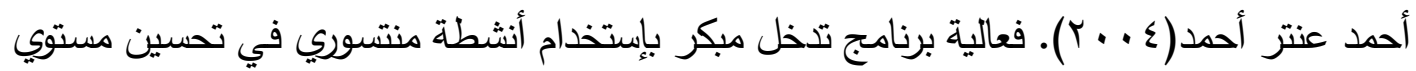

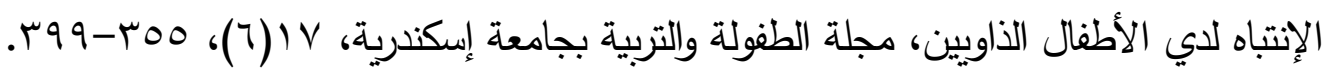

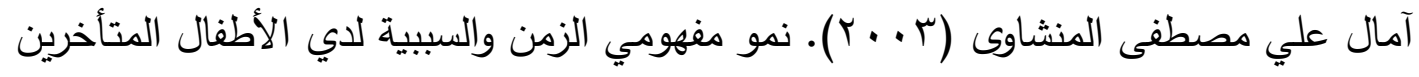
عقليا (فئة التأخر العقلي البسيط)، رسالة ماجستير، كلية الآداب، جامعة المنوفية. أمل معوض الهجرسي (1 . . r). تربية الأطفال المعاقين عقليا، الرياض. داهير، دار الزهراء.

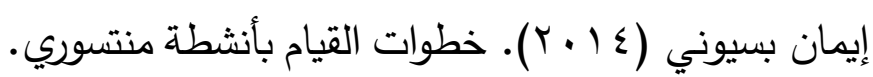
http://ebda3altadres.blogspot com/2014/09/blog-post_6.html.

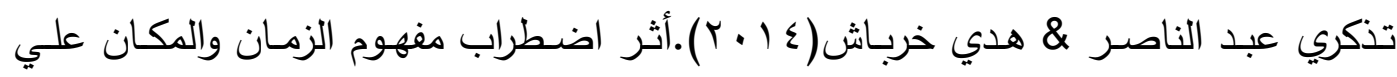

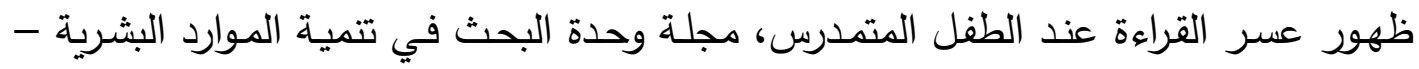

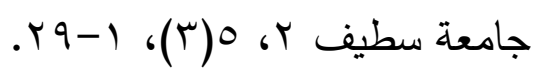

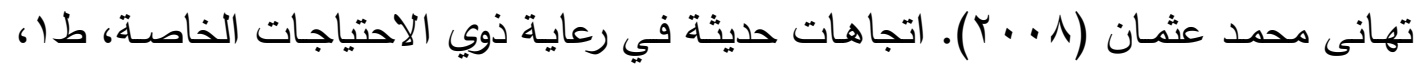
مكتبة الأنجلو المصرية، القاهره.

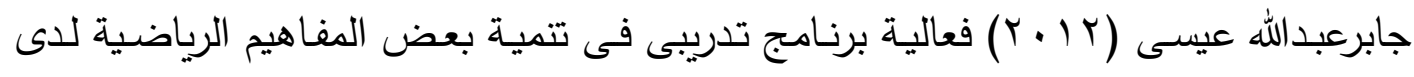

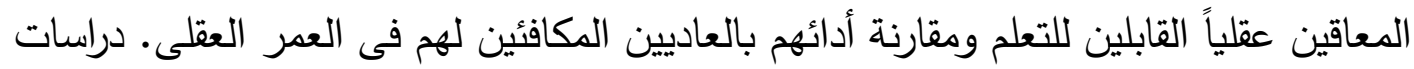
تربويه ونفسيه -مجلة كلية التربية الزقازيق. جاد البحيري مسعد \& غافين ريد (• ( • (ب). تدريس الأطفال المتعسرين قرائياً (دليل المعلم)، طا، سلسلة إصدارات مركز تقويم وتعليم الطفل، الكويت.

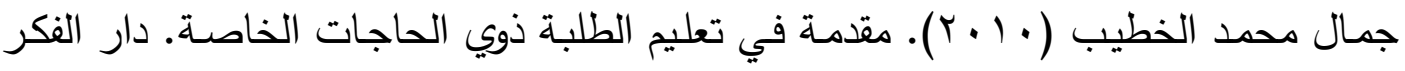
للنشر والتوزيع: الأردن. جمال محمد الخطيب، (T . . ץ).تعديل سلوك الأطفال المعوقين. دار الفلاح: الأردن. 


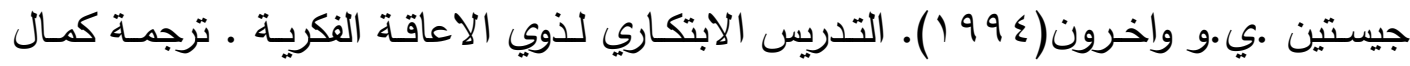
سالم، مكتبة النهضة المصرية، القاهرة.

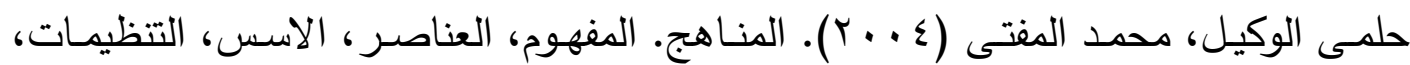
التطوير • القاهرة، مكتبة الانجلو المصرية.

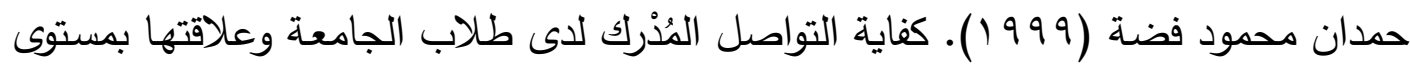

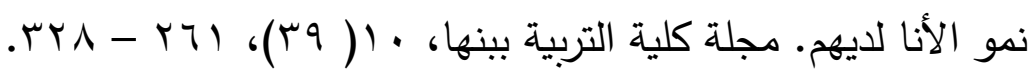

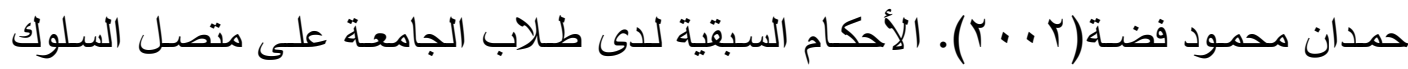
الاجتماعى.، مجلة الإرشاد النفسى، مركز الإرشاد النفسى، جامعة عين شمس.

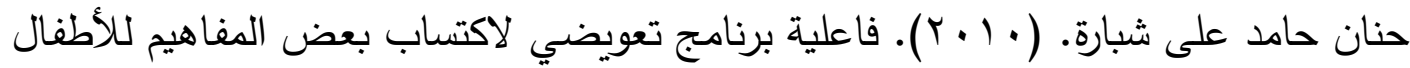
المعاقين بصريًا. رسالة دكتوراه. معهد الدراسات العليا للطفولة. جامعة عين شمس.

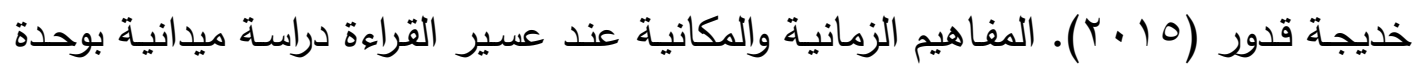

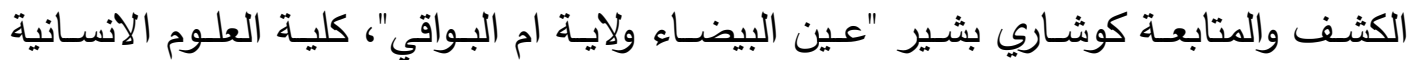
والاجتماعية، جامعة العربي بن مهيدي-أم البواقي. خليل ميخائيل معوض (r . . (Y). سيكولوجية النمو "الطفولة والمراهقة". مركز الأسكندرية للكتاب.

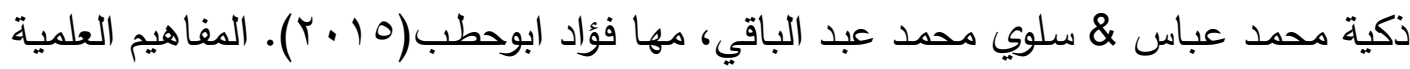

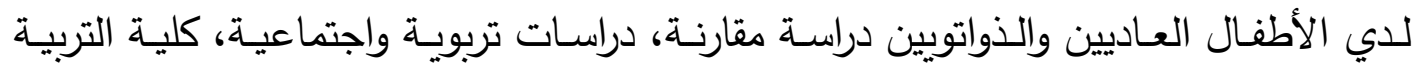

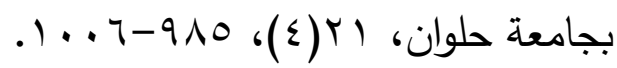

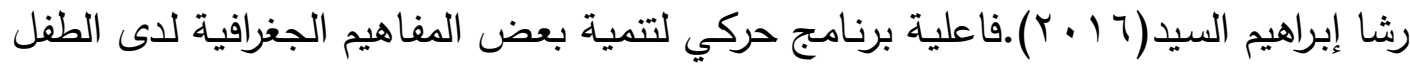

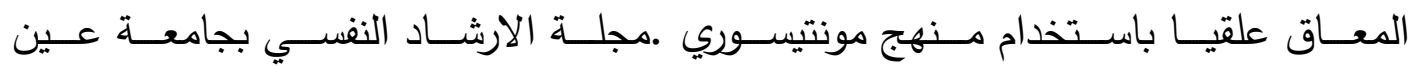

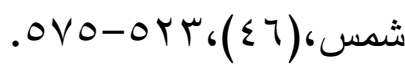

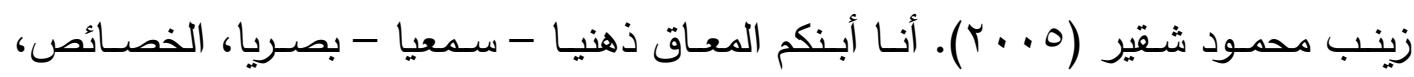

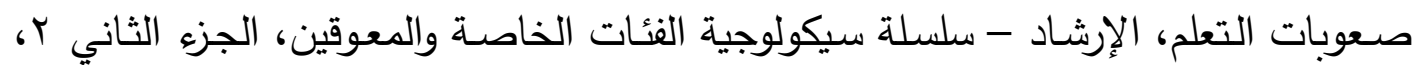
طب، مكتبة النهضة المصرية، القاهرة.

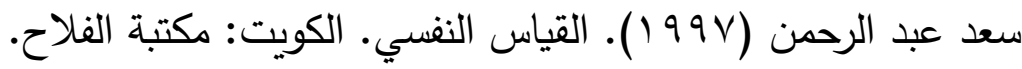

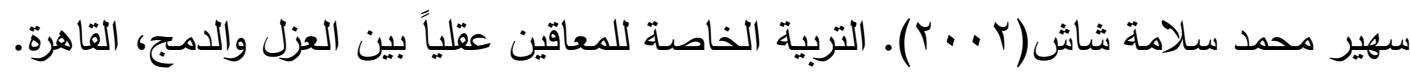
مكتبة زهراء الشرق. صباح هرمز، يوسف ابراهيم (911 ()). علم النفس التكويني (الطفولـة والمراهقة)، مطبعة جامعة الموصل. 
عبد المجيد نشواتي (T1911). علم النفس التربوي. دار الفرقان، الأردن.

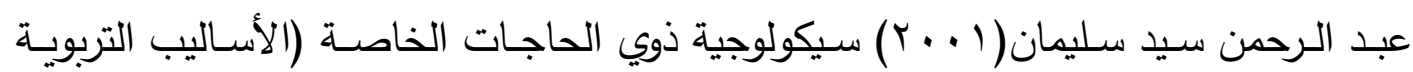

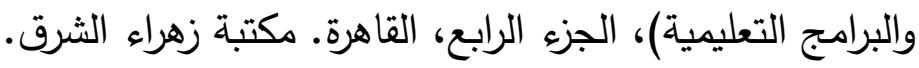

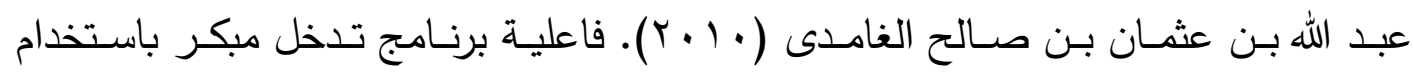

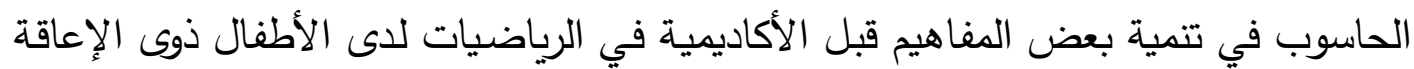

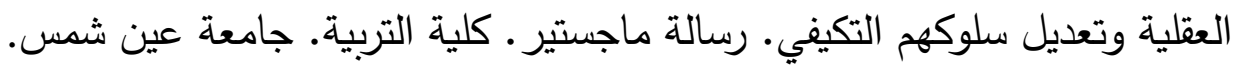

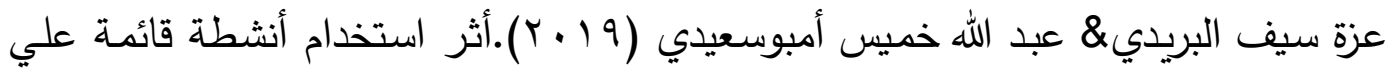

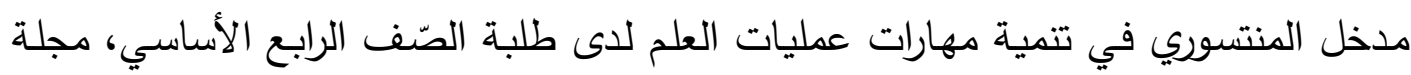

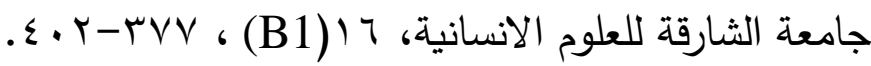

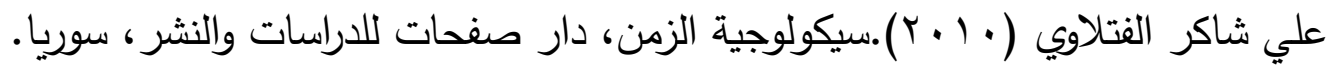

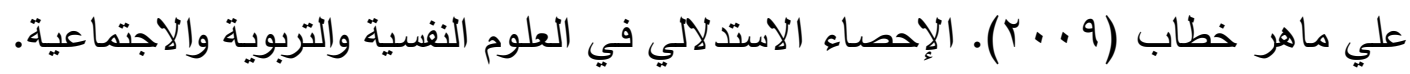
القاهرة: مكتبة الأنجلو المصرية.

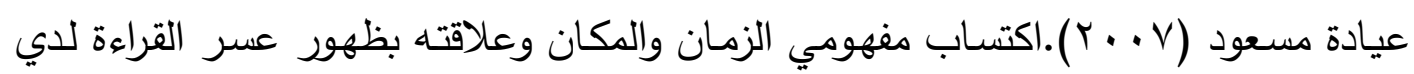

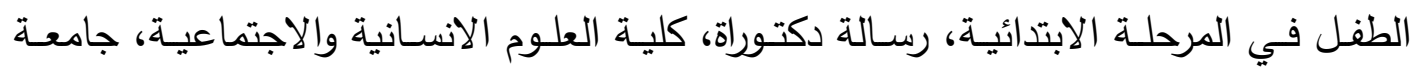
منتوري - فسطينية الحزائرية.

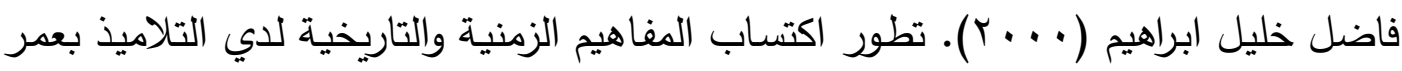

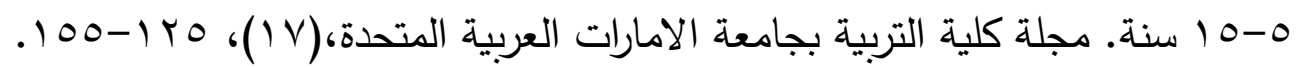

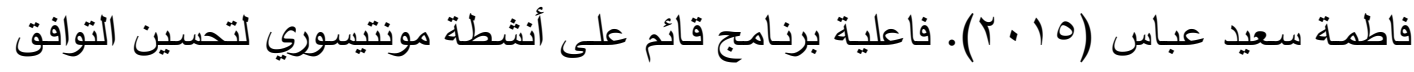
النفسي لاى عينة من الأطفال ذوي الإعاقة العقلية، رسالة ماجستير في التربية، كلية التربية، جامعة عين شمس. فطيمة دبراسو (T ( + ب). اضطراب مفهوم الزمن والفضاء وعلاقتهما بصعوبة تعلم القراءة والكتابة

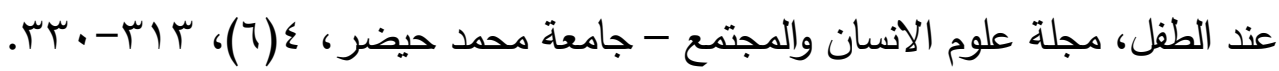

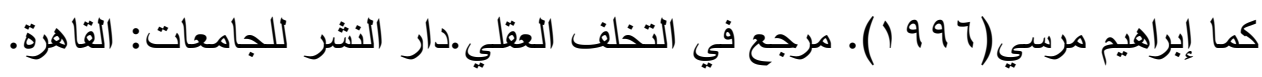

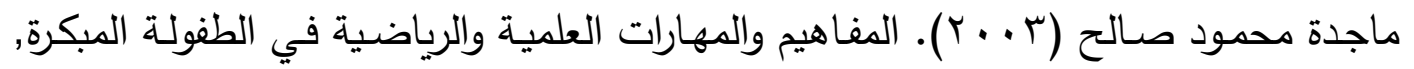

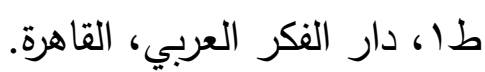

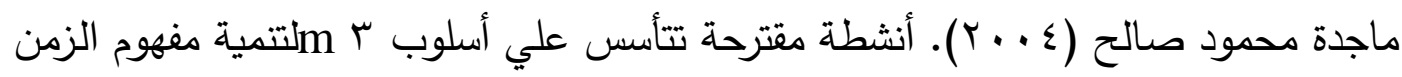

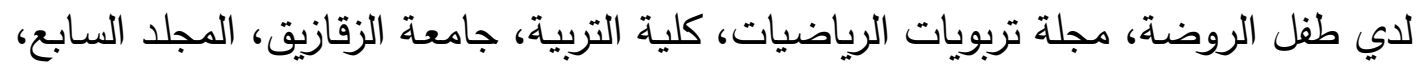
الأول، يوليو. 
ماجدة محمود صالح \& رشا اسماعيل خليل (T I ـ (Y).فاعلية إكساب الأطفال المعاقين عقليا القابلين للتعلم بعض المفاهيم الزمنية باستخدام الأنشطة التربويـة، الجمعية المصرية للقراءة

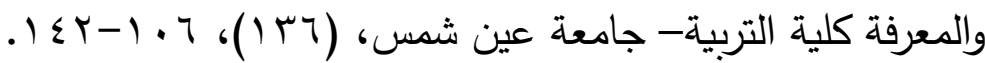
ماجدة محمود صالح، سهى نصر أمين ( ( . ץ). فاعلية برنامج باستخدام إستراتيجية تعليم الأقران في تتميـة بعض المهارات الرياضية، لدي الأطفال المتخلفين عقليا القابلين للتعلم، الجمعية المصرية للمناهج وطرق التدريس، العدد التاسع والثمانون، أكتوبر، لقاهره

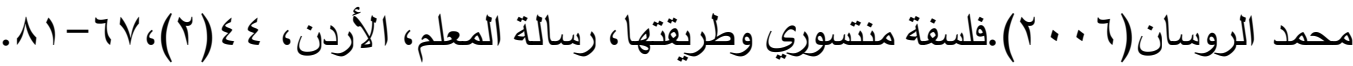
محمد خليفـة إسـاعيل متولي (10 ( ب). مدخل منتسوري وأثره في إكسـاب بعض مهارات الحياة العملية لدي طفل الروضة من وجهة نظر الأمهات، مجلة كلية التربية -جامعة أسيوط،

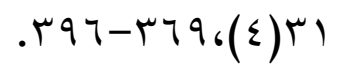

محمد صبري وهبة (1/ • ب).التربية النفس حركية للأطفال ذوي الإضطرابات النمائية (ذوي الاعاقة الفكرية وذوي التوحد).مكتبة الانجلو المصرية، القاهرة. مريم سليم(ب . . ץ). علم نفس النمو • دار النهضة العربية، بيروت. نايف عابد الزارع (ج . †).تأهيل ذوي الإحتياجات الخاصة. دار الفكر ، الاردن. نجوي جوبالي \& أسماء بن عافية (9 ( ب ). فاعلية برنامج قائم علي الذكاءات المتعددة في تتمية المفاهيم المتعلقة بالزمن لدي عينـة من ذوي الإعاقة السمعية المتوسطة بمركز رعاية

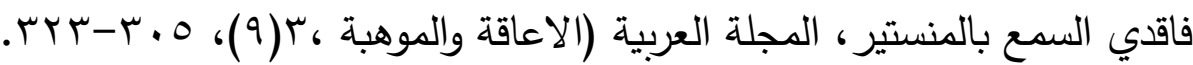
نصيرة خلوفيه فطيمة زينات (ع . . ؟). مفهوم الزمن لدي المصابين بأعراض داون، رسالة ماجستير، كلية العلوم الإنسانية والاجتماعية قسم علم النفس وعلوم التربية، جامعة الجزائر.

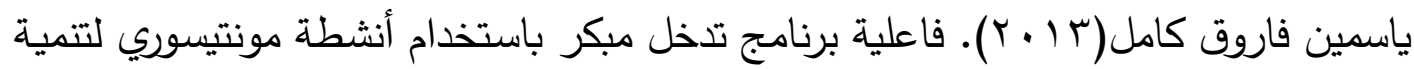
المهارات المعرفية والتواصلية لدى الأطفال التوحديين، رسـالة ماجستير غير منشورة، كلية التربية، جامعة عين شمس. يعلاوي خليدة (ع ا • Y).أثر الادماج المدرسي في تحسين اكتساب مفهوم الزمن المباشر لدي الطفـل الحامـل التثلث الصـبغي اب القابـل للتـدريب، دراسـات في الطفولـة- مركز البصـرة للبحوث والاستشارات والخدمات التعليمية، ؟(0)، اس- ـــ. 


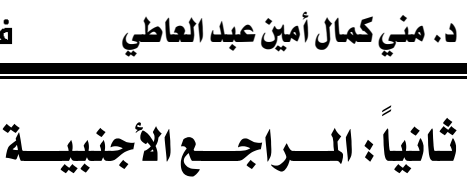

Aimard P.(1994). Troubles du language chez 1 enfant, (3 ed), p. u. f, paris.

Boehm, A. E. (1990). Assessment of Children's Knowledge of Basic Concepts. In C. R. Reynolds \& R. W. Kamphaus (Eds.), Handbook of Psychological \& Educational Assessment of children: Intelligence and Achievement (pp. 654-670). New York: The Guilford Press.

Boehm, A. E. (1991). Assessment of basic relational concepts. In B. A. Braken (Ed.), The Psychoeducational Assessment of Preschool Children (2nd ed., pp. 241-258). Boston, MA: Allyn and Bacon.

Boehm, A. E. (2004). Assessment of basic relational concepts. In B. A. Bracken (Ed.), The psychoeducational assessment of preschool children (p. 186-203). Lawrence Erlbaum Associates Publishers.

Boehm, A. E. (201 lb). Boehm Test o f Basic Concepts-3: Technical Report. Retrieved from http://www.pearsonassessments.com/hai/images/Products/Boehm3 /BoehmlllTechRPT.pdf

Boehm, A. E. (2011 la). The challenges of linking basic concept assessment to intervention [Webinar]. Retrieved November 7, 2011 from http://www.pearsonassessments.com/hai/images/PDF/Webinar/boehml $\underline{0112011 . p d f}$

Boehm, A.E. (2001a). Boehm Test of Basic Concepts-3. San Antonio, TX: The Psychological Corporation.

Boehm, A.E. (2008). Children's knowledge of basic concepts: An essential component of direction following and problem solving. In C.R. Reynolds \& R. W. Kamphaus (Eds.), The handbook of school psychology (4th ed., pp. 269-286). New York: Wiley.

Boucher, J., Pons, F., Lind, S., Williams, D., (2015). Temporal cognition in children with autism spectrum disorder: tests of diachronic thinking. J. Autism Dev. Disord. 37, 1413-1429. 
Busby Grant, J., \& Suddendorf, T. (2009). Preschoolers begin to differentiate the times of events from throughout the lifespan. European Journal of Developmental Psychology, 6(6), 746-762.

Busby Grant, J., \& Suddendorf, T. (2011). Production of temporal terms by 3-, 4-, and 5-year-old children. Early Childhood Research Quarterly, 26(1), 87-95.

Busby, J., \& Suddendorf, T. (2005). Recalling yesterday and predicting tomorrow. Cognitive Development, 20(3), 362-372.

Busby, J., \& Suddendorf, T. (2010). Young children's ability to distinguish past and future changes in physical and mental states. British Journal of Developmental Psychology, 28(4), 853-870.

Dogru, S. S. (2015). Efficacy of Montessori education in attention gathering skill of children, Academic Journals, 10)6(, 733-738.

Droit-Volet, S., (2013). Time perception in children: a neurodevelopmental approach. Neuropsychologia ,51 (2), 220-234.

Droit-Volet, S., (2016). Development of time. Curr. Opin. Behav. Sci. 8, 102-109.

Faryadi, Q. (2017). The application of Montessori method in learning mathematics: an experimental research. Open Access Library Journal, 4, 1-14.

Gabriela V. Nelson (2006). Basic Relational Concept Acquistion In Children Who Are And Are Not At Risk For Learning Disabilities, Doctoral thesis presnted in PSYCHOLOGY St. John's University, New York

Helayna A. Herschkom (2015) Basic Relational Concept Acquisition Among Children With And Without Autism Spectrum Disorde, Doctoral thesis presented in St. John's University, New York

Hiles, E(2015). Measuring Parent Perception and Understanding of Montessori Education at three Massachusetts Montessori Schools. Published Doctoral Dissertation. Pepperdine University, USA. 
Isaacs, B. (2015). Bringing the Montessori Approach to your Early Years Practice. Cornwall, Routledge Group.

James, B. Pace (1971). Operant Conditioning Procedures With Profoundly Retarded Children In The Acquisition Of concepts, Doctoral Theology of presented to the faculty of psychology of university of Ottawa, Canada.

Janeslatt, G., Granlund, M., Alderman, I., Kottorp, A., (2008). Development of a new assessment of time processing ability in children, using Rash analysis. Child Care Health Dev. 34 (6), 771-780.

Janeslcatt, G., Kottorp, A., Granlund, M., (2013). Evaluating intervention using time aids in children with disabilities. Scand. J. Occup. Ther. 1-10.

Jonson, G., Blake, K. (1965). learning performance of retarded and normal children, New York, MG Graw- Hill, 328-329

Katharine A., Marghetis, T., Barner, D., Srinivasan M., (2017). Today is tomorrow's yesterday: Children's acquisition of deictic time words. Cognitive Psychology, 92 ,87-100

Kaya1, M. \& Yildiz, K. (2019). The Effect of Montessori Programme on The Motion and Visual Perception Skills of Trainable Mentally Retarded Individuals, Journal of Education and Training Studies,7(2),120-128.

Kayili, G., \& Ari, R. (2011). Examination of the effects of the Montessori method on preschool children's readiness to primary education. Educational Sciences: Theory \& Practice, 11(4), 2091-2109.

Labrell, F., C^amara Costa H., Perdry H., Dellatolas G. (2020).The Time Knowledge Questionnaire for children, Heliyon (6), e03331

Lovell, k. slater, A. (1960)The growth Of The Concept of Time: A Comparison Study, Child Psychology And Psychiatry,179-190.

Martin, A. Bentley B. Sc., M. Sc., (1983). An investigation of time concepts in Swazi children and adults A Doctor dissertation submitted to the faculty of Science, University of Aberdeen.

Martins S., ' Guillery-Girard B., Jambaqu I., Dulac O., Eustache F. (2006).How children suffering severe amnesic syndrome acquire new concepts?, Neuropsychology 44 (2006) 2792-2805 . 
Martins, S., Ere-Girard, B., Jambaque, I. (2006). How children suffuring severe amnesic syndrome acquire new concepts, neuropsychologia, 2792-2805.

Mash. E., Brakely, R.(2003).child Psychology (znd ed). New York: The Gulford Press.

Montanaro, S. Quattrocchi (1991). Understanding the Human Being: Importance of the First Three Years of Life. Nienhuis Montessori USA.

Montessori, M. (1976). From Childhood to Adolescence. New York: Schocken Books Inc.

Montessori, M. (1985). The Secret of Childhood. Delhi, Orient Longman.

Montessori, M. (1995). The Advanced Montessori Method. London, Thoemmes Press.

Montessori, M. (1997). Child Education Montessori Method. Translator; Güler Yücel. zgür Publication, 5.

Mujs, D. \& Renolds, D. (2001). "Effective psychology (2 $2^{\text {nd }}$ ed.). Newyork: The Guilford.

Nain Liu (2012). "The Effect of Naming Systems on the Acquisition of and Reasoning about Time Concepts. Ph.D. Dissertation, University of Hawai'i at Manoa.

Orogern, s. Ozlem, D. Yazlik (2018). Investigation of Mathematical Concept Skills of Children Trained with Montessori Approach and MoE Pre-school Education Program, European Journal of Educational Research, 8(1), 9-19.

Piaget, J. B. (1969).Psychology of the child translated by Helen Wever, New York.

Piaget, J. \& Inhelder, B.(1982).The Psychology of The child. New York: Basic Books.

Poyraz, H. (2001).The principles and the methods of preschool education. Ani publication, Istanbul.

Qingfen $\mathrm{Hu}$, Meng Zhang (2019). The development of symmetry concept in preschool children, Cognition, 189, 131-140 
Reynolds, C. R., \& Kamphaus, R. W. (Eds.). (2003). Handbook of Psychological and Educational Assessment of Children: Intelligence, Aptitude, and Achievement (2nd ed.). New York: Guilford.

Roinson, N., Roinson, H.(1976).Mentally Retarded Child. New York MC Graw Hiu, 241-264.

Sema orngoren \& Ali ihsan (2009). The Effectiviness Of Montessori Education Method In The Acquisition Of Concept Of Geometrical Shapes, Procedia Social and Behavioral Sciences 1, 1163-1166.

Shu-kwong chao, R.(1978). The Relation of Piagetian Operation Time Concepts And Mental Age In Mentally Retarded Adults, Master Degree, University of South California.

Springer, A. and Campbell, p. (2000): Theoretical frame work for preschool time experiences young children. 24 (2).

Suddendorf, T. (2010). Linking yesterday and tomorrow: Preschoolers' ability to report temporally displaced events. British Journal of Developmental Psychology, 28(2), 491-498.

Suddendorf, T., Nielsen, M., \& Von Gehlen, R. (2011). Children's capacity to remember a novel problem and to secure its future solution. Developmental Science, 14(1), 26-33.

$\mathrm{Xu}$, F., \& Tenenbaum, J. B. (2007). Word Learning as Bayesian Inference. Psychological Review, 114(2), 245-272. 